Portland State University

PDXScholar

6-8-2004

\title{
Risk Factors for Pre-Post Monsoon Cholera Epidemics in Bangladesh from 1992-1994
}

Rhonda Rae Robb

Portland State University

Follow this and additional works at: https://pdxscholar.library.pdx.edu/open_access_etds

Part of the Bacterial Infections and Mycoses Commons, and the Other Geography Commons Let us know how access to this document benefits you.

\section{Recommended Citation}

Robb, Rhonda Rae, "Risk Factors for Pre-Post Monsoon Cholera Epidemics in Bangladesh from 1992-1994" (2004). Dissertations and Theses. Paper 1691.

https://doi.org/10.15760/etd.1690

This Thesis is brought to you for free and open access. It has been accepted for inclusion in Dissertations and Theses by an authorized administrator of PDXScholar. Please contact us if we can make this document more accessible: pdxscholar@pdx.edu. 


\section{THESIS APPROVAL}

The abstract and thesis of Rhonda Rae Robb for the Master of Science in Geography were presented June $8^{\text {th }}, 2004$, and accepted by the thesis committee and the department.

COMMITTEE APPROVALS:

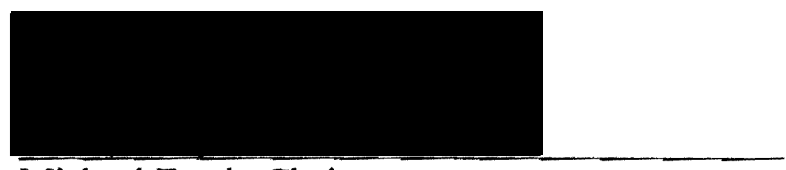

Michael Emch, Chair

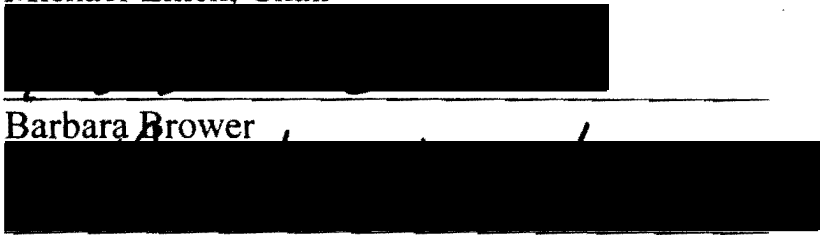

Martha Works

David Boone

Representative of the Office of Graduate Studies

DEPARTMENT APPROVAL:

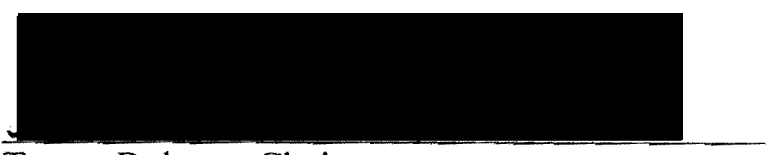

Teresa Bulman, Chair

Department of Geography 


\begin{abstract}
An abstract of the thesis of Rhonda Rae Robb for the Master of Science in Geography presented June 8, 2004.
\end{abstract}

Title: Risk factors for pre-post monsoon cholera epidemics in Bangladesh from 1992-1994.

The primary objective of this thesis is to differentiate between the risk factors for pre- and post-monsoon cholera epidemics in rural Bangladesh by analyzing the complex interaction between select environmental, cultural/behavioral, and socioeconomic variables over space and time. In rural Bangladesh, cholera epidemics correspond with the annual monsoon: the first, and smallest, occurs between March and June, while the larger cholera peak occurs between September and December. The differences between the spatial and temporal patterns of seasonal cholera are analyzed, and the risk factors are calculated for pre- and post-monsoon cholera epidemics.

The theoretical approach that underlies this medical geographical study is disease ecology, which espouses that risk of disease is caused by an interaction between people and their environment. This thesis is structured around a holistic understanding that human-environment interactions are inseparable.

In Bangladesh, the monsoon season typically starts between May and June. The 1992 and 1993 cholera peaks occurred just before the monsoon in April and March respectively, while the 1994 cholera peak occurred between April and June. In 
1992 and 1993 cholera incidence increased in the post-monsoon period, and peaked in October. The 1994 post-monsoon cholera peak occurred in November. There is a regular temporal pattern to cholera, as the peaks followed a seasonal pattern with the smaller epidemic occurring in the pre-monsoon period and the larger epidemic occurring in the post-monsoon period.

This study shows that there are different risks associated with pre-monsoon cholera epidemics and post-monsoon cholera epidemics. The two main risk factors associated with cholera incidence pre-monsoon were bari population (i.e., crowding) and a house located within the flood controlled area. These two variables were even more strongly associated with post-monsoon cholera incidence to a greater degree, along with a number of other variables including water use, sanitation practices, and socioeconomic status. 


\section{RISK FACTORS FOR PRE-POST MONSOON CHOLERA EPIDEMICS IN}

BANGLADESH FROM 1992-1994.

by

RHONDA RAE ROBB

A thesis submitted in partial fulfillment of the requirements for the degree of

\section{MASTER OF SCIENCE \\ in GEOGRAPHY}

Portland State University 2004 


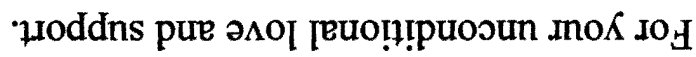
'pep pure urou Ku oL 


\section{ACKNOWLEDGEMENTS}

I would like to thank my graduate advisor, Michael Emch, for providing the data in which to complete this thesis and for his guidance throughout each stage of this research. I would also like to thank Barbara Brower for her belief in my abilities and for her support over the years. Thank you to Martha Works and David Boone for serving on my thesis committee. Thank you to Randy Murphy for so graciously offering to edit my thesis. Thank you to Recinda Sherman-Seitz and the team at OSCaR for providing me with a Research Assistantship.

I would also like to thank my fellow colleagues for their friendship and inspiration:

Christina Friedle, you greatly enhanced my experience at Portland State University. Thank you for your support and friendship. Keith Jackson, I am forever indebted to you for your guidance and motivation. Thank you for making me laugh. Huessan Basagic, Mike Boeder, Gerad Dean, Tiaan and Lindley Van Der Linde, Jennifer Karps- thank you for your laughter, the coffee breaks, music, support, and good times! Eli Schmitz, John Hutchison, and Jenny Zickovich, thank you for your support and the good times!

I would also like to thank a number of people who have inspired me to finish this thesis: Jennifer Bader, Mary Miller, Maia Highsmith, Kerri Kimball, Sera Bonds, Sarah Serata, Dave Galat, Ben Friedle, Bill Riordan, Jess, Drew Falkman, Eve Talbot, Jennifer Koeninger, Lesley Davidson, Linda Lewis, Tara Steele, Mary Fairbairn, Tally Fisher, Scott and Wendy TenEyck, Kendall Cook, Tommy Lien, Garri Dee Griffith, Erin Fagley, Donna Veraguth, Jenny Prokos, Chris and Karen Gragg, Shannon Cavanagh, Pat Robb, Gary Robb, and Jake - the best friend a girl could have. 


\section{LIST OF TABLES}

LIST OF FIGURES

$\mathbf{v}$

GLOSSARY

vi

1. INTRODUCTION 1

2. STUDY AREA

3. MEDICAL GEOGRAPHY 16

3.1 Risk factors $\quad 18$

3.2 Disease ecology 22

4. CHOLERA: LITERATURE REVIEW 26

4.1 Cholera etiology 26

4.2 Cholera ecology 30

$\begin{array}{lll}4.3 & \text { Cholera epidemiology } & 40\end{array}$

4.4 Cholera and seasonality 41

4.5 Cholera risks 46

5. METHODS: RESEARCH QUESTIONS, DATA SOURCES, AND 46

ANALYTICAL METHODS

5.1 Specific research questions 46

5.2 Data sources and collection methods 46

5.2.1 Creation of the study area geographic information system database $\quad 47$

$\begin{array}{ll}\text { 5.2.2 Dependent variables } & 49\end{array}$

5.2 .3 Independent variables $\quad 49$

5.2.4 Questionnaire 50

5.2.5 Collection of secondary data from ICDDR,B Demographic Surveillance 52 System (DSS) records and community health worker record books

5.2.6 Collection of data on the distribution of latrines and tubewells in the 52 study area

5.2.7 Spatial calculations of new variables using Matlab GIS database 53

5.3 Specific hypotheses about individual independent variables 53

5.4 Analytical methods 56 


\section{FINDINGS}

6.1 Temporal distributions $\quad 62$

6.2 Disease maps 66

6.3 Descriptive information about study population 69

6.4 Non-parametric case-control study for categorical variables $\quad 79$

6.5 Simple regression analysis for continuous variables 86

7. DISCUSSION OF FINDINGS AND CONCLUSION 92

7.1 Patterns of pre- and post- monsoon cholera epidemics 92

7.2 Risk factors of pre- and post-monsoon cholera epidemics 94

7.3 The disease ecology of cholera 99

$\begin{array}{ll}7.4 & \text { Implications for research } \\ & 102\end{array}$

$\begin{array}{ll}\text { REFERENCES } & 103\end{array}$

APPENDIX A: DESCRIPTION OF INDEPENDENT VARIABLES 109

APPENDIX B: ENGLISH TRANSLATION OF QUESTIONNAIRE 120 


\section{LIST OF TABLES}

Table 2.1 Seasonal climatic variation in Matlab 6

Table 5.1 Continuous independent variables $\quad 50$

Table 5.2 Categorical independent variables $\quad 51$

Table 5.3 1992 post-monsoon: variable- canal water for bathing 58

$\begin{array}{lr}\text { Table } 6.1 \text { Frequencies of categorical variables } & 80-82\end{array}$

Table 6.2 Relative risks for categorical variables

$\begin{array}{ll}\text { Table 6.3 Descriptive statistics for continuous independent variables } & 87\end{array}$

Table 6.4 Simple logistic regression for continuous independent variables $\quad 88$

Table 6.5 Pre-monsoon logistic regression for categorical variables $\quad 89$

Table 6.6 Post-monsoon logistic regression for categorical variables $\quad 90$ 


\section{LIST OF FIGURES}

Figure 2.1 Study area location 5

Figure 2.2 Study area superimposed on a Landsat TM satellite image 7

$\begin{array}{lll}\text { Figure 2.3 Flood protected area within Matlab } & \mathbf{8}\end{array}$

Figure 2.4 Large-scale fishing in Matlab on the Meghna River 9

Figure 2.5 Small-scale fishing in Matlab on the Meghna River 10

$\begin{array}{lll}\text { Figure 2.6 Layout of a bari } & 11\end{array}$

$\begin{array}{lll}\text { Figure 2.7 Detail of a ghar } & 12\end{array}$

$\begin{array}{lll}\text { Figure 2.8 A bari pre-monsoon season } & 13\end{array}$

$\begin{array}{lll}\text { Figure 2.9 A bari post-monsoon season } & 13\end{array}$

$\begin{array}{lll}\text { Figure 2.10 Distribution of baris in Matlab } & 15\end{array}$

$\begin{array}{lll}\text { Figure 3.1 The ecology of disease and health } & 19\end{array}$

Figure 4.1 Electron micrograph of Vibrio Cholerae 26

$\begin{array}{lll}\text { Figure } 4.2 & \text { The pathophysiology of cholera } & 28\end{array}$

Figure 4.3 A permanent reservoir (canal) during the dry season 36

$\begin{array}{lll}\text { Figure 4.4 Cholera transmission routes } & 39\end{array}$

Figure 4.5 Hanging latrine in Matlab 42

$\begin{array}{lll}\text { Figure 4.6 Tubewell in Matlab } & 43\end{array}$

Figure 4.7 Bangladeshi women doing their chores 44

$\begin{array}{lll}\text { Figure 5.1 Spatial database for study area } & 48\end{array}$

$\begin{array}{lll}\text { Figure 5.2 } & \text { Pre-monsoon cholera cases } & 57\end{array}$

$\begin{array}{lll}\text { Figure 5.3 Post-monsoon cholera cases } & 57\end{array}$ 
Figure 6.1 Pre- and post-monsoon cholera cases from 1992-1994 62

Figure 6.2 1992 pre-monsoon cholera cases 64

$\begin{array}{lll}\text { Figure } 6.3 & 1993 \text { pre-monsoon cholera cases } & 64\end{array}$

$\begin{array}{lll}\text { Figure } 6.4 & 1994 \text { pre-monsoon cholera cases } & 64\end{array}$

$\begin{array}{lll}\text { Figure } 6.5 & 1992 \text { post-monsoon cholera cases } & 65\end{array}$

$\begin{array}{lll}\text { Figure } 6.6 & 1993 \text { post-monsoon cholera cases } & 65\end{array}$

$\begin{array}{lll}\text { Figure } 6.7 & 1994 \text { post-monsoon cholera cases } & 65\end{array}$

Figure 6.8 Pre-monsoon case/control distribution from Jan. 1992 to Dec. 67 1994

Figure 6.9 Post-monsoon case/control distribution from Jan. 1992 to Dec. 67 1994

$\begin{array}{lll}\text { Figure } 6.10 & \text { Pre-monsoon cholera cases by year } & 68\end{array}$

$\begin{array}{lll}\text { Figure 6.11 Post-monsoon cholera cases by year } & 68\end{array}$

$\begin{array}{lll}\text { Figure 6.12 Pre-monsoon: water used for drinking } & 69\end{array}$

$\begin{array}{lll}\text { Figure } 6.13 \text { Post-monsoon: water used for drinking } & 69\end{array}$

$\begin{array}{lll}\text { Figure 6.14 Pre-monsoon: water used for cooking } & 70\end{array}$

$\begin{array}{lll}\text { Figure 6.15 Post-monsoon: water used for cooking } & 70\end{array}$

$\begin{array}{lll}\text { Figure 6.16 Pre-monsoon: water used for bathing } & 70\end{array}$

$\begin{array}{lll}\text { Figure } 6.17 \text { Post-monsoon: water used for bathing } & 70\end{array}$

$\begin{array}{lll}\text { Figure } 6.18 & \text { Pre-monsoon: water used for washing } & 71\end{array}$

$\begin{array}{lll}\text { Figure 6.19 Post-monsoon: water used for washing } & 71\end{array}$

$\begin{array}{lll}\text { Figure 6.20 Pre-monsoon: Tubewell used for drinking } & 72\end{array}$

$\begin{array}{lll}\text { Figure 6.21 Post-monsoon: Tubewell used for drinking } & 72\end{array}$

$\begin{array}{lll}\text { Figure 6.22 Pre-monsoon: Drinking river water } & 72\end{array}$ 
Figure 6.23 Post-monsoon: Drinking river water

Figure 6.24 Pre-monsoon: Cooking w/ tubewell water 73

Figure 6.25 Post-monsoon: Cooking w/ tubewell water 73

Figure 6.26 Pre-monsoon: Cooking w/ river water 73

Figure 6.27 Post-monsoon: Cooking w/ river water 73

Figure 6.28 Pre-monsoon: Cooking w/ canal water 74

Figure 6.29 Post-monsoon: Cooking w/ canal water 74

Figure 6.30 Pre-monsoon: Cooking w/ tank water 74

Figure 6.31 Post-monsoon: Cooking w/ tank water 74

Figure 6.32 Pre/Post monsoon: Bathing w/ tubewell water 75

Figure 6.33 Pre-monsoon: Bathing w/ river water 75

Figure 6.34 Post-monsoon: Bathing w/ river water 75

Figure 6.35 Pre-monsoon: Bathing w/ canal water 76

Figure 6.36 Post-monsoon: Bathing w/ canal water 76

Figure 6.37 Pre-monsoon: Bathing w/ tank water 76

Figure 6.38 Post-monsoon: Bathing w/ tank water 76

Figure 6.39 Pre-monsoon: Adult males and latrine use 77

Figure 6.40 Post-monsoon: Adult males and latrine use 77

Figure 6.41 Pre-monsoon: Adult females and latrine use 77

Figure 6.42 Post-monsoon: Adult females and latrine use 77

Figure 6.43 Pre-monsoon: Adult male children and latrine use 78

Figure 6.44 Post-monsoon: Adult male children and latrine use 78 
Figure 6.45 Pre-monsoon: Adult female children and latrine use

Figure 6.46 Post-monsoon: Adult female children and latrine use

Figure 6.47 Pre-monsoon: Number of households sharing a latrine

79

Figure 6.48 Post-monsoon: Number of households sharing a latrine

79

Figure 7.1 A conceptual model for the ecology of cholera

100

Figure 7.2 Variables associated with pre- and post-monsoon cholera

101 transmission 


\section{GLOSSARY}

Antigens: Substances capable of inducing a specific immune response and of reacting with the products of that response.

Asporogenous: Not producing spores. Spores are reproductive elements of organisms. Elements are the simple substances (material constituting an organ or body), which cannot be decomposed by chemical means.

Autochthonous: Descended from the original flora or fauna in the region in which it was found.

Cholera Toxin (CT): An essential determinant of virulence within the O1 serogroup of $V$. cholerae strains that do not produce CT have not yet demonstrated the potential to cause epidemic cholera.

Classical cholera: The classical biotype disappeared in 1973 and re-emerged in 1982. Comma-bacillus: Comma-shaped bacteria that cause Asiatic cholera.

Copepods: A relative of the shrimp that forms part of the zooplankton population in the aquatic habitat. It lives in the salty or brackish wasters of ponds, lakes, and rivers, and travels with currents and tides. Copepods harbor dormant, nutrient-deprived, and culturable Vibrio.

Cyanobacteria: Water dwelling organisms important for the health and growth of many plants, as they can convert inert atmospheric nitrogen into an organic form. El Tor: The biotype El Tor was first identified in Matlab in 1969 and has dominated since. 
Facultatively: Capable of functioning under varying environmental conditions (i.e., bacteria that can live with or without oxygen).

Hypovolemic shock: A condition where the heart is unable to supply enough blood to the body because of inadequate blood volume or blood loss.

Metabolic acidosis: An excess of acidity in human blood.

Pathogenesis: The lifecycle of a disease; its origin and the events leading to its development.

Phage: Short for bacteriophage, a virus living within bacteria.

Plankton: Marine and freshwater organisms that drift on or near the surface of the water. Important algae groups in the phytoplankton include diatoms and cyanobacteria. The other component of plankton, zooplankton, is comprised of protozoa and small crustaceans, jellyfish, worms, and mollusks, together with the eggs and larvae of the many animal species inhabiting marine and fresh waters.

Scaphoid abdomen: An abdomen whose anterior wall is hollowed out.

Skin turgor: Skin turgor is the skin's degree of resistance to deformation and is determined by various factors, such as the amount of fluids in the body (hydration) and age. When a person has cholera there is an abnormality in the skin's ability to change shape, returning to normal elasticity.

Thermostable: An enzyme that is not readily subject to destruction or by heat. Uremia: A condition resulting from advanced stages of kidney failure in which urea and other nitrogen-containing wastes are found in the blood. 
Viable but Nonculturable (VNC): Vibrio cholerae enters into a dormant state under unfavorable conditions, yet it keeps biological activity (protein synthesis) and remains infectious.

Virulence: The ability of an agent of infection to produce disease. The virulence of a microorganism (i.e., bacteria) is a measure of the severity of the disease it is capable of causing. 


\section{Introduction}

Bangladesh is home to over 133 million people who are packed into an area slightly smaller than the state of Iowa (approximately $144,000 \mathrm{sq} . \mathrm{km}$ ), with nearly 923 people per square kilometer (CIA 2003). Historically, the crowding in Bangladesh has distinguished it as one of the most densely populated countries in the world. This concentration of people affects both the health of its people and their surrounding environment. Inadequate sanitation facilities and poor hygienic practices contribute to the prevalence of the cholera pathogen in the surface water of Bangladesh. Assessing risk for cholera involves understanding the dynamic interaction between the environmental, socioeconomic, and cultural/behavioral risk factors through time and space. The objective of this study is to differentiate between the risk factors for pre- and post-monsoon cholera epidemics.

In Bangladesh, cholera is endemic and epidemics occur seasonally. Cholera epidemics correspond with the annual monsoon: the first, and smallest, occurs premonsoon between March and June, while the larger cholera peak occurs between September and December post-monsoon. I hypothesize that the risk factors will be different between the seasonal cholera epidemics because both the environment and the ways in which Bangladeshis interact with their environment change seasonally.

While there have been numerous cholera studies in Bangladesh, none has differentiated between the risk factors for pre- and post-monsoon cholera epidemics. Establishing seasonal risk factors will prove valuable to health officials by providing a base knowledge of the critical risks associated with seasonal cholera, which will help 
them develop future disease prevention programs. Health officials may also use this information to help Bangladeshis understand that their interaction with their environment can lead to cholera contamination.

This study identifies the risk factors for pre- and post-monsoon cholera. There are differences in the risk factors for seasonal cholera because the ecology of the disease functions within a dynamic spatio-temporal structure causing varying degrees of human exposure to the disease.

Analysis is premised on the expectation that the changing environmental conditions greatly affect different human behaviors, and those behaviors are believed to be risks to cholera transmission. For example, the beginning of the cholera season in Bangladesh (pre-monsoon) coincides with the dry season: warm temperatures, cessation of rainfall, and low water levels. During the dry season, few natural aquatic habitats exist in which the pathogens can survive. Despite the fact that there is less surface water in the pre-monsoon period, the remaining water areas provide the perfect niche for pathogen survival, (i.e., the stagnant water with ideal growing conditions). The dry season also provides few areas for humans to extract water for their everyday needs (i.e., cooking and washing). In short, the combination of water areas with higher concentrations of cholera and humans using those contaminated sources daily, suggests one reason why cholera is endemic in Bangladesh.

Just as the changing environmental conditions impact human behaviors in the pre-monsoon season, it is my belief that environmental conditions impact behavior during the post-monsoon season. For example, larger volumes of water during the 
post-monsoon season can transmit cholera throughout rural Bangladesh. The majority of this area is submerged by water during the monsoon season, this combined with the fact that many people in this area defecate in open, unsanitary locations, could potentially cause disease transmission.

This study is based on medical geography's theoretical approach called disease ecology (see Chapter 3). It also employs ecological association analysis, using quantitative methods to model the strength of association between the independent variables and cholera occurrence. This approach provides an understanding of disease causation.

This research project provides essential information about the disease ecology of cholera. More specifically, the study accomplishes the following goals. It:

- differentiates between the risk factors for the biannual cholera epidemics.

- offers corroborating evidence that seasonal cholera epidemics are caused by both human behaviors and by environmental situations.

- shows that risk factors are different seasonally; thus, showing that epidemiology studies on cholera should consider seasonal differences when calculating risk.

This study uses secondary data collected in rural Bangladesh from January 1, 1992 through December 31, 1994. 


\section{Study area}

Since 1963, the field staff and scientists at the International Centre for Diarrheal Disease Research, Bangladesh (ICDDR,B) have regularly collected and analyzed data concerning the demographic, socioeconomic, and health of the people living in this area. The underlying goal is to learn about the ecology and epidemiology of common diseases (i.e., cholera), and to implement scientific methods into epidemiological studies.

Matlab, the field station of the ICDDR, B and study area for this research, has one of the world's largest demographic surveillance system (DSS) operating in a developing country since 1966 (Bairagi et al. 2001). The DSS conducts a periodic census that registers the births, deaths, and migration of the people in Matlab. The unique feature common to all studies conducted in Matlab is the implementation and use of individual identification numbers, which allows for an easy linkage between the demographic and socioeconomic data to cholera incidence data. The Matlab study area is an ideal location for a cholera study. Not only are the data regularly collected and maintained, but it is an area with high population density, high cholera rates, and a hospitable environment for the pathogen year-round.

Between the years 1992 and 1994 there were roughly 200,000 people living in Matlab, an area of approximately 184 sq. $\mathrm{km}$ (Ali et al. 2002). There are 142 villages in the study area, 128 of which are predominately Muslim and 14 Hindu. Matlab is located in the middle of the Ganges-Meghna delta floodplain approximately $45 \mathrm{~km}$ from Dhaka, the capital of Bangladesh. Figure 2.1 shows the study location within 
Figure 2.1: Study area location.

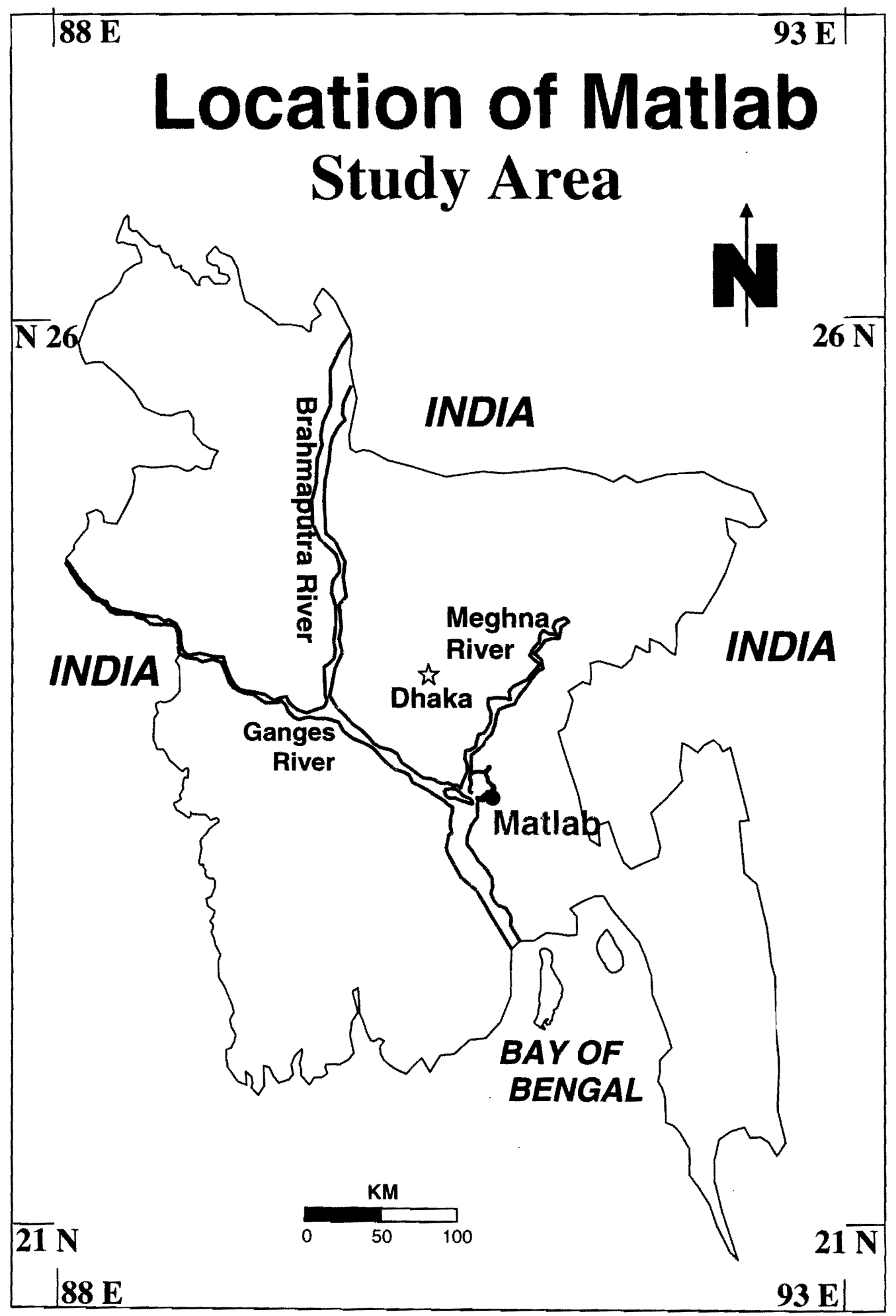


Bangladesh relative to Dhaka, the Bay of Bengal, and the location of the areas three largest rivers of Bangladesh, the Ganges, the Brahmaputra, and the Meghna Rivers (GBM).

The GBM is intersected by a system of streams, channels, and tidal rivers that cover the entire study area. The many water sources in Matlab are affected by annual monsoons which begin in May or June. A monsoon, or borsha to the Bangladeshi's (Shaw 1992), is defined as a seasonal shift in a wind regime, associated with periods of heavy rainfall. In Bangladesh, 70-85 percent of the annual rainfall occurs during the monsoon (Reavill and Rahman 1995), accumulating an average of $152 \mathrm{~cm}$ of rainfall each season, with over 80 percent of the 1,350 billion cubic meters of rainfall runoff occurring with the GBM catchments during the monsoon (Aziz 1994). Annually, the water levels fluctuate by more than 4 meters from a high water peak during the monsoon season to low water levels in the dry season between January and April. Most of the monsoon flooding in Bangladesh is caused by hydrological cycle fluctuations from rainstorm river floods, snow-melt floods, coastal floods, and failure of flood embankments (Reavill and Rahman 1995). Table 2.1 lists average monthly temperature and rainfall data that were collect at a weather station near Matlab.

Table 2.1: Seasonal climatic variation in Matlab.

\begin{tabular}{|l|c|c|c|c|c|c|c|c|c|c|c|c|}
\hline MI & 0.66 & 2.7 & 4.98 & 19.3 & 28.6 & 52.2 & 52.7 & 41.6 & 29.1 & 23.7 & 4.88 & 0.69 \\
\hline Mhrt & 26.1 & 29.5 & 33.6 & 33.8 & 33.6 & 32.2 & 31.4 & 31.9 & 31.2 & 31.8 & 29.9 & 26.9 \\
\hline Mut & 10.7 & 14.8 & 17.9 & 22.2 & 23.2 & 23.8 & 25.1 & 24.7 & 24.2 & 22.9 & 18.2 & 11.8 \\
\hline
\end{tabular}

RF: Rainfall (cm) 1947-1977

MaxT: Maximum Temperature (degrees C) 1947-1977

MinT: Minimum Temperature (degrees C) 1947-1977 
During the monsoon, Matlab is inundated with water. Most of the footpaths and agricultural fields are submerged by water and transportation is mainly via boat. Figure 2.2 shows the Matlab study site relative to the Meghna River and the Dhonagoda River, which is a tributary of the Meghna River. The abundant rivers, canals, and ponds provide the primary water sources for those living in rural Bangladesh, and thus these people are directly affected by the seasonal changes in the water levels.

A flood control embankment was built in the mid-1980's as part of The Bangladesh Flood Action Plan in an attempt to increase agriculture production in nearly half of the Matlab study area. The Meghna-Dhonagoda Irrigation Project regulates the amount of water that enters the embanked area from the Meghna and Dhonagoda Rivers. Figure 2.3 shows the flood embankment. The area northwest of the embankment is regulated during the monsoon season when flooding occurs, and the area southeast of the embankment is the unregulated area.

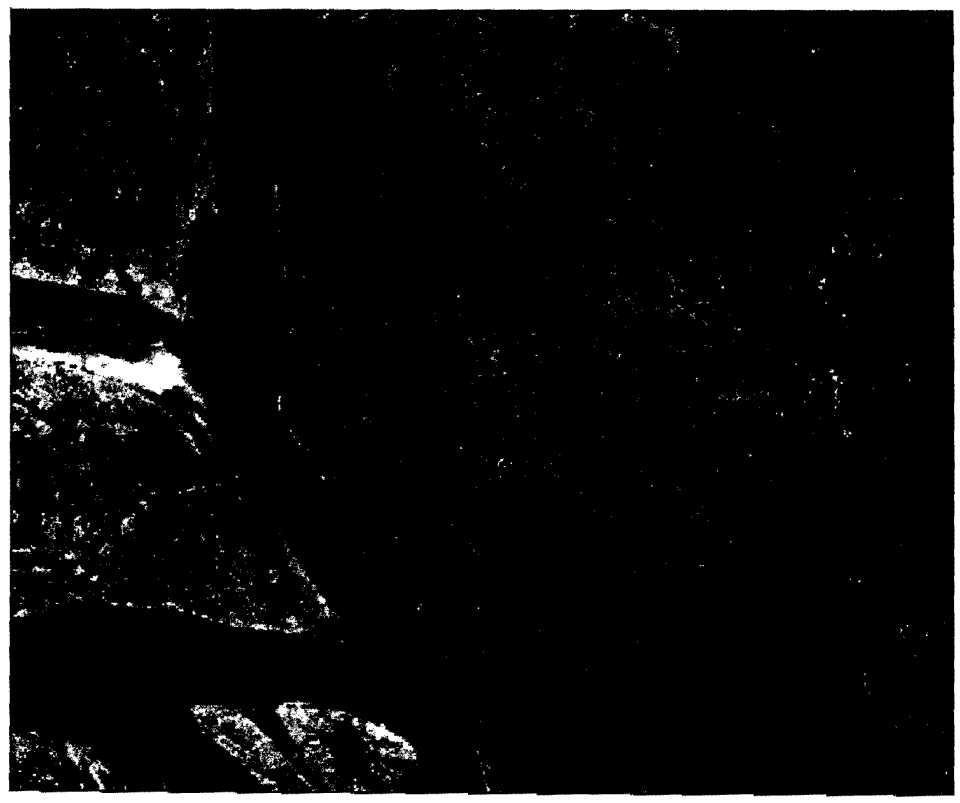

Figure 2.2: Study area superimposed on a Landsat TM satellite image. 
Figure 2.3: Flood protected area within Matlab.

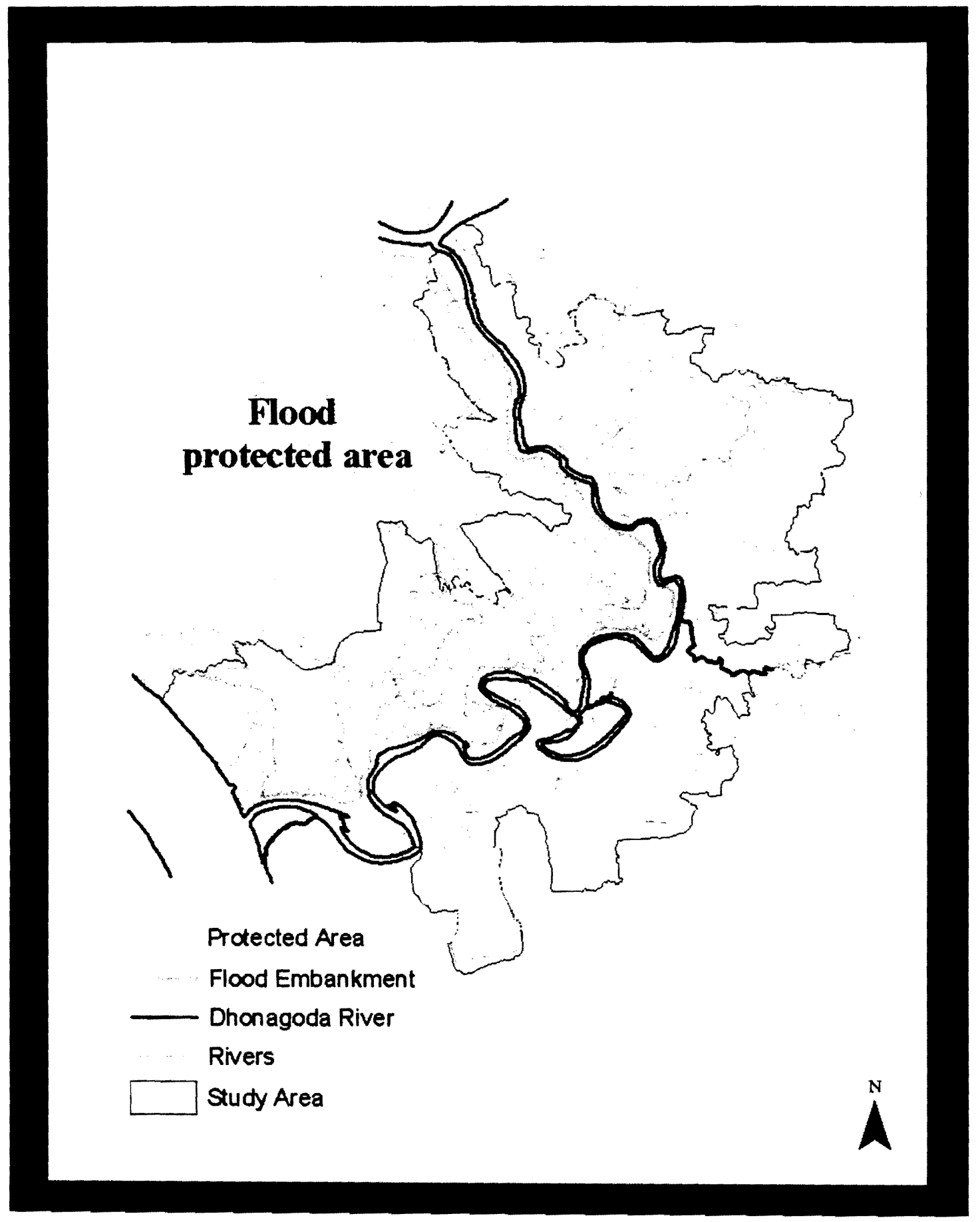


The Bangladeshi people suffer from endemic cholera in many ways other than through poor health; they also run into socioeconomic problems caused by medical expenses and lost productivity. Unemployment and underemployment are significant problems in Bangladesh. Being a poor country, the people fortunate enough to find employment make a small income by agriculture and fishing. Most of the arable land is given over to rice farming, which is the dietary staple. Rice farming begins late autumn, between November and December (McCormack et al. 1969), months that have significant cholera cases. Rice farming often puts workers at risk of contracting cholera because of their direct contact with contaminated, stagnant surface waters.

When Matlab is at its peak water level, all of the agricultural land is submerged (Aziz 1994) and the Bangladeshis turn to fishing to make a living. Fishing represents the livelihood of nearly five million Bangladeshis, many of whom migrate when the fishing season begins during the post-monsoon season (McCormack et al. 1969). Agriculture, fishing, and other income-generating methods are not technologically advanced; rather, century-old methods are still in practice (Aziz 1994). For example,

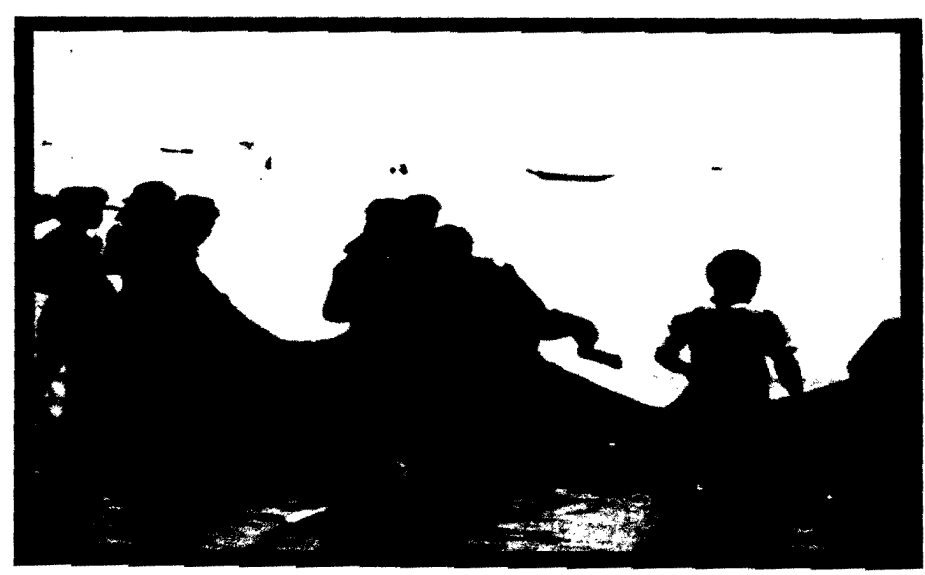

Figure 2.4:

Large-scale fishing

on the Meghna

River, Matlab. 


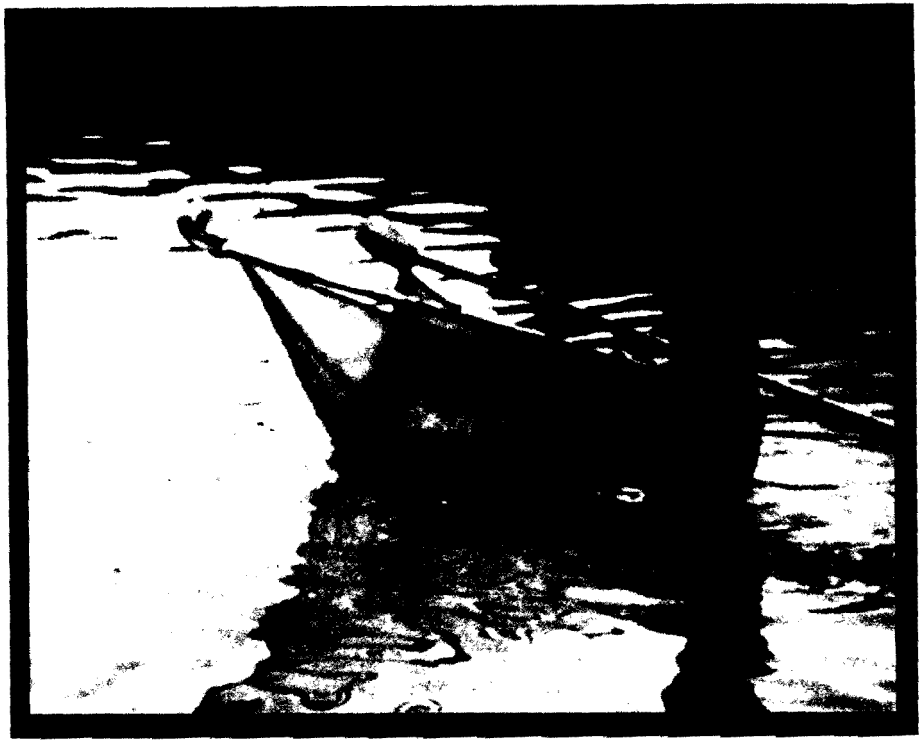

Figure 2.5:

Small-scale

fishing in Matlab on the Meghna River.

the diverse types of fishing practices within the study area are shown in Figures 2.4 and 2.5 .

As the surface waters ebb and flow seasonally, so does the health of Bangladeshis. Matlab has two distinct cholera peaks that correspond to the pre- and post-monsoon seasons. Seasonal water availability may impact biannual cholera epidemics. For example, many Bangladeshi homes are constructed on mounds (bhiti) high enough to escape the post-monsoon floods (Briscoe 1978; Shaw 1992). The dirt used to build the platforms creates large excavated areas that fill with water during the monsoons, and these excavated areas are often used as tanks that provide open water sources for the Bangladeshis. Water supply is of prime importance, and where nature's provision is lacking particularly during the dry season (pre-monsoon), these tanks are used for multiple purposes, such as a drinking water reservoir, a public bath, a cattle trough, and a buffalo soak (Shaw 1992). Tanks are believed to be sources for 
vibrios to survive in endemic areas such as Bangladesh (Khan et al. 1984). The extreme seasonal fluctuations in Matlab's surface waters are believed to be environmental risks to biannual cholera epidemics.

A bari is a homestead, which is a group of households sharing the same courtyard; a village is a group of contiguous baris. Generally, in rural Bangladesh, baris follow a similar

blueprint. Figure 2.6 shows

the layout of a small

homestead, one that is

typical of someone who is

reasonably well off. The

entire bari is surrounded by

a bamboo matting fence,

Figure 2.6: Layout of a bari.

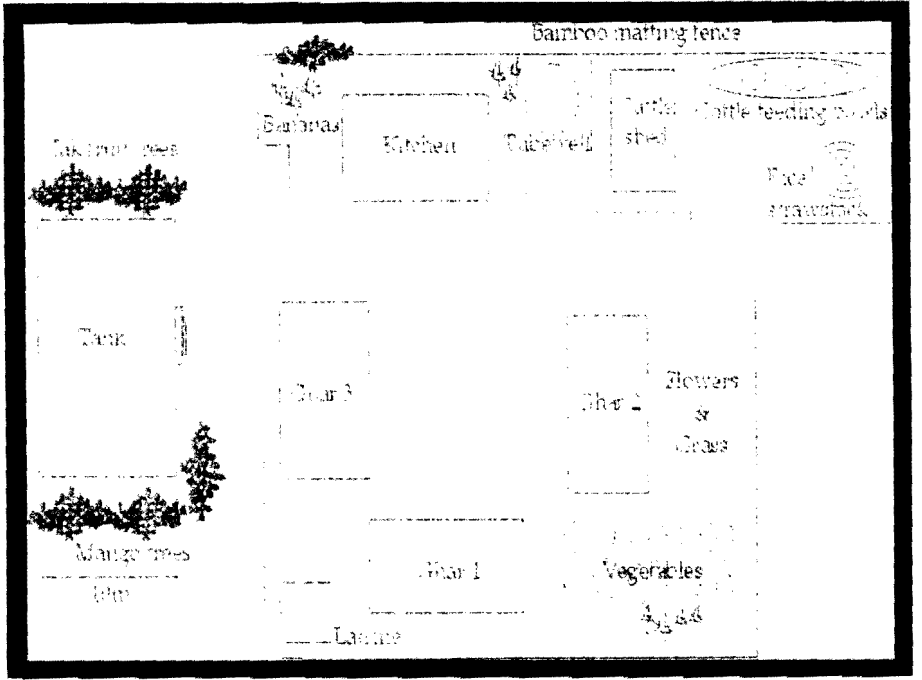

which is meant to provide

privacy. The tank lies just outside of the bari perimeter and is used by those dwelling within that bari. Although the latrine is shown in the corner of the bari, many of the inhabitants of a bari prefer to relieve themselves outside of the homestead perimeter (Johnson 1982). Each bari consists of small ghars ranged around the central courtyard. A ghar, or household, is a unit that accommodates all members within a particular family (Aziz 1994). Patriarchal in character, the ghar usually includes kin members and their married partners, and the inhabitants range from one to three generations (Aziz 1994). Figure 2.7 is a detailed diagram of a ghar. Households in this study area 
are built with a variety of materials including tin and brick in the wealthiest households, to bamboo and thatched straw in the poorer households.

Bangladeshis build the ghars Figure 2.7: Detail of a ghar. on mud plinths, approximately $50 \mathrm{~cm}$ high, in order to avoid the annual monsoon floods (Johnson 1982). Figure 2.8 is a picture of a bari during the dry season and Figure 2.9 is a

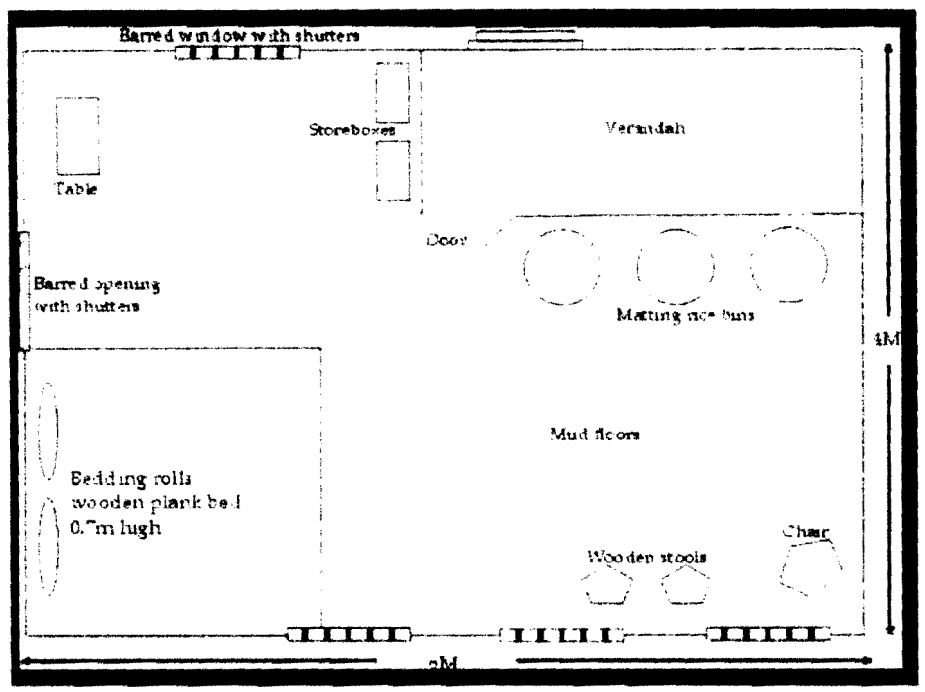
picture of a bari during the monsoon.

Since life is primarily organized around the household unit, a certain amount of sharing occurs between the residents within a bari. For example, households often share cooking utensils (Aziz 1994). Among the commonly shared resources are the tanks, the latrines, and the tubewells. Each bari has a tank where water is stored and obtained for personal and domestic purposes such as bathing and cooking (Aziz 1994). While sharing household items is practical, if proper hygiene is not practiced, secondary cholera transmittance is likely to occur. 


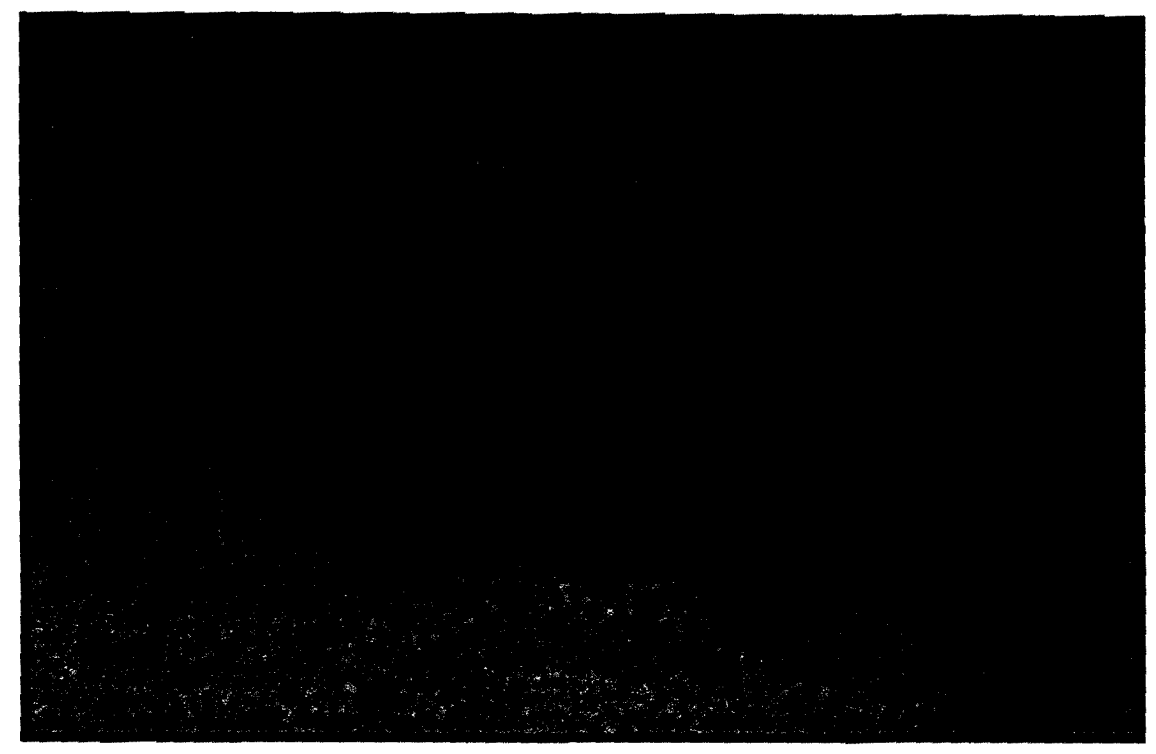

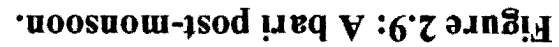

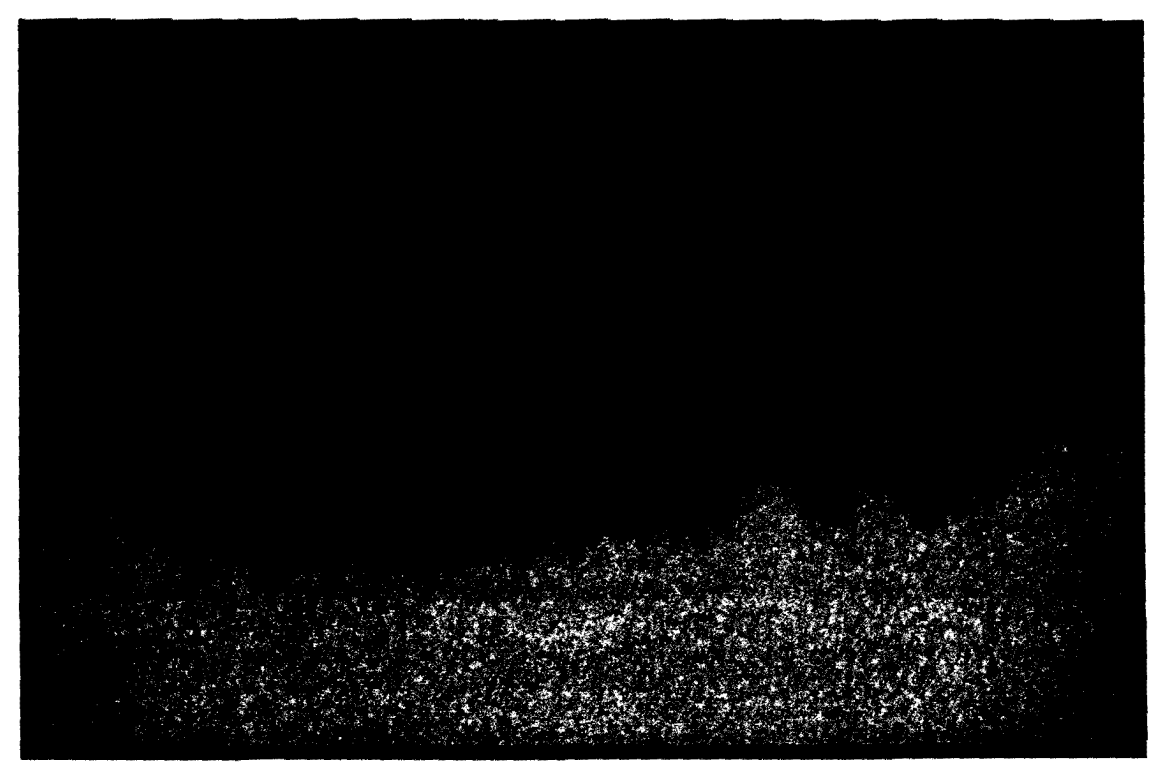

•uoosuou-a.d !̣kq $\vee: 8 \cdot \tau$ a.In8!! 
There is no part of the study area where the inhabitants have access to treated, running water, and thus, tubewells are the cleanest water source. A tubewell is a pipe sunk into a water-bearing stratum, and is fitted with a strainer at the bottom and a hand-pump at the top. An ideal water and sanitation situation in the study area is one that all members of a bari have access to a tubewell and a sanitary latrine and also use them. When a latrine is not sanitary (i.e., drains into the environment instead of a septic system) or a latrine is not used by someone within the bari. I hypothesize that people in that bari are more likely to contract cholera. Household sanitation, which depends on socioeconomic status and education, is very slow to improve in rural Bangladesh (Yusuf et al. 1990).

Since 1963 each person living in Matlab has been traced with a unique identification number that links him or her to their bari. The baris are all identified by an ICDDR,B, DSS census number and maintained within the structure of a geographic information system (GIS) database. Figure 2.10 shows the distribution of baris in Matlab. Because each bari has an exclusive identification number it is easy to link the demographic and socioeconomic data to the cholera incidence data for years 1992 through 1994. More specifically, each cholera case can be linked to a specific bari location and to the surrounding environment. Regular data collection provides an accurate base in which to investigate possible risks to cholera epidemics. Section 5 discusses the data sources in detail. 
Figure 2.10: Distribution of baris in Matlab.

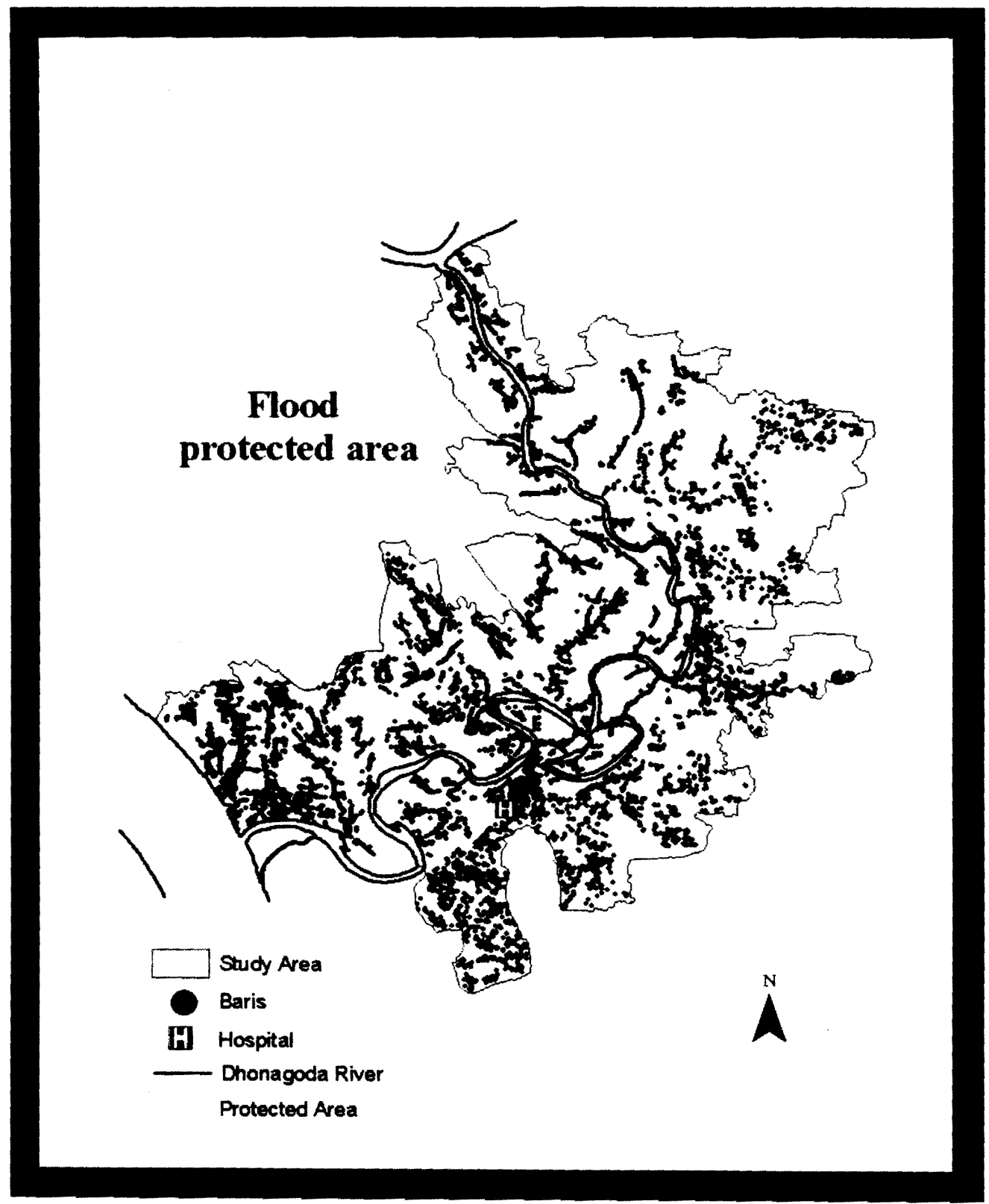




\section{Medical geography}

Over the years Geographers have disputed the nature of their discipline. Some dichotomized geography between the systematic and the synthesis sciences (May 1970), while others believed that both nature and history were the backbone of geography (Semple 1911). Separating and contesting the nature of geography has provided a useful framework for creating a scientific discipline concerned with identifying, explaining, and analyzing spatial and temporal patterns and variation, which helps to explain the link between humans and their environment.

Medical geography is both an ancient perspective and a new specialization. Historically, great minds such as Hippocrates understood the importance of culturalenvironmental interactions on health studies. His ecological perspective on disease and health was carried through until the emergence of the germ theory in the nineteenth century (Meade 1988). With a growing knowledge of how diseases are transmitted, many physicians began to incorporate geography into healthcare practices under the guise of maintaining the holistic Hippocratic tradition (Hirsch 1886). But only within the last thirty years has the term medical geography been incorporated into disease analysis and health-care investigations. Presently, medical geographers use concepts (e.g., patterns and processes of spatial diffusion) and techniques (e.g., GIS and remote sensing) from the various sub-disciplines within geography to investigate health-related topics. Meade and Earickson (2000) explain the objectives of a medical geographer as: “...want[ing] to know not only how a disease is spread in a population, but how that spread occurs over space; not only how many cases might occur at a 
future point in time but where those cases are likely to occur" (Meade and Earickson 2000 p.262).

Because geography is at the crux of many disease investigations, medical geographers can provide valuable input into such studies. Jonathon Mayer provides an analogy that sums up the link between geography and health, "geography is both the anatomy and physiology of regions: anatomy because of its emphasis on form and physiology because of its emphasis on process and function" (Mayer 1984 p.2680).

The combination of geography and health has provided medical geographers with the perfect niche to study the patterns and processes of disease transmission. There are two objectives within most medical geographical studies. The first is to determine the origin of a disease, and the second is to explain the patterns of disease distribution by incorporating all possible causal variables. In short, the medical geographer takes a holistic approach in a disease investigation by analyzing and understanding the combination of different possibilities that help create an epidemic. There are many influential factors involved with disease spread within our changing world, such as globalization, over population, inadequate sanitation infrastructure, and environmental change. These factors impact the distribution of emerging and reemerging diseases. In order to prepare for the spread of current and future diseases, it is important to fully understand all possible factors involved: biological, socioeconomic, environmental, cultural, and behavioral. 


\subsection{Risk factors}

Analyzing cholera risk during the pre- and post-monsoon seasons in rural Bangladesh requires a theoretical foundation that incorporates spatial and temporal complexities. This thesis demonstrates the importance of a medical geographic approach that integrates different variables associated with contracting a disease, by investigating the myriad of variables of pre- and post-monsoon cholera. These are:

Environmental risk factors: Any element in the environment that predisposes the host to a disease. Contaminated surface water is an example of an environmental risk factor.

Socioeconomic risk factors: Any factor that affects the coincidence of host and pathogen, such as working practices.

Cultural/Behavioral risk factors: A situation or an action that associates an individual or group of individuals to a pathogen. Examples are: bathing practices, washing practices, hygiene practices, cooking practices, and where people obtain their drinking water.

While different combinations of these factors will determine the spatial and temporal pattern of seasonal cholera, there is one common thread between them: the concept of “a-point-in-time," coined by Jacques May (1958). As May observed, a disease arises because environmental and organic factors intersect both temporally and spatially:

Disease cannot arise without the convergence at a certain point in time and space. . of two orders of factors: factors that take the form of an environmental stimulus. ., and second, factors that condition the 
response of the tissues. These stimuli... are not the same in every environment. They vary with geographical or cultural location. The response is conditioned by the genetic make-up of the recipient. (May $1958 \mathrm{p} 3)$.

May defines "stimulus" to be anything inorganic, organic, or socio-cultural, all working in a dynamic cycle to balance or imbalance health and disease. Figure 3.1 is a model demonstrating May's dynamic structure of the ecology of disease and health.

Figure 3.1: The ecology of disease and health. Source: Meade 1988.

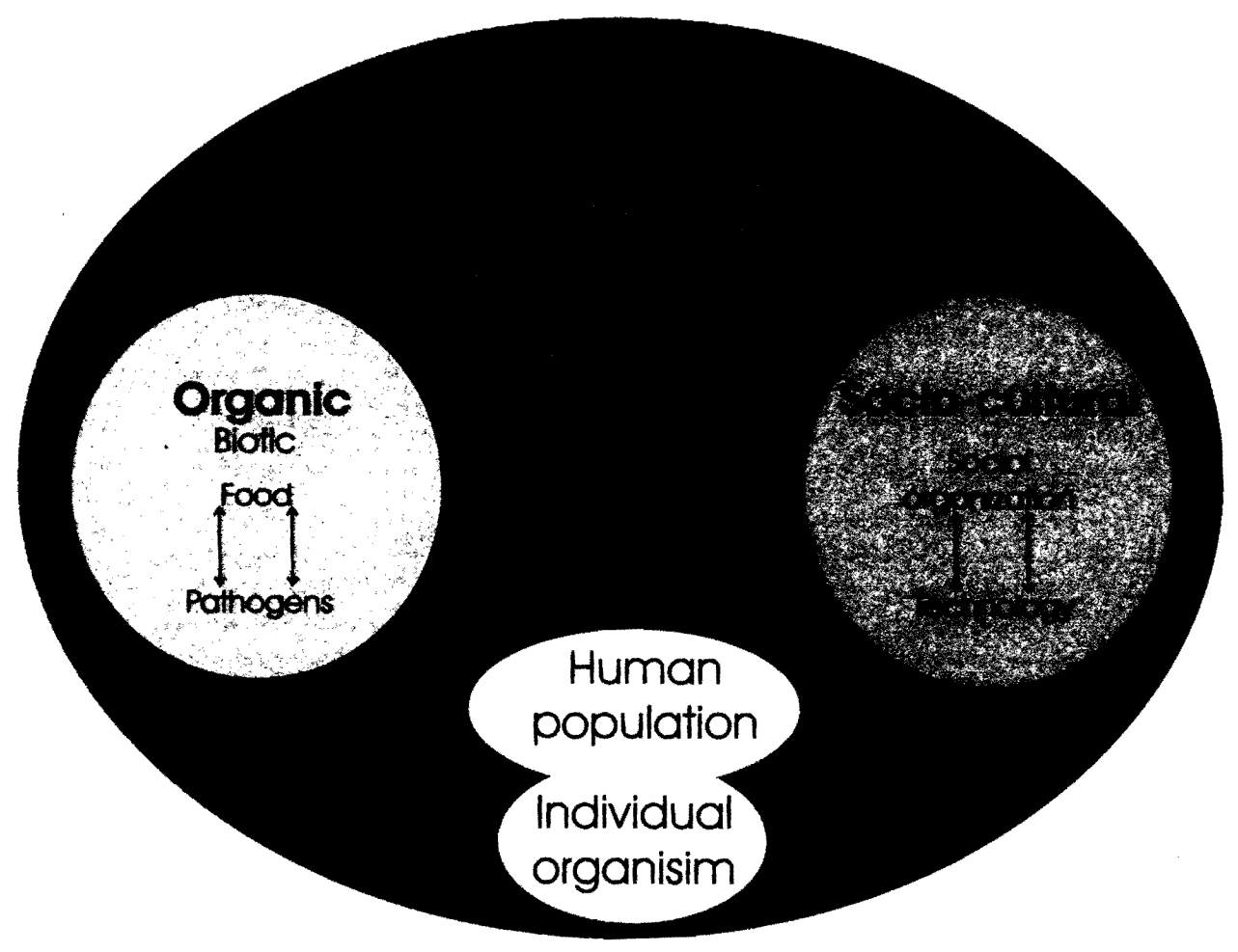


Inorganic factors are climatic (e.g., temperature and precipitation) and affect humans either directly or indirectly. Direct action encompasses how the climatic physical elements affect humans directly. Indirect action is how climatic factors influence all organisms that inhabit an area, for example, climate's affects on agricultural cycles. Flooding during the Bangladesh monsoon season can wipe out crops, leaving large numbers of people without food. Malnourishment can lead to a weakened immune system, creating a situation in which the body cannot fight off an infectious disease. Seasonal flooding was one reason why the flood embankment was built in Matlab. It was constructed to aid in the management of the Bangladeshi water resources, providing water during the dry season, and protection against monsoon floods. For all the good the embankment was meant to provide, Emch (1999) and others have found that people living with this flood-controlled embankment were more likely to be hospitalized with cholera.

Organic factors are the things (e.g., food and shelter) that support an organism's survival, balancing the platform in which various plants, animals, and human societies live and reproduce (May 1958). For example, an upsetting factor, such as heavy rainfall, provides favorable habitats for $V$. cholerae to reproduce, but can cause flooding problems for the Bangladeshi people, thus offsetting the balance between host/pathogen coexistence and disease outbreak.

May also believes that social and cultural factors provide a range of stimuli that contribute to epidemics: "Certain situations inherent to cultural and social patterns create stress in the human system that may facilitate the aggression and detrimental 
effects of living disease agents (May 1958 p. 9)". The socio-cultural factor includes cultural practices, social norms, economic constraints, and technological advancement. Poverty, for example, is an element which involves different human exposures to the environment than those less deprived. Many residents in rural Bangladesh are poor and have inadequate sanitation facilities, and thus are forced to obtain water from contaminated sources. Poverty is an experience that can influence human behavior in a way that hinders a person's health status by increasing harmful exposures. Through their behavior, people expose themselves to, or protect themselves from their environmental conditions; providing hazards and opportunities to the population's immunology, genetics, and nutrition. In short, socio-cultural status influences human interaction with their environment, which in turn influences their health.

In order to determine what variables are important for the different cholera epidemics it is important to establish when there is an excess of disease over what is expected. Because there is no precise measurement for this determination, epidemiologists and medical geographers incorporate the terms endemic and epidemic into their disease analysis to help determine the dynamics of disease transmission. Endemic is defined as the habitual presence of a disease within a given geographical area. An epidemic is defined as the occurrence of a disease in a community or region that is clearly in excess of normal expectancy. Bangladesh is one of few areas in the world where cholera is endemic, and epidemics occur biannually. The factors that influence epidemic cholera in endemic areas are changing environmental conditions, 
host behavior, and pathogen etiology, all of which are impacted by the ecology of the disease.

\subsection{Disease ecology}

Within medical geography, the oldest theoretical approach is disease ecology (Paul 1985), the tenet that underlies this study. Disease ecology maintains that a disease results from a dynamic, complex set of variables that coincide in time and space. Though its origin can be linked back to Hippocratic roots of environmental medicine, German physicians Fuchs and Muhry laid the foundation of disease ecology in the late eighteenth and early nineteenth centuries. Between the nineteenth and midtwentieth centuries, few researchers incorporated disease ecology into their studies, and it was not until the twentieth century that May re-introduced this medical geographical approach to health related studies (Paul 1985). Today, medical geographers often incorporate disease ecology into their analysis because it provides a powerful way to understand the emergence and reemergence of a disease (May 1958; Mayer 2000; Meade and Earickson 2000).

In order to understand the ecology of cholera it is imperative to study the dynamic, inter-related risk factors associated with the disease. Determining these factors will advance our understanding of the ecology of cholera, help explain how cholera varies both spatially and temporally, and potentially lead to important clues of disease causation. This study analyzes the risk factors of cholera, focusing on those human and environmental variables that occur in the pre- and post-monsoon season. 
To some extent, every disease varies over time and space, and it is because of this variation that medical geographers incorporate disease ecology into their analysis.

While disease ecology provides the theoretical ideology for understanding the dynamic factors associated with medical geographic studies, the ecological association approach is the methodology that will be used to focus on the risk factors that influence the disease. The emphasis underlying the ecological association approach is on the dynamic and interrelated interaction between people and their environment (Mayer 1986). For example, an ecological model looks at why the host and pathogen come into contact with one another. Within the context of this research the risk factors associated with the human-pathogen interaction falls into one or more of the following categories: environmental, socioeconomic, and/or cultural/behavioral. These factors influence the behavior and biology of the host and pathogen, and all relate to the environment that directly influences human health. Once the risk factors are identified, statistical measurements, such as logistic regression analysis, are used to establish an association between disease and its risk factor. However, there are problems associated with this methodology, such as spurious conclusions. According to Mayer (1986) one of the biggest challenges of the ecological association approach is when more than one factor is involved with a disease study. For example, cholera has been linked to environmental changes (e.g., higher water temperatures); however it is unlikely that this environmental variable is the only reason that cholera is shifting its geography (moving up estuaries). Actually, it is probable that other factors, such as seasonal water levels, are involved. When using the ecological association approach 
in combination with disease ecology and statistical models, the challenge of including multiple factors becomes less of an issue because all risk factors of seasonal cholera are considered holistically so they are not spuriously correlated.

Since the inception of disease ecology and ecological association, studies are increasingly paying more attention to temporal patterns, spatial scale, and statistical methods. Disease studies should always incorporate a temporal dimension because temporal changes in risk factors (e.g., monsoons) often affect the interaction between host and pathogen. Spatial analysis is important because disease association can vary from one spatial scale to another. By identifying patterns of geographical variation of a disease at a variety of scales one can determine at what level variation is occurring. For example, if the disease exhibits little variation, then there is little point in further spatial analysis. If there is variation, researchers must determine the statistical significance of that variation. Using the spatial analysis methods within a GIS you can specify the units at which variation is significant, and then select a set of independent variables that may enter the analysis meaningfully.

This thesis is structured around a holistic understanding that humanenvironment interaction is inseparable. It is my belief that medical geographic studies should include the environmental, socioeconomic, cultural/behavioral, and biological variables at various temporal and spatial scales in order to understand the disease ecology of a particular place. However, this study is limited to one spatial scale, and, it excludes biological variables associated to seasonal cholera. Many studies include biological risk factors in their analysis for a complete disease investigation, but the 
biological variable is excluded from this study because data were not available. In order to have a complete understanding of the risk factors associated with pre- and post-monsoon cholera in rural Bangladesh, I believe that it is necessary to do further. research on the biological variables involved in the ecology of this disease.

The following chapter discusses the etiology, ecology, epidemiology, and seasonality of cholera in rural Bangladesh, as well as the various risks associated with the disease. 


\section{Cholera: Literature review}

Cholera is an acute intestinal infection caused by a bacterium from the Vibrionaceae family. Vibrio is the genus and Vibrio cholerae is the type species. V. cholerae causes a lifeFigure 4.1: Electron micrograph of Vibrio cholerae. Source: threatening infection with an incubation period ranging from less than one day to five days (World Health Organization 2000). The disease is characterized by watery diarrhea, http://microbes.historique.net/cholerae.html

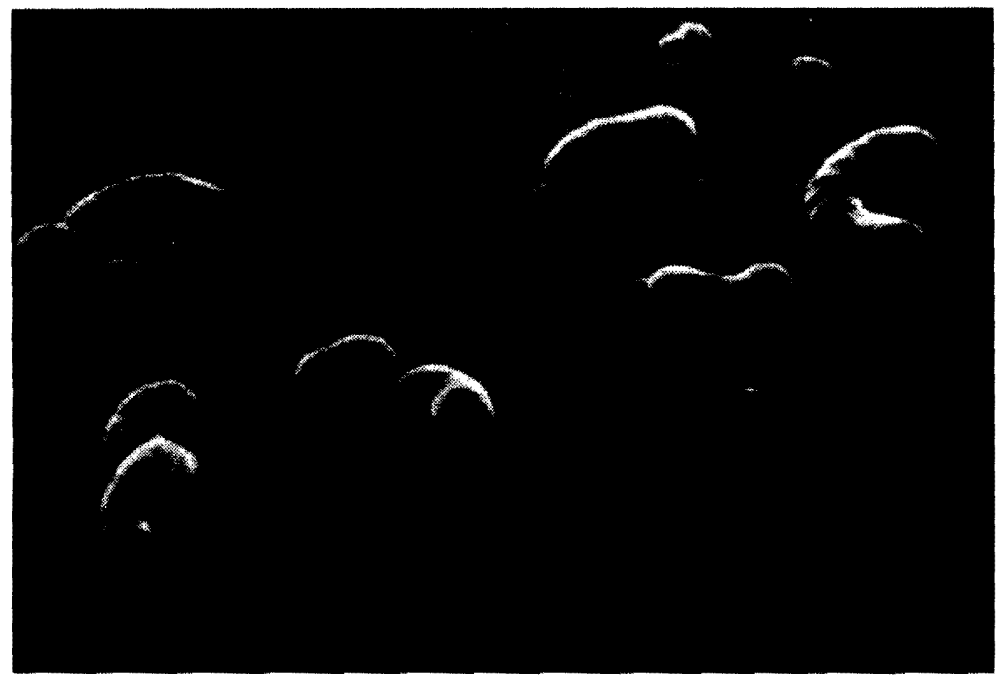

muscle cramps, vomiting, and dehydration. The severity of the disease is influenced by a number of factors, such as, short incubation periods, inadequate medical treatment, poverty, crowding, insufficient sanitation systems, poor hygiene practices, and as suggested in this study, changing environmental conditions. All of these factors are conducive to the growth and reproduction of the pathogen. Figure 4.1 shows a microscopic image of the cholera pathogen.

\subsection{Cholera etiology}

$V$. cholerae is divided into serogroups based on patterns of agglutinations with specific antisera. Currently, there are more than 150 known serogroups of the 
pathogen (Bopp et al. 1999), and only two of those serogroups are related to the spread of cholera: $\mathrm{O} 1$ and $\mathrm{O} 139$. The isolates of $V$. cholerae $\mathrm{O} 1$ can be broken into two biotypes: cholerae classical and El Tor. Cholerae classical has been linked to the fifth (1881-1896) and sixth pandemic (1899-1923) pandemics. With the onset of the seventh pandemic (1961-current), the El Tor biotype has become the predominate cause of cholera epidemics throughout the world (Baura 1992).

Both serogroups $\mathrm{O} 1$ and $\mathrm{O} 139$ are prevalent in Bangladesh, with the later becoming more virulent than the former over time (Dalsgaard and Larsen 1995; Ali et al. 2001). Since O139 first appeared in 1993 it has spread faster than the O1 El Tor biotype despite the fact that they both share similar environmental niches (Ali et al. 2001). This suggests that just as El Tor virtually replaced classical cholera in Bangladesh, it is possible that $\mathrm{O} 139$ could replace the $\mathrm{O} 1 \mathrm{El}$ Tor biotype. The emergence of $\mathrm{O} 139$, along with the re-emergence of $\mathrm{O} 1$, may be one reason why the seasonal cholera epidemics of 1993 and 1994 were different than the 1992 epidemic. In 1992, the cholera peaks were higher in the pre-monsoon epidemic and lower after the monsoon, which was just the opposite of the 1993 and 1994 epidemics (Emch and Ali 2001). An explanation of why the number of cholera cases was higher during the 1993 and 1994 post-monsoon disease peaks is that the Matlab population was inundated with not one, but two types of cholera strains. 
Figure 4.2: The Pathophysiology of cholera. Revised image from: Finkelstein 1996.

\section{Disease \\ Hypovolemic shock \\ Acidosis \\ Vomiting \\ Diarrhea \\ Muscle cramps}

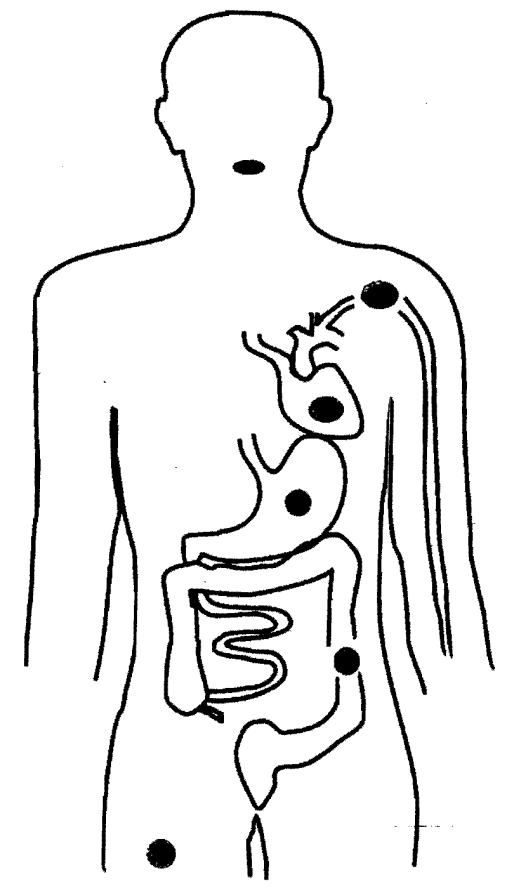

1. Entry

2. Colonization

4. Exit (in 1 to many liters of fluid per day)

In order to establish infection, the pathogen must enter into the host orally reaching the gut where it colonizes through intestinal attachment, upon which the multiplication process begins. Following the incubation period, cholera begins with an abrupt bout of diarrhea, and often severe vomiting. Several liters of fluid can be secreted within hours, leading to hypovolemic shock.

When water and electrolytes are lost from body tissues, a deluge of health issues can occur; muscle cramps, loss of skin turgor, scaphoid abdomen, and a weak pulse are all characteristic of cholera. The disease runs its course in 2 to 7 days, and the outcome depends upon the extent of water and electrolyte loss as well as the adequacy of water and electrolyte repletion therapy. Death can occur from hypovolemic shock, metabolic acidosis, and uremia resulting from acute tubular 
necrosis. The virulence of $V$. cholerae is dependent primarily on its ability to find a host and produce the cholera toxin that is responsible for cholera.

The cholera pathogen is a parasite capable of causing disease, and the degree of pathogenicity varies from slightly, to highly virulent. The virulence of a microorganism (i.e., vibrios) is a measure of the severity of the disease. There are two factors that influence the virulence of $V$. cholerae: toxin-coregulated pilus (TCP) and cholera enterotoxin (CT) (Morris 1994). Intestinal colonization is believed to be mediated by colonization factors expressed by vibrios, the best known of which is the TCP. Cholera enterotoxin is a protein that consists of two major components, the A peptide and the B peptide. Peptide A is responsible for the toxic effect, whereas the non-toxic peptide $B$ is responsible for the internalization and transport of the toxin within the axons (nerve fibers) and cell bodies. The production of virulence factors including $\mathrm{TCP}$ and $\mathrm{CT}$ in the human pathogen $V$. cholerae depends on a single regulatory protein called ToxR, which is strongly influenced by environmental conditions (Zhu et al. 2002). For example, the protein ToxR senses environmental signals such as $\mathrm{pH}$, osmolarity, and the presence of certain amino acids to control the selective expression of genes involved in cholera pathogenesis. Enhancement of virulence may occur when the pathogen survives in a dangerous environment of the living host. Survival and replication in a hostile environment requires affirmation of pathogenicity viewed as the selection of spontaneously occurring mutants (Hoeprich 1994). The pathogens ability to sense its changing environment is an important element when it transitions from an aquatic lifestyle to a human host. 


\subsection{Cholera ecology}

$V$. cholerae has been present in the deltas of the Ganges and Meghna Rivers for at least a millennium. The pathogen is primarily a waterborne disease surviving in the dense organic matter, algae, zooplankton, and phytoplankton that populate the numerous estuarine and marine environments of Bangladesh, but it can also be found in the ponds, rivers, and tanks scattered throughout the rural landscape. The constant presence of this pathogen in these aquatic environments is why the disease is endemic in Bangladesh, and the biannual epidemics are the result of different variables associated to disease transmission.

Members of $V$. cholerae are facultatively anaerobic, asporogenous, selfpropelled, straight or curved gram-negative rods that are 1.4-2.6 um in length (Kay et al. 1994), and autochthonous (Colwell and Huq 1994). The abiotic conditions that influence vibrio growth and reproduction are: water temperature, $\mathrm{pH}$, sodium $\left(\mathrm{Na}^{+}\right)$, and salinity. When water temperature raises (a climatic outcome of the post-monsoon season) both the flora and fauna living in the aquatic environment begin to flourish (Colwell and Spira 1992). Various types of flora and fauna are believed to provide a breeding ground for $V$. cholerae. The ideal water temperature for the pathogen ranges from 30 to $37^{\circ} \mathrm{C}$ (Kay et al. 1994). The pathogen will grow in alkaline conditions up to $\mathrm{pH} 10$; however, growth is inhibited when the $\mathrm{pH}$ drops to 6.0 or below (Sakazaki 1992) (Kay et al. 1994). V. cholerae can survive in reduced levels of sodium, but the optimum growth conditions range from 5 to $15 \mathrm{~mm}$ of sodium (Kay et al. 1994). Salinity is important for vibrio survival. After heavy rains when large quantities of 
fresh water are at the mouth of a river, salinity levels are upset, and the organisms begin to multiply and move upstream. Other factors that influence cholera survival include seasonal effects such as monsoons, precipitation, temperature, and sunlight (Lipp et al. 2002).

The local flora and fauna of Bangladesh are affected by the aforementioned abiotic factors, by promoting survival of $V$. cholerae. For example, in a laboratorybased study, Islam et al. (1990) observed that $V$. cholerae live longer when attached to the common duckweed, Lemna minor, rather than in water alone. The pathogen has also been found to adhere to water hyacinth (Spira et al. 1981) as well as other hydrophytic plants (Islam and Aziz 1981). V. cholerae can also thrive in aquatic environments where fauna such as crustaceans and copepods (zooplankton) live. These species provide attachment sites for vibrios to reproduce, as well as serving as vectors to transmit the disease from one geographic region to another. Studies conducted by Colwell et al. (1984) and Hood et al. (1983) found that changing environmental conditions in estuaries suggests that $V$. cholerae can adapt to a wide range of salinity and temperature conditions by adhering to the local fauna. The adherence of $V$. cholerae to chitin appears to provide an ecological advantage for the pathogen. For example, the pathogen attaches to the chitin, which provides transportation for the pathogen to more nutrient-rich sediments during times of nutrient depletion.

Copepods are also significant to the lifecycle of $V$. cholerae (Colwell and Spira 1992). Using remotely sensed imagery, Huq et al. (1996) found that increased water 
levels and water temperatures occurred with subsequent cholera outbreaks in Bangladesh. For example, when waters heat up, phytoplankton blooms. The increased phytoplankton populations provide more food for the copepods (zooplankton), which increases this population. Copepods live in the brackish waters of ponds, rivers, and canals, and travel with the seasonal rise and fall of the tidewaters. They harbor dormant, nutrient-deprived, culturable vibrios that can survive in the gut and the surfaces of the copepods in between cholera epidemics (Colwell 2002). Colwell (2002) suggests there is a link between this process and cholera epidemics in Bangladesh, which take place shortly after sea-surface temperatures and water levels, are at their peak post-monsoon.

Organisms will either adapt or die when their natural habitat changes. When aquatic conditions change, $V$. cholerae adapts to the shift by employing different adaptation mechanisms. A common strategy used to survive in inhospitable environments is to become dormant. It is believed that dormancy, or in a "viable but nonculturable" (VNC) state is how V. cholerae responds to nutrient deprivation and other changing environmental conditions (Xu et al. 1984; Colwell et al. 1985; Islam et al. 1990; Colwell and Spira 1992). Xu et al. (1982) coined "nonculturable" to describe starved yet viable cells in a dormant or survival state of existence. They observed $\mathrm{VNC}$ after an actively growing culture of $V$. cholerae $\mathrm{O} 1$ was placed in a nutrient-free microcosm (i.e., a solution free saline and incubated at low temperatures). Under unfavorable conditions $V$. cholerae converts into a $\mathrm{VNC}$ form, entering into a dormant 
state while still maintaining biological activity (protein synthesis) and remaining infectious (Colwell and Huq 1994).

Studies on the physiology of $V$. cholerae have provided new information on the seasonality of cholera. Temperature and salinity relationships, adherence, and colonization on zooplankton are believed to impact the seasonality of cholera (Huq et al. 1984). Differences in genetic or phenotypic properties have been noticed between biotypes $\mathrm{O} 1$ and $\mathrm{O} 139$ isolated during different epidemic studies conducted by Siddique et al. (1994) and others (Nakasone et al.1987; Mukhopadhyay et al. 1998). Knowing the ecology of cholera will help explain its relationship with environmental risk factors such as temperature, salinity, nutrient concentration, and zooplankton blooms, and will perhaps provide evidence that these variables instigate seasonal epidemics in Bangladesh.

Cholera has been defined as a two-factor complex between host and agent (May 1958); however, recent research has included a third factor in the ecology of cholera that lengthens its lifecycle and provides an explanation as to why cholera is endemic in Bangladesh with seasonal epidemics: the aquatic reservoir. An aquatic reservoir, such as a river or canal, provides a long-term, natural habitat for the pathogen to survive in. Until the early 1980 s, the natural habitat for $V$. cholerae was thought to be within a human host, a concept supported by researchers who believed pathogens had no ability to survive longer than a few days outside of the human intestine (Colwell and Spira 1992). Today, research has proven that $V$. cholerae 01 and $\mathrm{O} 139$ can actually survive in the aquatic environment for much longer periods of 
time, which has increased the pathogen's lifecycle and subsequently, its ability to spread disease (Spira 1981; Colwell and Spira 1992; Emch 1999; Ali et al. 2001).

The possibility of a relationship between aquatic reservoirs and $V$. cholerae was disregarded until the 1970's when new evidence on the presence of atypical $V$. cholerae $\mathrm{O} 1$ in aquatic environments was documented. For example, through research on seasonality and phage typing in Bangladesh, Glass et al. (1982) found evidence supporting the belief that surface water is associated with the ecology of endemic cholera because it provides natural conditions for survival, reproduction, and transmission. Over a period of time, the physical, biological, and chemical changes in the aquatic environment trigger a bloom and/or increases the virulence of vibrios, which then can cause an epidemic. The existence of the aquatic reservoir explains the association between cholera outbreaks and contaminated surface water, the association between water contamination and infection over time, and the numerous smaller unconnected cholera outbreaks occurring within a single cholera season. Patterns show a multitude of small outbreaks, scattered in space but clumped in time, such as pre- and post-monsoon cholera peaks. Simultaneous small outbreaks in different villages suggest either a common mode of transmission (fecal/oral or surface water), or some climatic triggering mechanism.

According to Islam et al. (1994) there are two types of environmental reservoirs that support the survival of $V$. cholerae in its association with blue-green algae: temporary and permanent. Temporary reservoirs are considered to be closed water systems (i.e., ponds and tanks), which help the pathogen to spread throughout 
the human population by way of seasonal multiplication of algae bloom (Islam et al. 1994). According to Islam et al. (1994) the presence of blue-green algae in tanks and ponds varies based on the size and depth of the aquatic reservoirs, and the amount of water in these water sources is affected differently by environmental conditions. In order to allocate for this variation, Islam et al. (1994) divided temporary reservoirs into long-term and short term. Long-term temporary reservoirs are large ponds that infrequently dry up, as during excessive droughts. In this habitat, when $V$. cholerae is associated with blue-green algae, the bacterium can survive for several years and theoretically produce epidemics (Islam et al. 1994). Short-term temporary reservoirs are smaller ponds that are filled by heavy rains (monsoon season) and dry up during the dry season. When smaller ponds begin to dry up, high nutritional content causes algae to bloom rapidly. If $V$. cholerae is introduced into these ponds naturally, the pathogen may multiply during the algae bloom (Islam et al. 1994). Temporary reservoirs are supplied with water from the monsoon rains, they are present in all baris, and they are used for washing, bathing, and cooking. These tanks and ponds are often polluted from latrines. Islam et al. (1994) found that nearly all latrine waste in rural Bangladesh reaches the tanks directly, or it is brought to the tanks by heavy rainfall, which perpetuates heavily contaminated areas that are rich in organic matter. Historically village tanks in Bangladesh have harbored vibrios in the environment; in 1884, Dr. Robert Koch isolated the comma bacillus from a tank in Calcutta during an 1883 cholera epidemic (Koch 1884). Figure 4.3 is an image of a canal in Matlab during the dry season. 
Permanent reservoirs are another type of aquatic reservoir that supports the survival of $V$. cholerae through its association with blue-green algae. These areas consist of open water sources such as canals, rivers, and estuaries, which do not dry up. Theories concerning the association between $V$. cholerae and algae habitats, and their existence in permanent reservoirs, are supported by various findings (Marshall, 1976; Huq et al. 1990; Tamplin 1990; Islam et al. 1994).

\subsection{Cholera epidemiology}

In order to understand

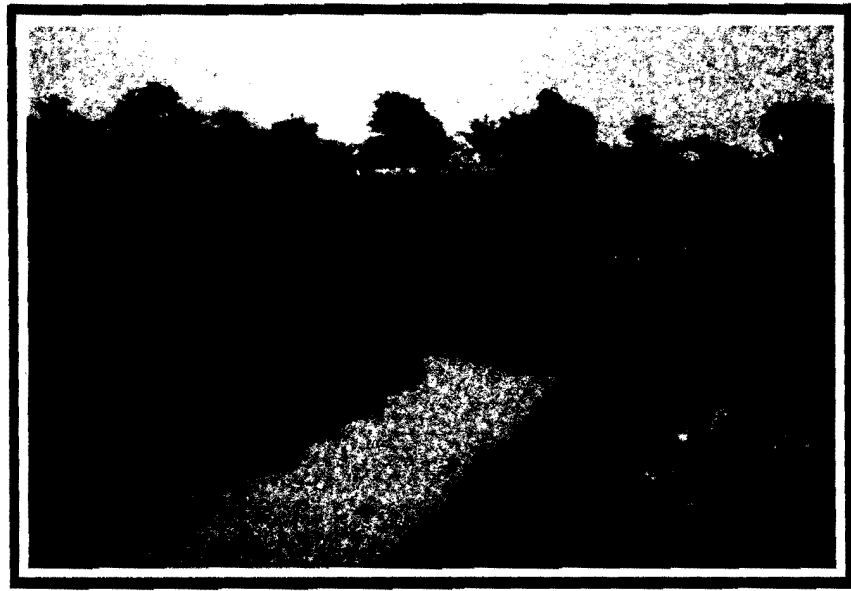

Figure 4.3: A permanent reservoir (canal) during the dry season.

the spatial and temporal distribution of cholera it is important to understand the processes and practices of disease transmittance. Two elements that help illustrate how a disease can be spread are spatial diffusion processes and human/environmental interaction.

Spatial diffusion refers to the relationship between the quantity and quality of whatever mode that transmits a disease from organism to organism (Mayer 2000), which is affected by environmental changes. For example, the niche for the cholera pathogen expands when water levels in the aquatic environment begin to rise and expand. The influx of pathogens into new areas increases the opportunity for humans and pathogens to make contact. Medical geographers conduct diffusion studies to 
expand. The influx of pathogens into new areas increases the opportunity for humans and pathogens to make contact. Medical geographers conduct diffusion studies to study the spread of medical innovations within a healthcare system, and to study the spread of an infectious disease (Meade and Earckson 2000). This study examines the diffusion of infectious disease.

Processes describing the transmission of cholera via human-environment interaction help clarify how the relationship between humans and their environment impacts the spread of disease. Over the past century, numerous studies have emerged to clarify how the human-environment relationship prompts cholera transmission. For example, in 1855 John Snow studied cholera incidence using scientific methods and spatial analysis techniques and concluded that cholera was a food or waterborne disease transmitted by fecal contamination (Feachem 1982). Robert Koch (1884), who is well known for identifying the bacterial agent that is responsible for cholera, also concluded that cholera was a food- and water- borne disease.

Over the years, cholera transmission investigations still continue. Studies by Mosley and Khan (1979), Spira et al. (1980), and Hughes et al. (1982) have all claimed that cholera is almost exclusively transmitted by surface water. Hughes et al. (1982) conducted a case-control analysis to study El Tor cholera in Matlab to determine the importance of surface water transmission. They found in neighborhoods with cholera, 44 percent of the surface water sources were positive for $V$. cholerae, whereas only 2 percent of the surface sources were positive in the control neighborhoods. This suggests that surface water is highly important to the 
transmission of $V$. cholerae. Spira et al. (1980) claimed that cholera was almost exclusively transmitted by water. They conducted research in Matlab from 1976 to 1977 on the microbiological surveillance of intra-neighborhood transmission of El Tor cholera. Based on their findings, they concluded that contaminated surface water was the primary mode in which intra-neighborhood and intra-family cholera was transmitted. This study emphasized the importance of using uncontaminated water sources for all purposes.

Growing evidence for the existence of $V$. cholerae within the surface water sources in Bangladesh points to the existence of two distinct modes of disease transmission: primary and secondary.

Secondary transmission constitutes fecal-oral contamination from people with primary infections. Poor sanitation practices between mother and child can create this situation. For example, a mother can become infected with cholera from the feces of her baby. Inadequate sanitation facilities, water availability, and water use are important factors to control for in order to reduce secondary cholera transmission (Emch 1999).

In primary transmission, vibrios pass from the aquatic environment to humans via edible aquatic flora and fauna, or by humans ingesting the bacteria- usually by swallowing contaminated water while bathing, washing, drinking, and/or cooking with the polluted surface water. Figure 4.4 shows the various modes in which cholera can be transmitted. In Bangladesh, contaminated water, along with poor sanitation practices, provides the main source for primary cholera transmission. For example, 
These open water sources, or aquatic reservoirs, facilitate cholera transmission and the consumption of water from these areas puts humans at risk for infection.

Figure 4.4: Cholera transmission routes.

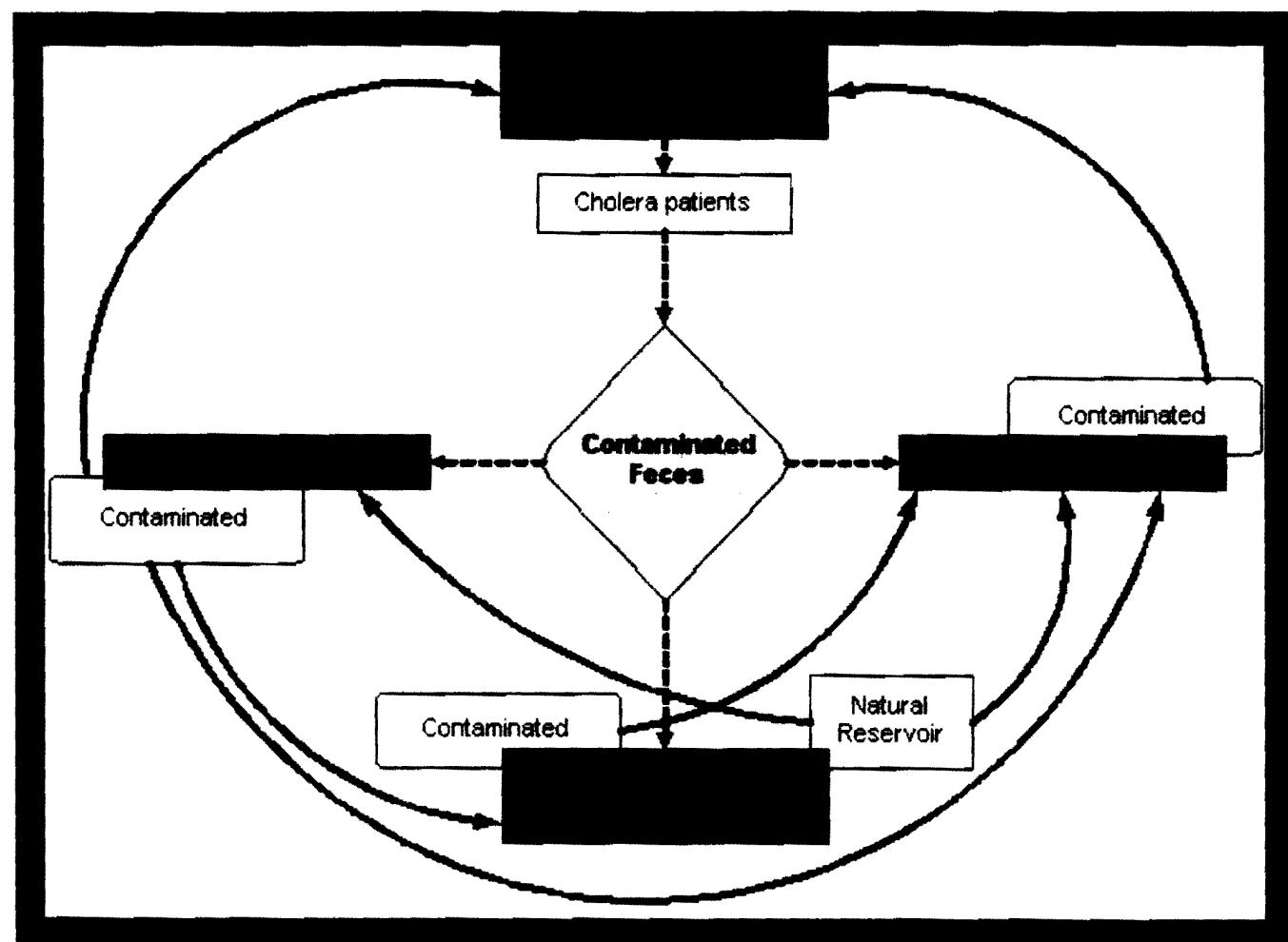

Whatever route cholera is transmitted to humans, the disease maintains a constant presence in Bangladesh's environment. Because of the known prevalence of the disease, Bangladesh is an ideal location to investigate the patterns and processes of biannual cholera epidemics.

\subsection{Cholera and seasonality}




\subsection{Cholera and seasonality}

Cholera epidemics have a history of being seasonal in Matlab. During the classical cholera period, the peaks occurred in the winter months of November through January. The peak season for El Tor usually occurs between September and December. For both cholera biotypes, a small peak occurred in the pre-monsoon months of March through June (Glass et al. 1982). Longini et al. (2002) studied cholera trends over a 33 year period in Bangladesh and found that despite the year to year fluctuations in cholera rates, the timing of the pre- and post-monsoon epidemics remain the same, regardless of the organism's biotype. As mentioned by Longini et al. (2002 p.249): "In Matlab, these seasonal outbreaks are predicted by increases in water temperature (lagged 4-8 weeks before the spring epidemics), increases in copepod (simultaneously), and increases in cyanobacteria concentrations in local water bodies (lagged 2 weeks before)". This study by Longini et al. (2002) provides evidence of a strong association between cholera peaks and Bangladesh's changing environment.

Seasonally, cholera epidemics occur spontaneously in widely spread out sites in Bangladesh. To explain the sudden appearance of cholera epidemics at multiple sites, Feachem (1982) reviewed different environmental aspects of cholera epidemiology. He hypothesized that some environmental factor was triggering growth of $V$. cholerae $\mathrm{O} 1$ in the environment. Islam et al. (1994) suggests that this trigger could be the blooming of blue-green algae. A study by Cockburn and Cassanos (1960) investigated the relationship between changing climatic conditions and cholera incidence in East Pakistan (now Bangladesh). They found that seasonal variation of 
cholera coincided with fluctuations in the salinity and $\mathrm{pH}$ levels in pond water; these abiotic conditions were influenced by the activity of blue-green algae in the water.

\subsection{Cholera risks}

Many studies have identified risk factors for cholera in rural Bangladesh and they can be roughly divided into three categories for the purpose of this study:

environmental, socioeconomic, and cultural/behavioral. Some of these risk factors can fit into more than one of these categories. Although not exhaustive, these studies represent the more significant findings that relate to cholera risk.

The subsequent studies have identified the following environmental risk factors to cholera. Hughes et al. (1982) found that using contaminated surface water for bathing and cooking led to cholera hospitalization. Latrines, tubewells, ponds, and tanks have all been associated with cholera contamination. Within most baris there is a tubewell that provides clean water. Cockburn and Cassanos (1960) found that the ponds, which were used as the source of village water supply, had higher potential to spread cholera. Khan et al. (1981) found that cholera incidence was higher for families with access to canal water as opposed to river or tank water. Emch (1999) found that people who shared latrines with other households were more likely to be hospitalized with cholera ( 2.8 times greater) than those not sharing latrines. Figure 4.5 shows an open latrine hanging over a water body. Glass et al. (1982) found that cholera was more common in villages that were not adjacent to the main river. Emch (1999) found that people living in flood-controlled areas were 2.47 times more likely 
to be hospitalized with cholera. A possible explanation for this is that the flood embankment inhibits the natural flow of flood waters, which move contaminated waters (Emch 1999).

Figure 4.5: Hanging latrine in Matlab.

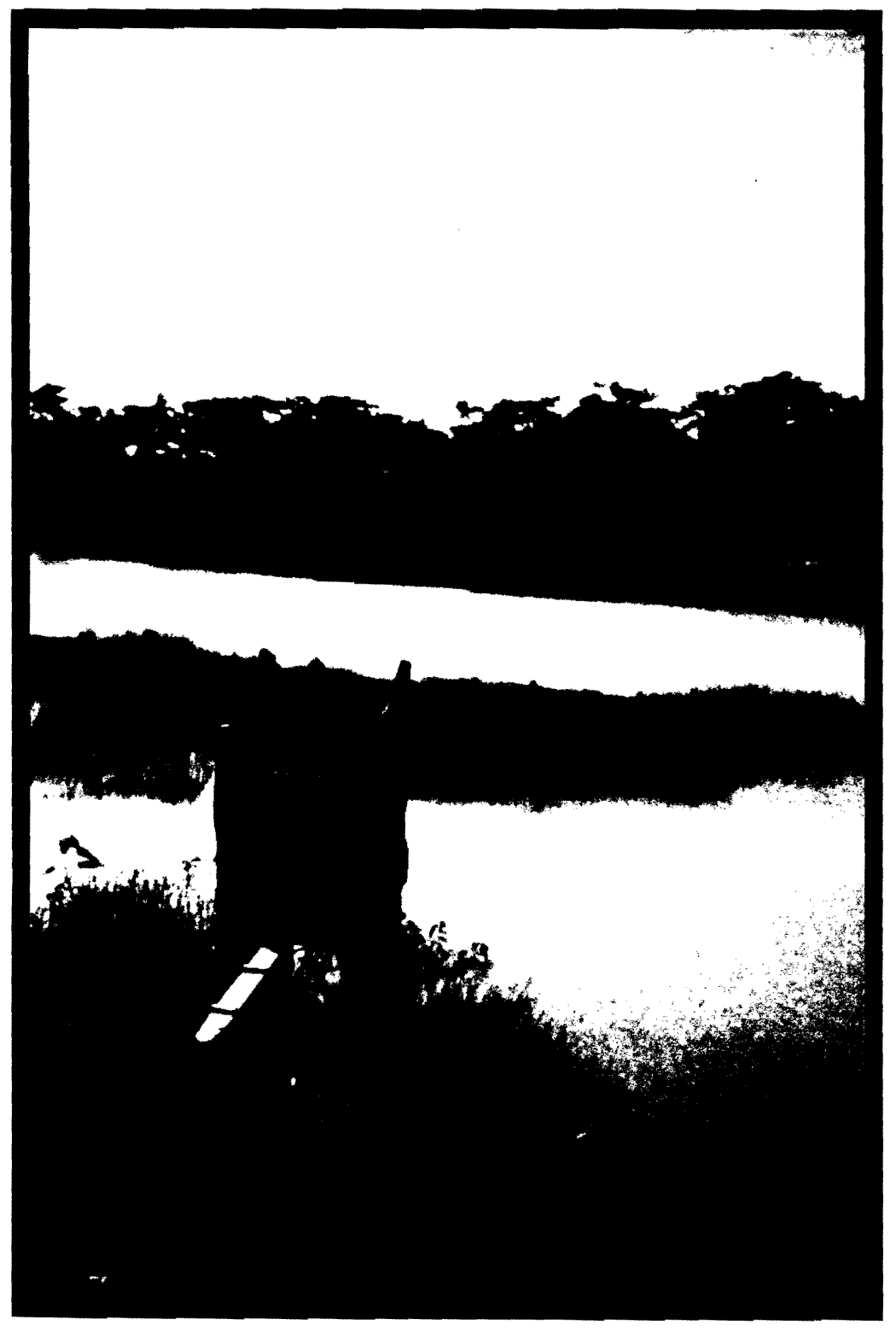


Several socioeconomic risk factors associated with cholera in rural Bangladesh have been identified. Glass et al. (1982) found that predominately Hindu villages have higher cholera rates. One theory for this is that because fishing is primarily a Hindu occupation (Aziz 1994), there may be an association between fishing and cholera. Cholera has been linked to fishing practices, possibly because of human's direct contact with contaminated water (Pollitzer 1959; Khan and Mosley 1967; McCormack et al. 1969). A study by Becker et al. (1986) found that children in poorer households were more likely to contract cholera than those in affluent households. This finding suggests that socioeconomic status might be a reflection on the differences of household hygiene for children. However, a study by Emch (1999) found that neither assets nor income were associated with cholera hospitalization.

The following studies have identifies cultural/behavioral risk factors to cholera. Research by Spira et al. (1980) and Hughes et al. (1982) found that the use of clean drinking water (from tubewells) does not protect against cholera if other water sources used for bathing and washing are contaminated. Figure 4.6 is an example of a

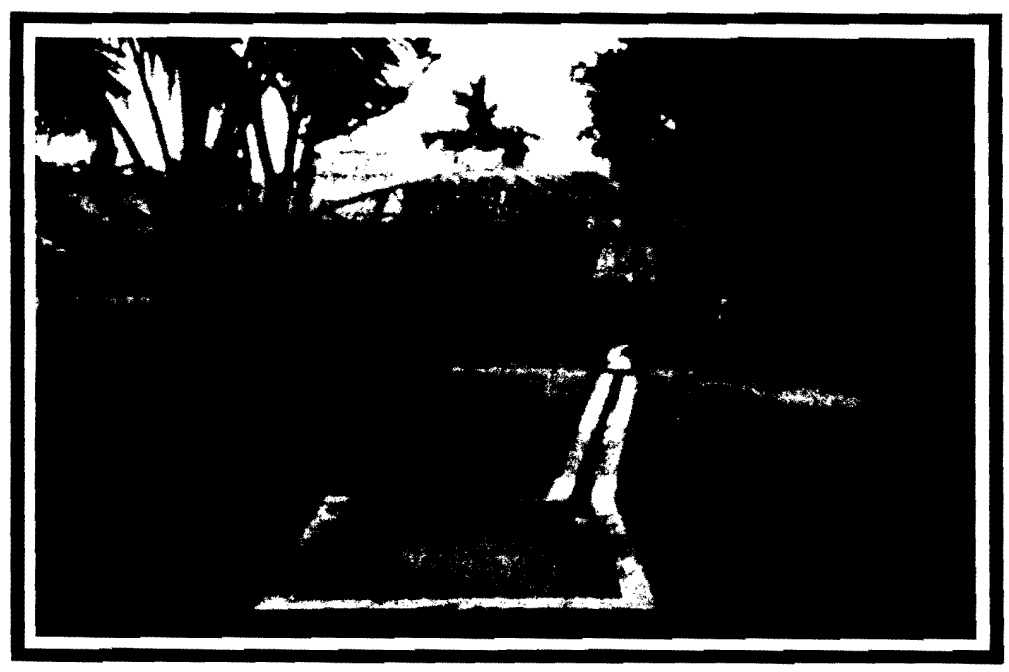

Figure 4.6:

Tubewell in Matlab 
tubewell in Matlab. People infected with $V$. cholerae can contaminate their surface water if they do not use safe hygiene and sanitation practices when using these areas for drinking, cooking, bathing, and washing. The contaminated water is then transmitted to other people, which in turn can infect them with the disease. Feachem (1982) believes that water used for bathing and washing by contaminated people is more likely to transmit cholera than water used for drinking and cooking because the prior cultural practices extract water from open and easily polluted waters, whereas the later cultural practices often use tubewells which are enclosed. Figure 4.7 shows two Bangladeshi women taking water from a pond. Sack et al. (2003) found a significant association between water sources and cholera outbreaks in Matlab, more specifically the act of washing cloths and utensils exclusively with tubewell water was found to have a protective effect. However, they found that the use of tubewell water for bathing and washing protected against cholera in Matlab. Emch (1999) found that

Figure 4.7: Bangladeshi women doing their chores. Source: R. Colwell.

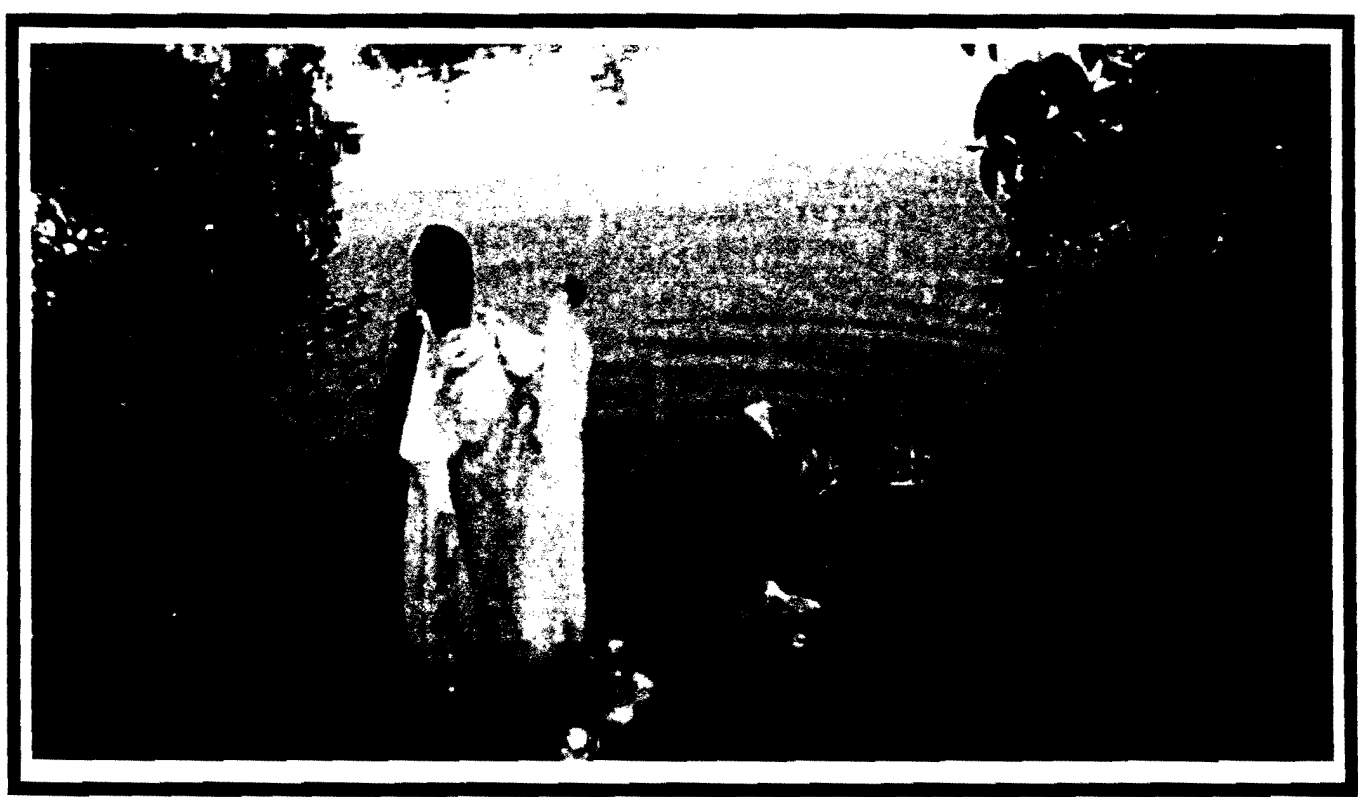


shellfish consumption was not associated with cholera transmission.

To some extent every disease varies over space and time, and it is this variation that the medical geographer attempts to explain. Determining the risk factors associated with seasonal cholera will advance our understanding of the ecology of the disease, which will help explain its epidemiology. The following chapter describes the specific methods that were used to investigate the risk factors associated with preand post-monsoon cholera epidemics in rural Bangladesh. 
5. Methods: Research questions, data sources, and analytical methods

\subsection{Specific research questions}

This research project measured which risk factors were associated with preand post-monsoon cholera epidemics. The following questions were addressed:

- What is the association between exposure to risk factors and pre- and postmonsoon cholera?

- Are there differences in risk factors between the two seasonal cholera epidemics?

\subsection{Data sources and collection methods}

A number of secondary data sources were used in this analysis and several data collection methods were used when the data were collected. They include:

- The creation of a computerized spatial database of the study area.

- The collection of cholera data (dependent variable) from hospital records.

- The collection of primary data for independent variables that are believed to be related to cholera. These data were collected by questionnaire given to cholera patients (cases) and people from the Matlab community without the disease (controls).

- The collection of secondary data from the ICDDR,B Demographic Surveillance System records and community health worker record books. 
- The administration of a survey to collect primary data on the distribution of latrines and tubewells in the study area.

- Spatial calculations of new variables using a GIS.

These data collection methods are each discussed in detail in sections 5.2.1 through

\subsection{7.}

\subsubsection{Creation of the study area geographic information system database}

A GIS database was used to model the spatial patterns of cholera as well as to measure several independent variables by performing spatial calculations. The spatial database was created in two steps, discussed in greater detail below.

- $\quad$ Base map accuracy assessment.

- Identification of individual baris on base maps.

Base map accuracy assessment:

In 1992, the ICDDR,B hired the Bangladesh Space Research and Remote Sensing Organization (SPARRSO) to map the Matlab study area. SPARRSO acquired air photos to facilitate mapping of baris, rivers, large ponds, and the flood embankment. They created six 1:10,000 scale maps; however it was impossible to identify the baris at this scale; thus field workers were hired to individually identify each bari on the map. 
Identification of individual baris on base maps:

The International Centre for Diarrheal Disease Research, Bangladesh (ICDDR, B) Demographic Surveillance System (DSS) manages a census of all individuals living in the Matlab area. The ICDDR,B employs field workers who regularly collect demographic, socioeconomic, and health data from the study population. These field workers identified the location of 7,517 baris from the base maps so that each bari location could be assigned a unique identification number. Figure 5.1 shows the features that were digitized with ArcInfo GIS software. Because each bari has its own identification number, it is easy to link the dependent and independent variables to the spatial database. This is important for the statistical and spatial analysis of this study.

Figure 5.1: Spatial database for study a rea.

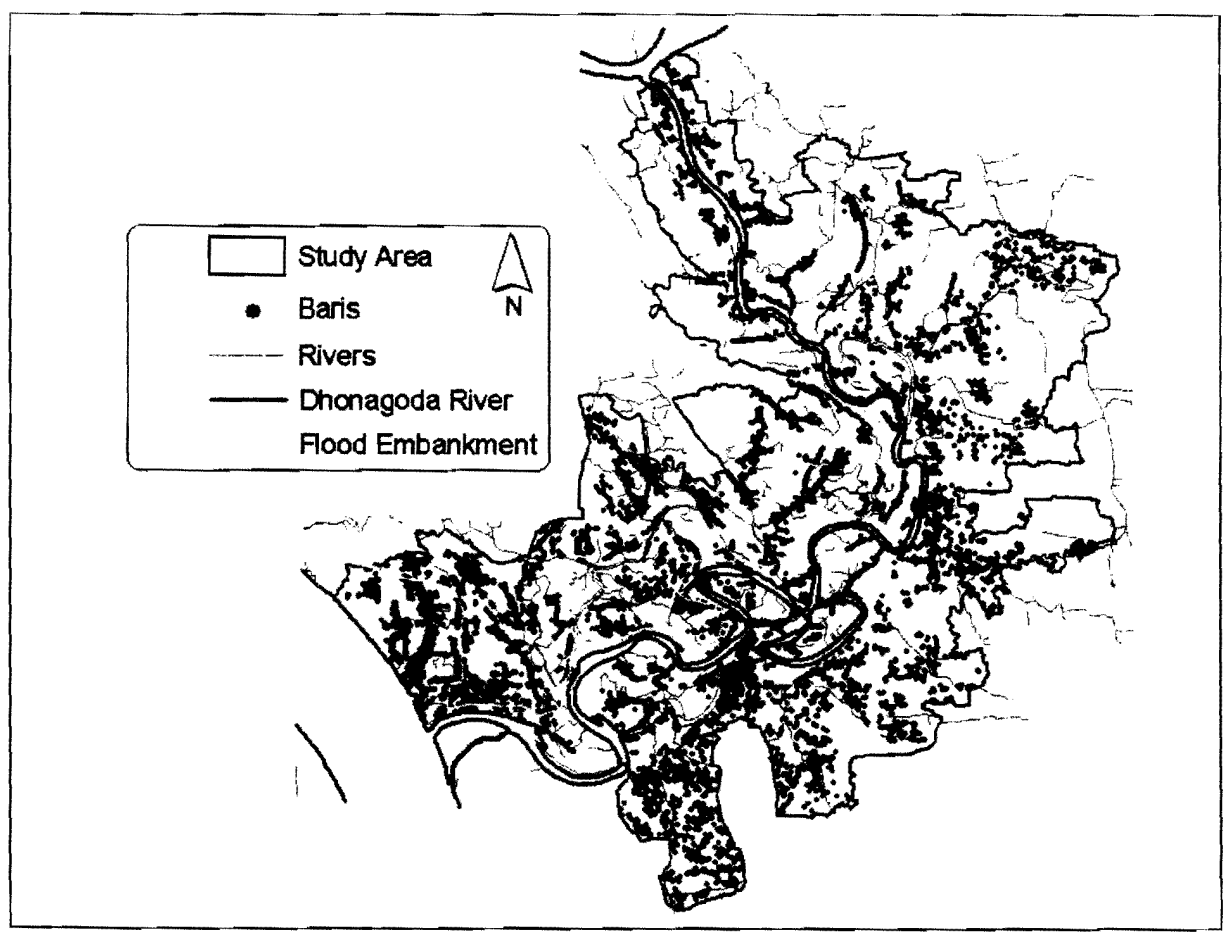




\subsubsection{Dependent variables}

Cholera data were collected from the people hospitalized at Matlab's diarrhea treatment center from 1 January 1992 to 31 December 1994 . The cases were chosen based on laboratory tests indicating a positive test for $V$. cholerae. The bari identification numbers were collected for all cholera cases so they could be mapped.

The control group, people without cholera, was randomly chosen from the Matlab study area. A person was eligible to be a control if they lived in Matlab, were not admitted into the diarrhea treatment center during the study period, and did not die of cholera during the study period.

\subsubsection{Independent variables}

Independent variables that were hypothesized to be related to cholera were chosen for this study. This information was collected from questionnaires, secondary data from DSS records and community health worker record books, and by calculated variables using a GIS. Independent variables were collected for both cases and controls, and are used in this study to determine risk factors to seasonal cholera. Tables 5.1 and 5.2 summarize the different continuous and categorical variables used in this analysis. Some of these variables were assigned values based on data from multiple sources. Appendix A discusses the methods used to calculate each variable. 


\subsubsection{Questionnaire}

Data collected by questionnaire was administered to a random sample of cases and controls from DSS hospital records (597 controls and 294 cases); answers make up some of the independent variables. The questionnaire was administered in Bengali and translated into English. Appendix B is the final questionnaire in English.

Table 5.1: Continuous independent variables.

\begin{tabular}{|l|l|l|}
\hline Bari population & $\begin{array}{l}\text { cultural/behavioral, } \\
\text { socioeconomic }\end{array}$ & count \\
\hline Population density around baris & $\begin{array}{l}\text { cultural/behavioral, } \\
\text { socioeconomic }\end{array}$ & persons per km2 \\
\hline $\begin{array}{l}\text { Number of households sharing a } \\
\text { latrine }\end{array}$ & $\begin{array}{l}\text { socioeconomic \& } \\
\text { environmental }\end{array}$ & count \\
\hline $\begin{array}{l}\text { Households sharing a tubewell in a } \\
\text { bari }\end{array}$ & $\begin{array}{l}\text { socioeconomic \& } \\
\text { environmental }\end{array}$ & count \\
\hline Number of latrines per 100 people & $\begin{array}{l}\text { socioeconomic \& } \\
\text { environmental }\end{array}$ & count \\
\hline Number of tubewells per 100 people & $\begin{array}{l}\text { socioeconomic \& } \\
\text { environmental }\end{array}$ & count \\
\hline Number of open latrines & environmental & count \\
\hline $\begin{array}{l}\text { Number of latrines with non-septic } \\
\text { without ring }\end{array}$ & environmental & count \\
\hline Number of ring latrine w/ septic tank & environmental & count \\
\hline $\begin{array}{l}\text { Number of latrines with concrete } \\
\text { septic }\end{array}$ & environmental & count \\
\hline Number of tubewells in a bari & environmental & count \\
\hline Household area & socioeconomic & square feet \\
\hline Distance from main river & environmental & kilometer radius \\
\hline
\end{tabular}


Table 5.2: Categorical independent variables.

\begin{tabular}{|c|c|c|}
\hline Flood embankment & environmental & yes or no \\
\hline Source of water used for cooking & $\begin{array}{l}\text { cultural/behavioral, } \\
\text { environmental }\end{array}$ & $1=$ yes, $0=$ no \\
\hline Source of water used for bathing & $\begin{array}{l}\text { cultural/behavioral, } \\
\text { environmental }\end{array}$ & $1=$ yes, $0=$ no \\
\hline Source of water used for washing & $\begin{array}{l}\text { cultural/behavioral, } \\
\text { environmental }\end{array}$ & $1=$ yes, $0=$ no \\
\hline Working tubewell & $\begin{array}{l}\text { cultural/behavioral, } \\
\text { environmental }\end{array}$ & yes or no \\
\hline Use another baris tubewell & $\begin{array}{l}\text { cultural/behavioral, } \\
\text { environmental }\end{array}$ & yes or no \\
\hline How often tubewell used for drinking & $\begin{array}{l}\text { cultural/behavioral, } \\
\text { environmental }\end{array}$ & $0=$ often, $1=$ not often \\
\hline How often river used for drinking & $\begin{array}{l}\text { cultural/behavioral, } \\
\text { environmental }\end{array}$ & $0=$ often, 1 -not often \\
\hline How often tubewell used for cooking & $\begin{array}{l}\text { cultural/behavioral, } \\
\text { environmental }\end{array}$ & $0=$ often, 1 -not often \\
\hline How often river used for cooking & $\begin{array}{l}\text { cultural/behavioral, } \\
\text { environmental }\end{array}$ & $0=$ often, $1=$ not often \\
\hline How often canal used for cooking & $\begin{array}{l}\text { cultural/behavioral, } \\
\text { environmental }\end{array}$ & $0=$ often, $1=$ not often \\
\hline How often tank used for cooking & $\begin{array}{l}\text { cultural/behavioral, } \\
\text { environmental }\end{array}$ & $0=$ often, $1=$ not often \\
\hline How often tubewell used for bathing & $\begin{array}{l}\text { cultural/behavioral, } \\
\text { environmental }\end{array}$ & $0=$ often, $1=$ not often \\
\hline How often river used for bathing & $\begin{array}{l}\text { cultural/behavioral, } \\
\text { environmental }\end{array}$ & $0=$ often, $1=$ not often \\
\hline How often canal used for bathing & $\begin{array}{l}\text { cultural/behavioral, } \\
\text { environmental }\end{array}$ & $0=$ often, $1=$ not often \\
\hline How often tank used for bathing & $\begin{array}{l}\text { cultural/behavioral, } \\
\text { environmental }\end{array}$ & $0=$ often, $1=$ not often \\
\hline Location of adult male defecation & $\begin{array}{l}\text { cultural/behavioral, } \\
\text { environmental }\end{array}$ & $1=$ latrine, $0=$ other \\
\hline Location of adult female defecation & $\begin{array}{l}\text { cultural/behavioral, } \\
\text { environmental }\end{array}$ & $1=$ latrine, $0=$ other \\
\hline Location of male child defecation & $\begin{array}{l}\text { cultural/behavioral, } \\
\text { environmental }\end{array}$ & $1=$ latrine, $0=$ other \\
\hline Location of female child defecation & $\begin{array}{l}\text { cultural/behavioral, } \\
\text { environmental }\end{array}$ & $1=$ latrine, $0=$ other \\
\hline Latrine in your household & $\begin{array}{l}\text { socioeconomic \& } \\
\text { environmental }\end{array}$ & yes or no \\
\hline Type of latrine drainage & environmental & $1=$ open, $0=$ septic \\
\hline \# of households sharing a latrine & environmental & $0=$ single, $1=$ multiple \\
\hline $\begin{array}{l}\text { How often males/females defecate in } \\
\text { latrine }\end{array}$ & $\begin{array}{l}\text { cultural/behavioral \& } \\
\text { environmental }\end{array}$ & $0=$ often, $1=$ not \\
\hline Occupation of participant \& father & socioeconomic & $1=$ water, $0=$ nonwater \\
\hline Occupation of participant's mother & socioeconomic & $\begin{array}{l}1=\text { domestic, } \\
0=\text { notdomestic }\end{array}$ \\
\hline
\end{tabular}




\subsubsection{Collection of secondary data from ICDDR,B Demographic Surveillance}

\section{System (DSS) records and community health worker record books}

The ICDDR,B DSS has a computerized database of every person living in the Matlab study area. Demographic data on births, deaths, and migration are regularly collected, maintained and updated. The age of each of the cases and controls within the study was taken from these records. Socioeconomic data was also taken from the community health worker record books.

\subsubsection{Collection of data on the distribution of latrines and tubewells in the study area}

Survey data accounted for the use of latrines and tubewells in the study area, as well as sanitation practices. An additional survey was conducted using a Global Positioning System (GPS), providing a secondary dataset that includes information on the sanitation and water sources of the study area: tubewell and latrine locations, river locations, and canal locations.

In the 1970's, international agencies headed by the United Nations Children's Fund (UNICEF) helped to install tubewells throughout rural Bangladesh to provide clean (cholera-free) drinking water. These shallow-water wells were placed throughout rural Bangladesh in an effort to reduce the numbers of people drinking surface water, which is believed to be one of the main sources of cholera epidemics in this country. Tubewells are now the main source of drinking water for the Bangladeshi people. 
In Bangladesh, there are two types of latrines: open and closed. Open latrines are fixed sites with little or no construction enclosing them. Open latrines are found hanging over water bodies, outside baris (a hole in the ground), or within a wooded area. Closed latrines may be a non-septic latrine without a ring, a ring latrine with a septic tank, or a latrine closed within a concrete septic. Closed latrines are usually sheltered and do not hang over water bodies. With a non-septic closed latrine without a ring, fecal matter drains out of the back onto the ground; because of this UNICEF has been building ring latrines with septic tanks in parts of rural Bangladesh. This system moves fecal matter into a septic system. A closed concrete septic system has cement walls and an enclosed septic system.

\subsubsection{Spatial calculations of new variables using Matlab GIS database}

The following variables were calculated using the GIS database: bari population density, distance from river, and flood control. See Appendix A for an explanation of variable creation.

\subsection{Specific hypotheses about individual independent variables}

The primary research goal of this study is to determine what environmental, socioeconomic, and cultural/behavioral variables are associated with pre- and postmonsoon cholera epidemics, and to determine whether the risk factors are different between the biannual epidemic seasons. The independent variables chosen for this 
analysis represent the key elements that will accomplish the primary goals of this research.

Most of the variables used in this study were concerned with water use and sanitation infrastructure. People in Matlab have several ways in which to obtain water for drinking, bathing, washing, and cooking from tubewells, canals, ponds, tanks, and rivers. Nowhere within Matlab do individuals have access to treated, running water, and thus, tubewells provide the cleanest water source. Latrine type, placement, and usage are also important factors to seasonal cholera epidemics. If an open latrine is placed next to a canal that is used for bathing, cholera transmission is likely to occur, especially if it is dry and the water in the canal is low and not moving fast enough to flush the waste away. The closer latrines are to rivers, pre-monsoon cholera rates will be greater because river and tank water is used more for everyday purposes in the dry season. The major consideration for a latrine is if it has a septic system or not. The different types of latrines are described in Section 5.2.6. It is hypothesized that cholera incidence will be higher in baris that have open latrines. An ideal water and sanitation condition in Matlab is one in which all bari residents have access to a sanitary, septic latrine, as well as a tubewell, and are using them both. Unfortunately, not all Bangladeshi's have access to these, and it is hypothesized that those without will be more likely to contract cholera.

The flood-control embankment variable was used to determine whether or not there was a difference in cholera incidence in- and outside of the embankment preand post-monsoon. Emch (1999) found that people living within the embankment 
were more likely to contract cholera. It is hypothesized that cholera rates are higher post-monsoon within the embankment because there is more stagnant water trapped from monsoon rains. Another environmental variable is distance from the main river. It is theorized that the further away a bari is from the river, cholera will occur at greater numbers during the pre-monsoon months because people are more likely to obtain water from nearby, stagnant water sources.

The socioeconomic variables used in this disease study were the occupation of the participant and the occupation of the men and women in their bari. It is hypothesized that if the male Figure, whether the participant or the father, is a boatman, fisherman, or an agricultural laborer, then cholera within that bari will be higher post-monsoon because of their direct interaction with contaminated water. These professions might put people at risk to cholera infection through secondary transmission. It is hypothesized that if the female Figure, whether the participant or the mother, is a housewife, doesn't work outside of the bari, or is a domestic laborer, secondary cholera will be higher within that bari post-monsoon. This may be the case especially for those without a tubewell in their bari because they are in contact with contaminated surface water more often because of domestic chores (i.e., gathering water for cooking). 


\subsection{Analytical methods}

The analytical methods used in this study include:

- Disease visual and mapping interpretation

- Non-parametric case-control methods

- Logistic regression models

The cholera data, which is the dependent variable in this analysis, were aggregated by season based on three variables in the following order: date of diarrhea onset (therapy sheets), date of arrival to hospital (therapy sheets), and date lab specimen was received (lab). The cases that fell between the dates of January 1 through June 30 were put into a new category called pre-monsoon. The cases that fell between the dates of July 1 through December 31 were put into a category called postmonsoon. The 597 controls were put into both databases. To determine whether there was any difference between the temporal patterns of cholera, each database was grouped into two month periods for all three years. Figure 5.2 shows the pre-monsoon cholera cases and Figure 5.3 shows the post-monsoon cholera cases. These graphs were visually examined to identify any seasonal patterns to cholera. 

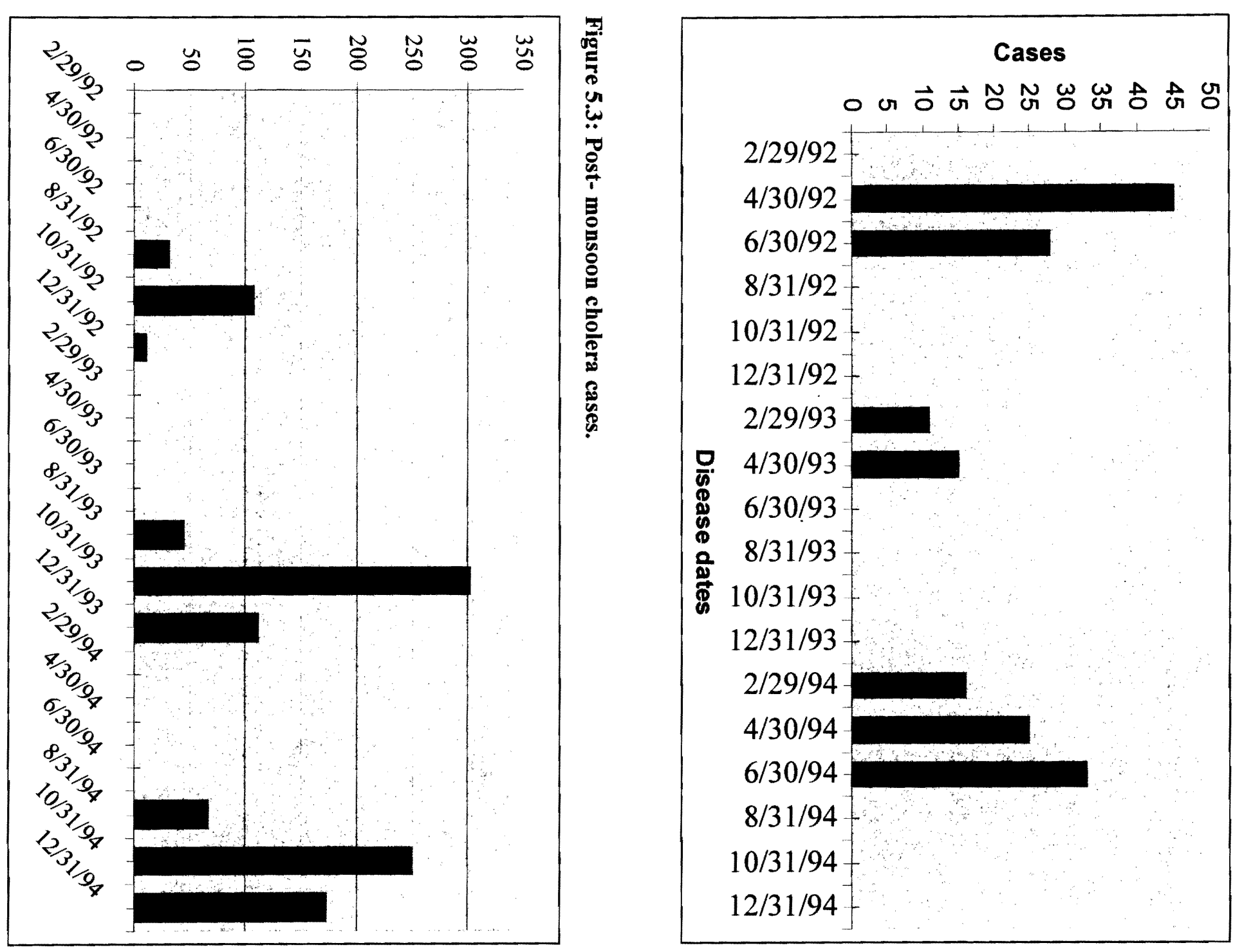

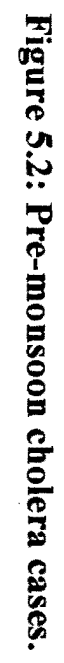


Cholera cases for the three-year study period were mapped using a GIS so that the spatial patterns could be visualized. Using a unique identification number, each cholera case was linked to a bari. Each bari represented on the disease map indicates at least one cholera case. It is theorized that there is a temporal association between cholera and the Bangladeshi seasons.

A case-control study was used to identify which variables are risk factors for pre- and post-monsoon cholera epidemics. In case-control studies, comparisons are made between a group of persons who have a disease (cases) and a group of persons who do not have a disease (controls). Relative risk ratios were used to statistically compare the dependent variable (cases and controls) to the independent variables.

Each calculation determined if there is an association between exposure to risk factors (independent variables) and the development of cholera.

The following is an example of a contingency table in which the relative risk ratio was calculated:

Table 5.3: 1992 post-monsoon: variable - canal water for bathing. Cholera cases/controls

\begin{tabular}{|r|c|c|c|}
\hline & \multicolumn{2}{|c|}{ Canal water for bathing } & Totals \\
\hline Canal water for bathing & often & not often & \\
\hline controls & 99 & 498 & 597 \\
\hline cases & 20 & 134 & 154 \\
\hline totals & 119 & 632 & 751 \\
\hline
\end{tabular}

The risk ratio is calculated by comparing the ratio of cases to controls for one class (e.g., using canal water for bathing) to another class (not using canal water for bathing). In this example, the ratio was 498 of controls, to 134 of cases for those who 
did not use canal water for bathing; to 99 of controls and 20 of cases who did use canal water for bathing. To calculate the relative risk, the ratio was divided as follows:

498 of controls not using / 134 of cases not using

99 of controls using / 119 of cases using

The relative risk ratio for using canal water for bathing is 1.33 . This states that the risk in exposure is greater than the risk in non-exposure. Thus, there is a positive association between using canal water for bathing and developing cholera.

This relative risk ratio does not take the number of observations into account. Therefore it is common to use confidence bounds with risk ratios. Using the above example, the lower and upper confidence bounds (95\%) were .794 and 2.234. This means that it is 95 percent certain that the risk ratio falls between these numbers. Chisquared tests were calculated to determine how well the observed frequencies of the contingency tables fit the expected frequencies. The critical probability value chosen for this study was 0.05 . A statistically significant relationship was accepted if the probability values were below this critical number. A weak relationship was accepted if there was an association at the 90 percent level. Risk ratios were used for the categorical data, which are ordinal and nominal. Chi-square values validate whether the observed distribution could be due to chance.

Simple logistic regression models were used to statistically analyze the one-to one relationship between continuous independent variables (e.g., latrine density, river 
distance, and population density) and the dependent variable, a binary cholera outcome for each bari. The logistic model is expressed as follows:

$$
\ln \frac{(P i}{\left(1-P_{i}\right)}=A_{1}+B_{1} X_{i}+u_{i}
$$

$$
\begin{array}{ll}
\mathrm{P}_{\mathrm{i}}= & \text { The probability of getting the disease. } \\
\left(1-\mathrm{P}_{\mathrm{i}}\right)= & \text { The probability of not getting the disease. } \\
\mathrm{A}_{1}= & \text { Constant. } \\
\mathrm{B}_{1}= & \begin{array}{l}
\text { Slope coefficient for variable } \mathrm{X}_{\mathrm{i}} \text { which is the change in the odds } \\
\text { ratio per unit change of variable } \mathrm{X}_{\mathrm{i}} .
\end{array} \\
\mathrm{u}_{\mathrm{i}}= & \text { Error term. } \\
\mathrm{P}_{\mathrm{i}} /\left(1-\mathrm{P}_{\mathrm{i}}\right)= & \text { The odds of getting the disease or the odds ratio. }
\end{array}
$$

To calculate the probability of getting cholera for an observation, the formula is as follows:

$$
P_{x}=\frac{1}{1+e^{-(a+b x)}}
$$

$P_{x}=$ The probability of the disease for a specific value of a variable represented as $x$.

This model estimates adjusted odds ratios to explain and make predictions about a dependent variable using information provided by an independent variable. For example, it is theorized that the proportion of persons with cholera among the population of individuals using tank water for bathing is higher in the post-monsoon season than the pre-monsoon season. Logistic regression models were created for the biannual cholera cases and selected variables (e.g., flood embankment, drinking, bathing, washing, and cooking water source). The cases were given a value of 1 and the controls were given a value of 0 . SPSS, a statistical software package, was used to calculate the relative risk ratios and the logistic regression models. 
Having just described the methods used to analyze and measure the risk factors for pre- and post-monsoon cholera epidemics, Chapter 6 will describe the results of this study. 


\section{Findings}

The findings in this study demonstrate that there are different spatial and temporal patterns of pre- and post-monsoon cholera epidemics in rural Bangladesh. The temporal distribution of cholera shows a clear seasonal pattern, as does the spatial distribution of the disease. The risk factors for the two seasonal epidemics are also different.

\subsection{Temporal distributions}

Figure 6.1 shows the frequency of cholera throughout the study period.

Disease onset was displayed in two month periods on the $\mathrm{X}$-axis, while the number of individuals with cholera is represented on the Y-axis. The number of individual cholera cases is discussed in Section 6.4.

Figure 6.1: Pre- and post- monsoon cholera cases from 1992-1994.

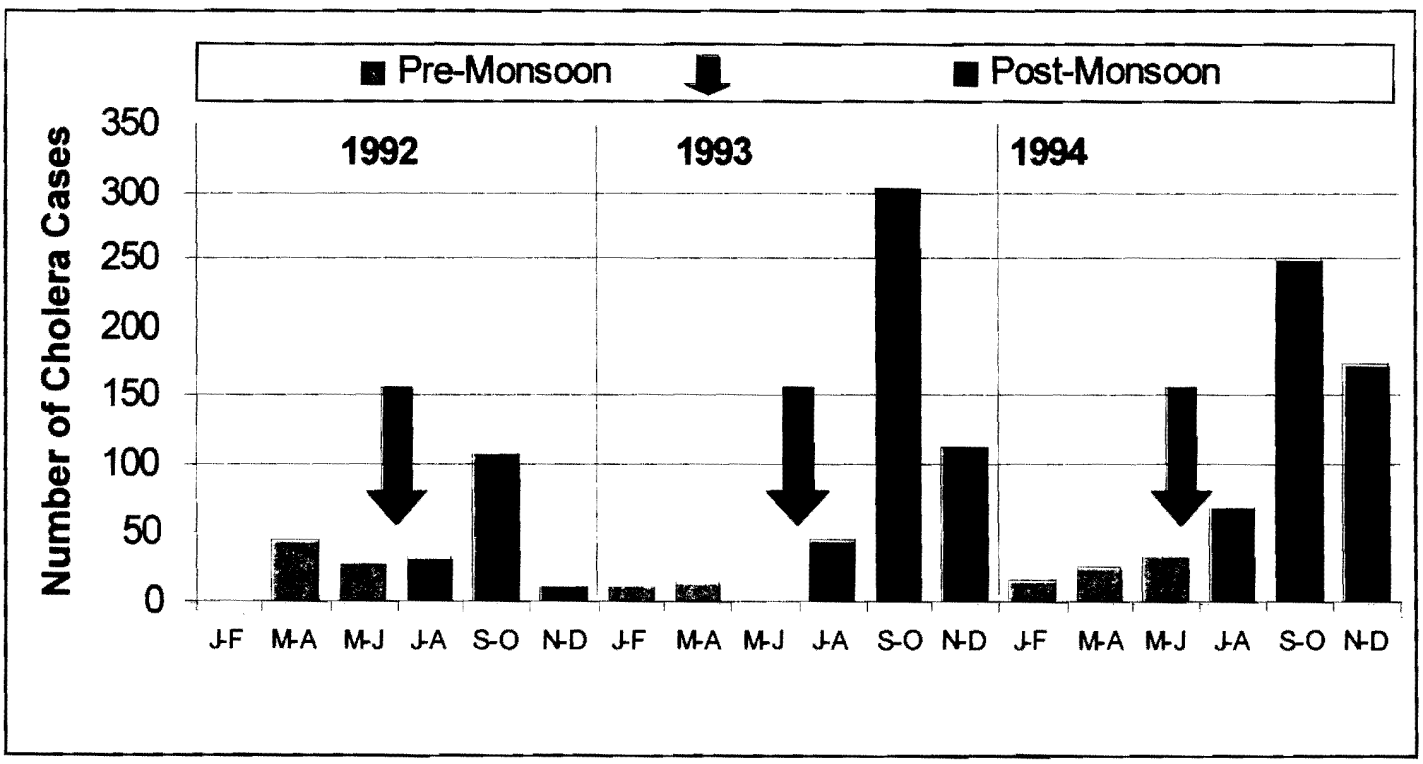


The pre-monsoon cholera epidemics had different patterns for each year.

Figures 6.2 through 6.7 show the temporal distribution of cholera by year. In 1992, the pre-monsoon cholera peak was in April. The 1993 pre-monsoon cholera epidemic was smaller: disease gradually increased in January and peaked in March. The 1994 pre-monsoon cholera epidemic had a larger number of cholera cases, with a peak in April and June. There were more cholera hospitalizations in the post-monsoon time period. The 1992 and 1993 post-monsoon cholera peak's occurred in October. The 1994 cholera peak occurred in November. 


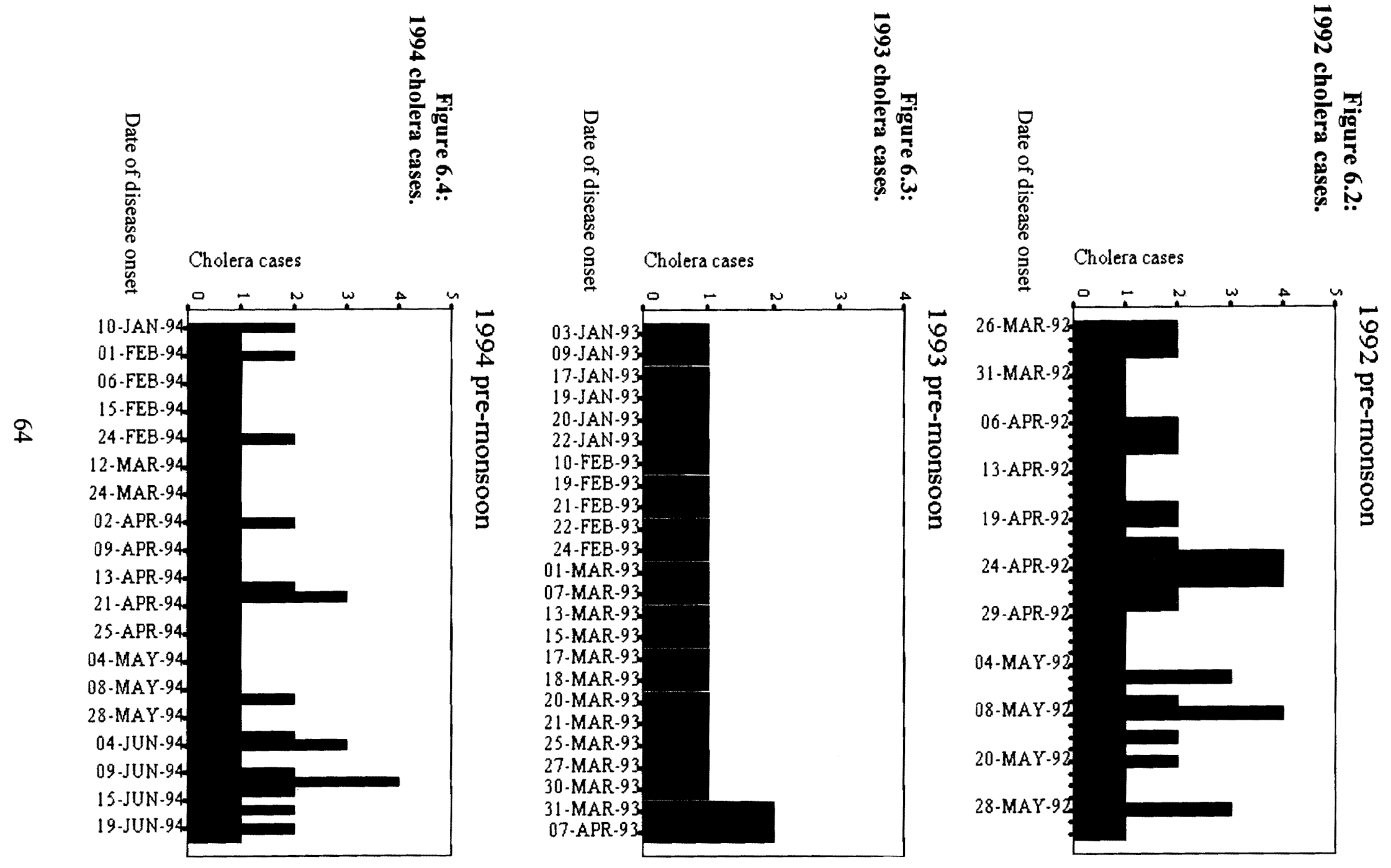




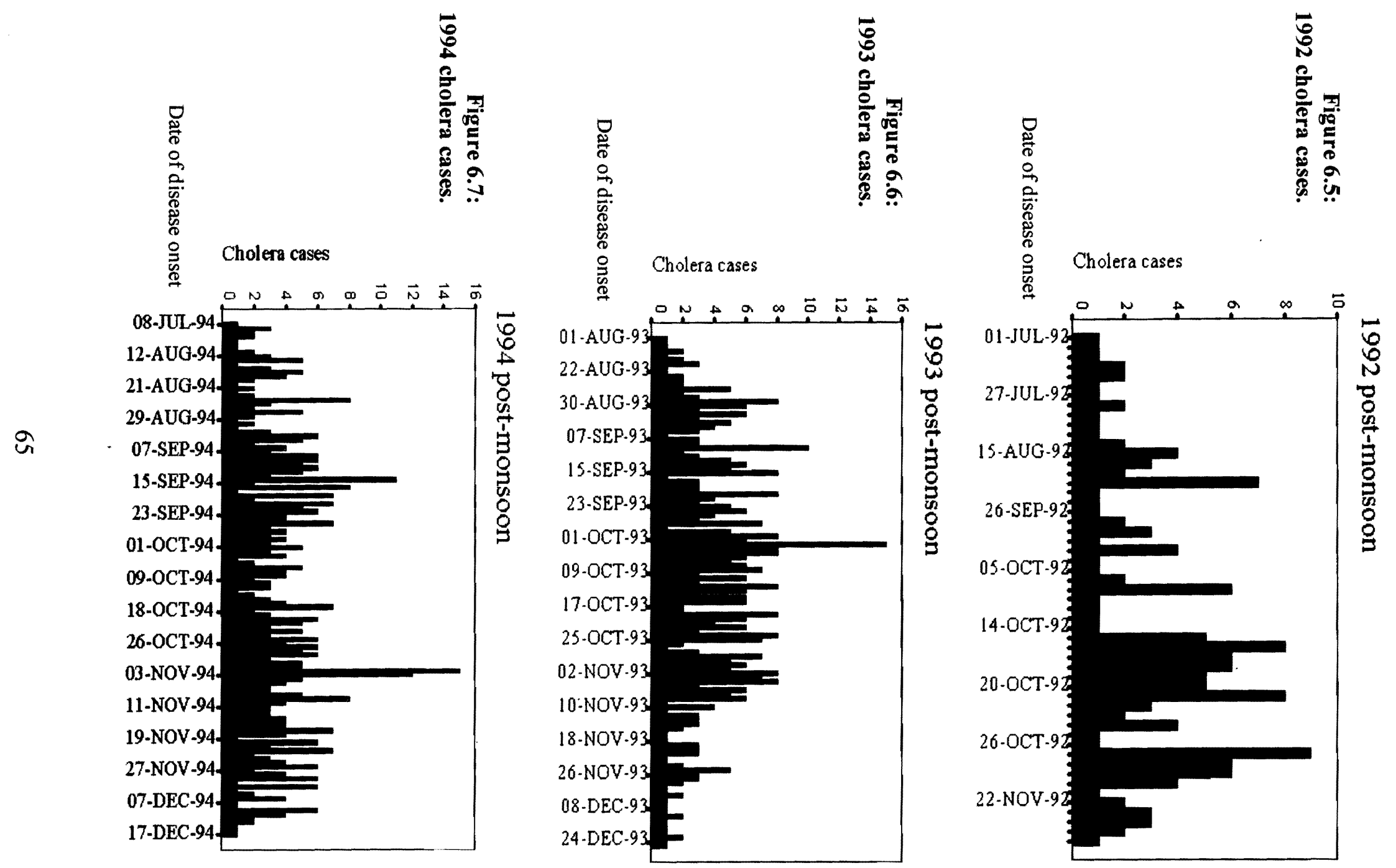




\subsection{Disease maps}

Maps were created and the spatial patterns of pre- and post-monsoon cholera incidence were visually inspected. A detailed description of how the GIS database was created is discussed in Section 5.2.1.

The distribution of cholera cases was mapped for the study period (January 1992 to December 1994). Figure 6.8 demonstrates the pre-monsoon time period and Figure 6.9 demonstrates the post-monsoon time period. Baris with at least one cholera case during this time period are symbolized with red dots. The baris of the control participants (those without cholera) are represented by yellow dots. The majority of cholera cases in these maps is in the southwest section of the study area, located near a waterway. Figures 6.10 and 6.11 demonstrate cholera incidence by year, which provides an obvious visual pattern for both epidemic seasons. The red dots represent 1992, the purple dots represent 1993, and the green dots represent 1994. These maps indicate what is known -- that the pre-monsoon cholera epidemics had fewer hospitalized cases of cholera than the post-monsoon epidemics. For both time periods the 1994 cases are dispersed throughout the study area, whereas the 1992 and 1993 cholera cases occurred mainly in the southwest corner of Matlab. Figure 6.11 shows an obvious cluster of cases in the southwest corner of the flood controlled area. 
Figure 6.8: Pre-monsoon case/control distribution from Jan. 1992 to Dec. 1994.

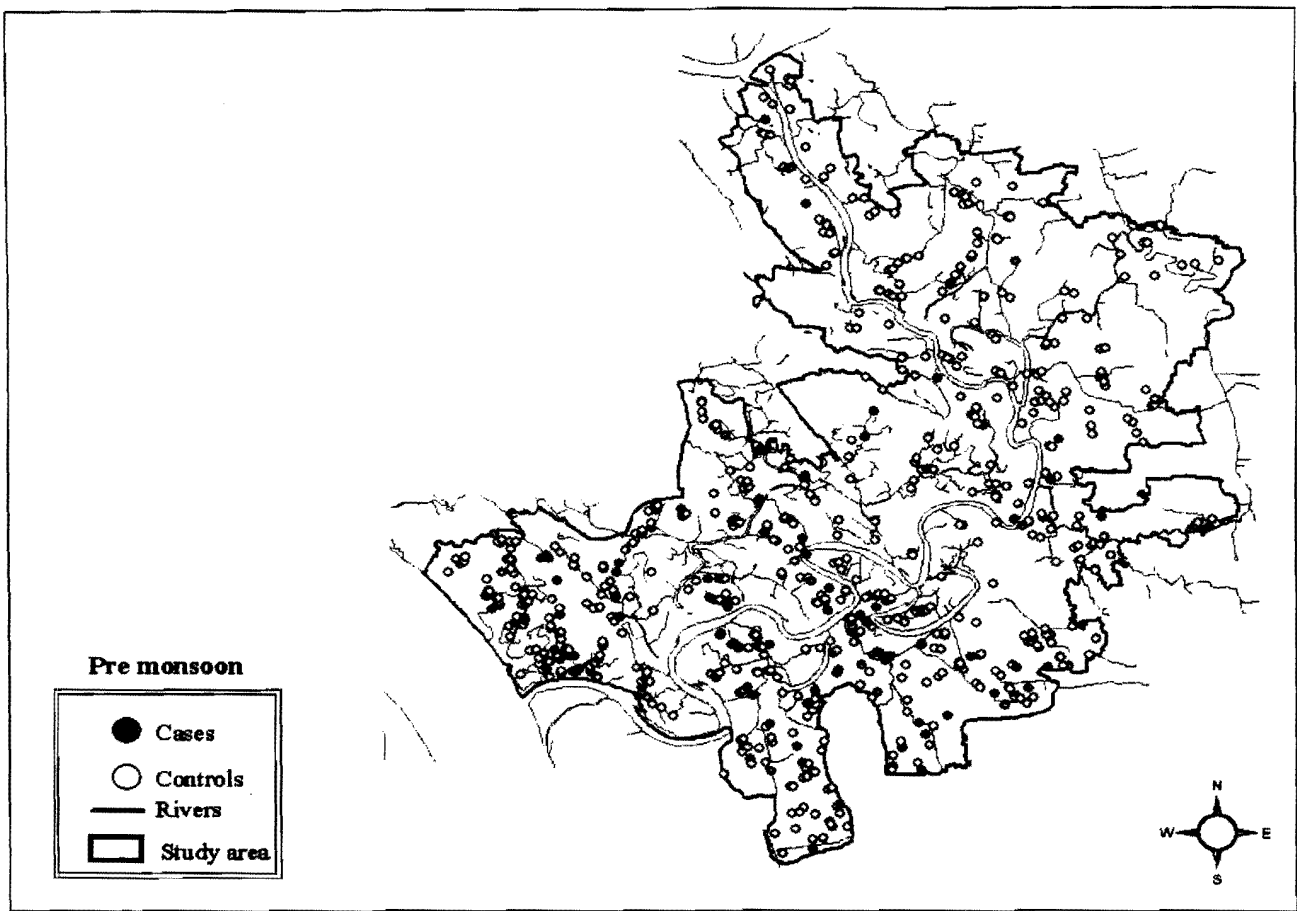

Figure 6.9: Post-monsoon case/control distribution from Jan. 1992 to Dec. 1994.

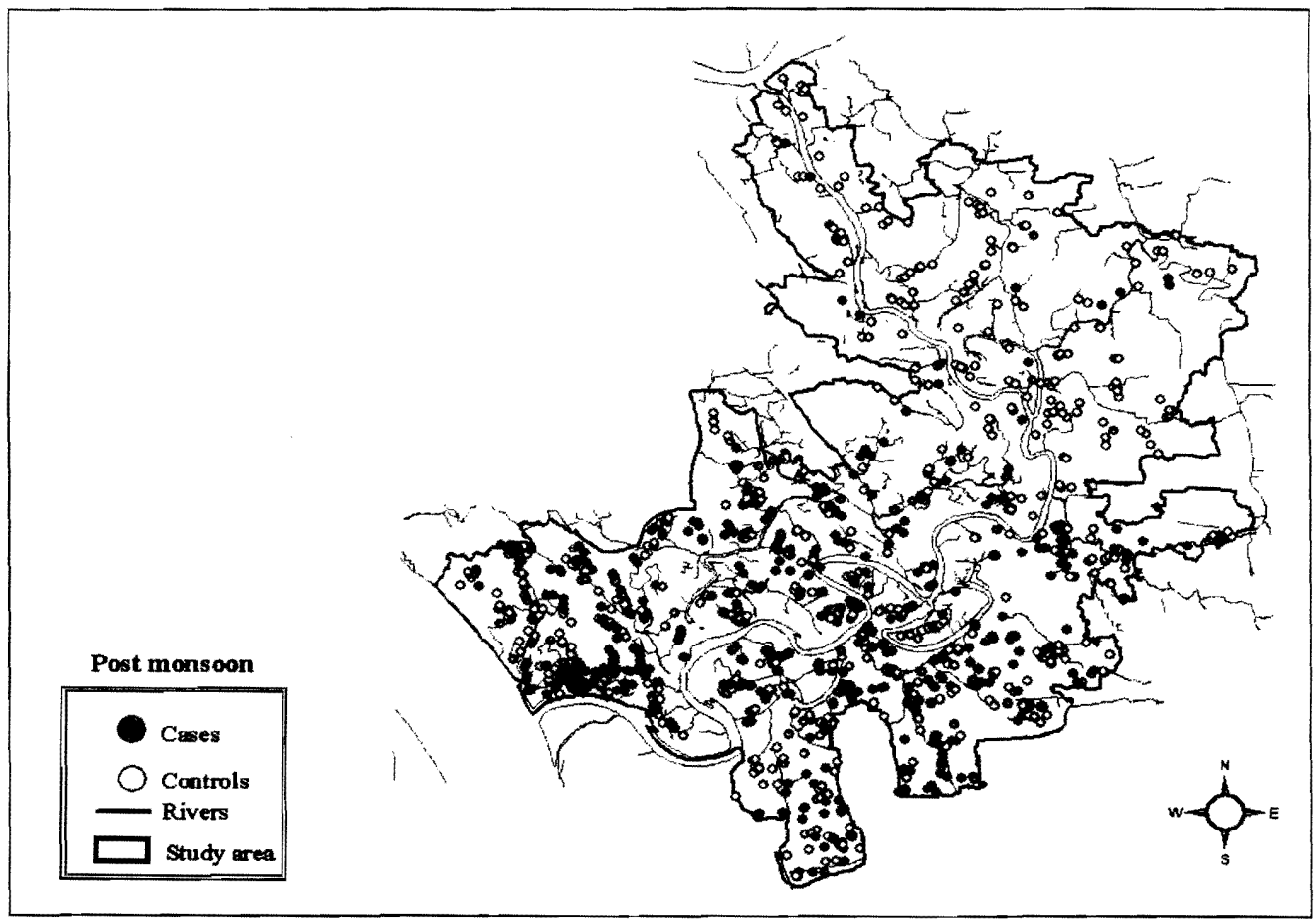


Figure 6.10: Pre-monsoon cholera cases by year.

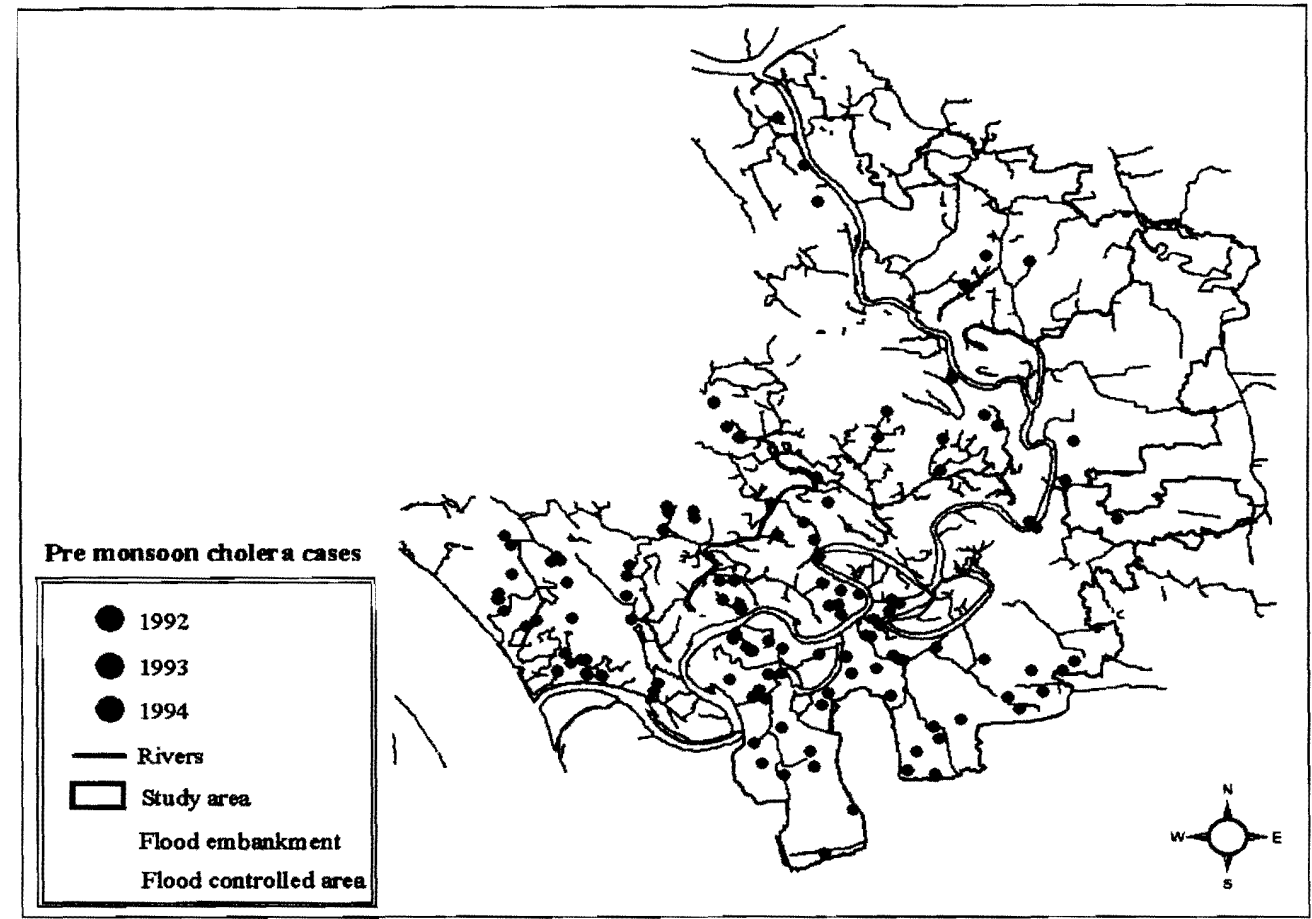

\subsection{1: Post-monsoon cholera cases by year.}

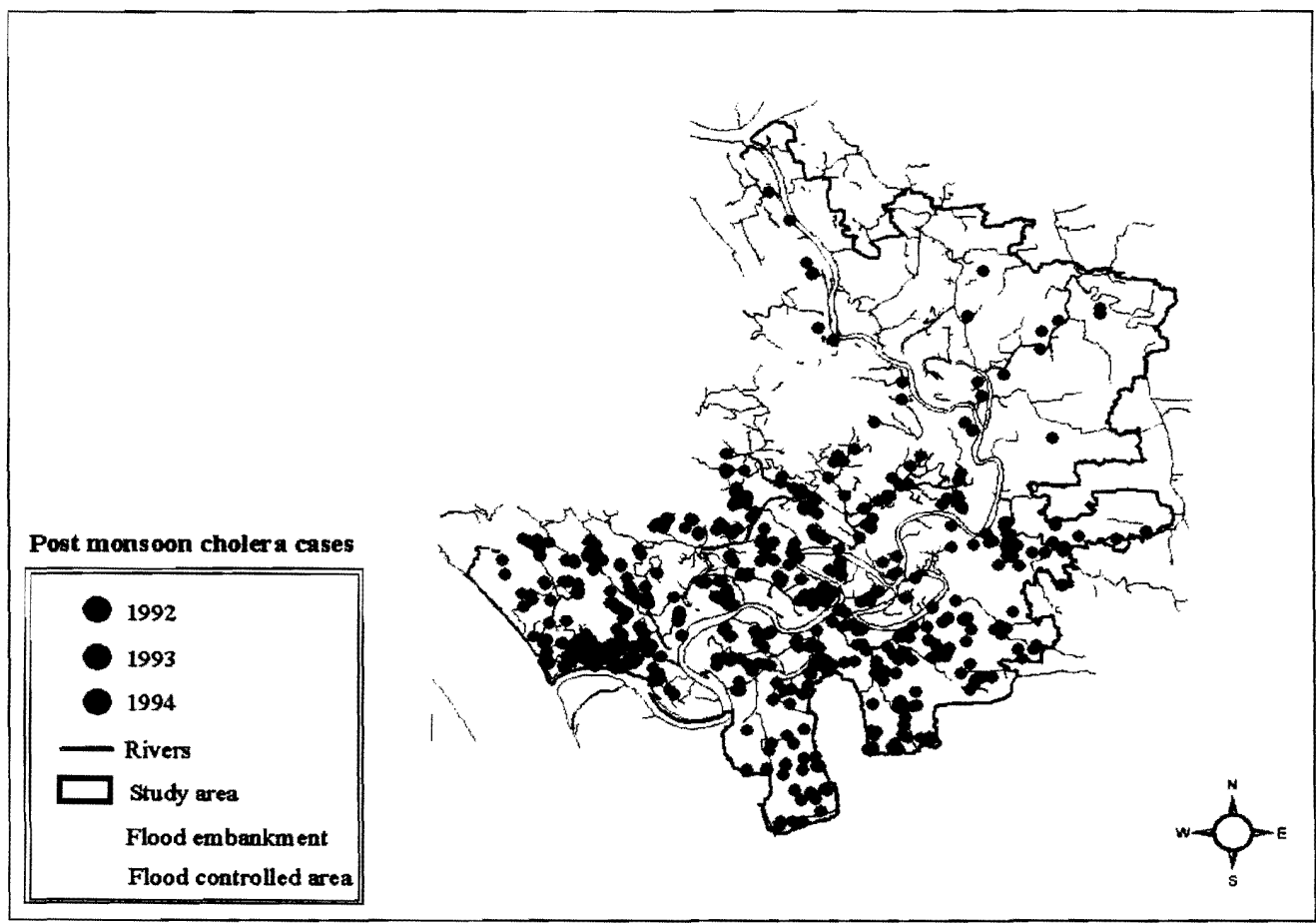




\subsection{Descriptive information about study population}

Independent variables were derived from a questionnaire, a secondary dataset from the ICDDR,B Demographic Surveillance System records and community health worker record books, a survey on the distribution of tubewells and latrines, and a GIS database. These data describe the study population's environment, behaviors, and socioeconomic status which could put people at greater risk of contracting cholera.

The questionnaire includes answers describing the water and latrine use of the participants. Figures 6.12 through 6.48 show the results of several of these questions. The Y-axis in these graphs refers to the percentage of participants who answered the question corresponding to the $\mathrm{X}$-axis categories. There were 611 responses from the pre-monsoon questionnaires, and 751 responses from the post-monsoon questionnaires.

Approximately 94 percent of the questionnaire participants reported using tubewell water as their main source of drinking water both pre-monsoon (Fig. 6.12) and post-monsoon seasons (Fig. 6.13).

Figure 6.12:

Pre-monsoon: Water used for drinking questionnaire responses

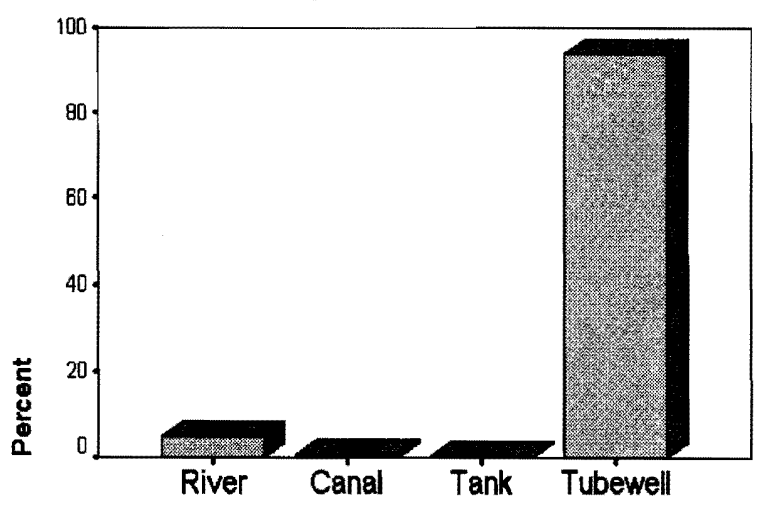

Water source
Figure 6.13:

Post-monsoon: Water used for drinking questionnaire responses

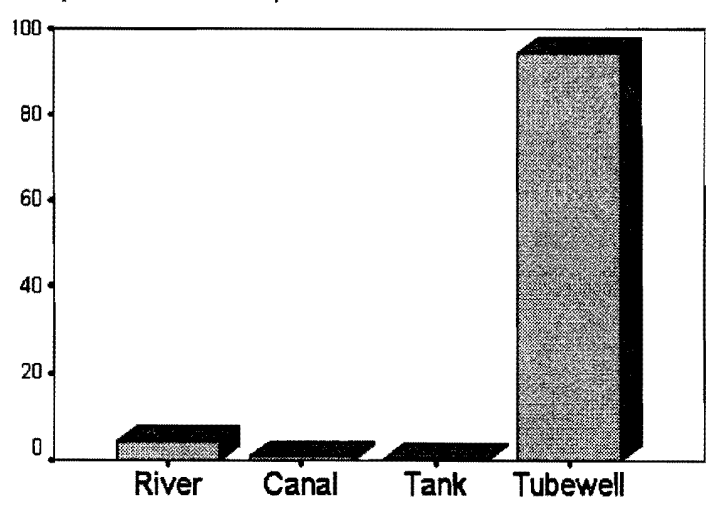

Water source 
Figure 6.14 demonstrates the pre-monsoon water source used for cooking and

Figure 6.15 shows the post-monsoon water source for this practice. Sixty-three percent of the respondents used tank water for cooking pre-monsoon, while 65 percent use tank water for cooking during the post monsoon season.

Figure 6.14:

Pre-monsoon: Water used for cooking

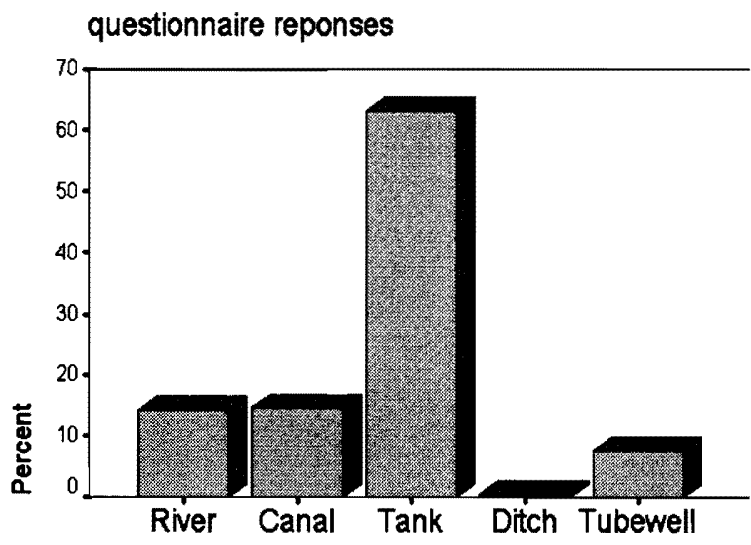

Water source
Figure 6.15:

Post-monsoon: Water used for cooking

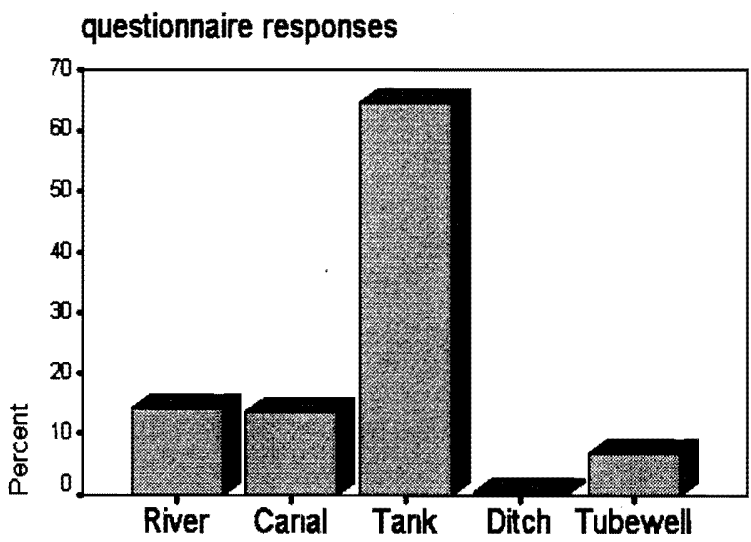

Water source

The largest number of respondents ( 67 percent) used tank water to bathe in pre-monsoon (Fig. 6.16), while 69 percent used this water source bathe in postmonsoon season (Fig. 6.17).

Figure 6.16:

Pre-monsoon: Water used for bathing questionnaire responses

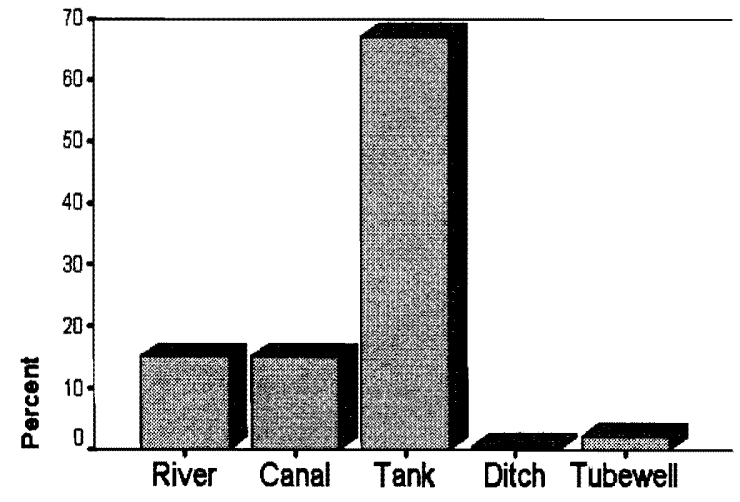

Water source
Figure 6.17:

Post-monsoon: Water used for bathing

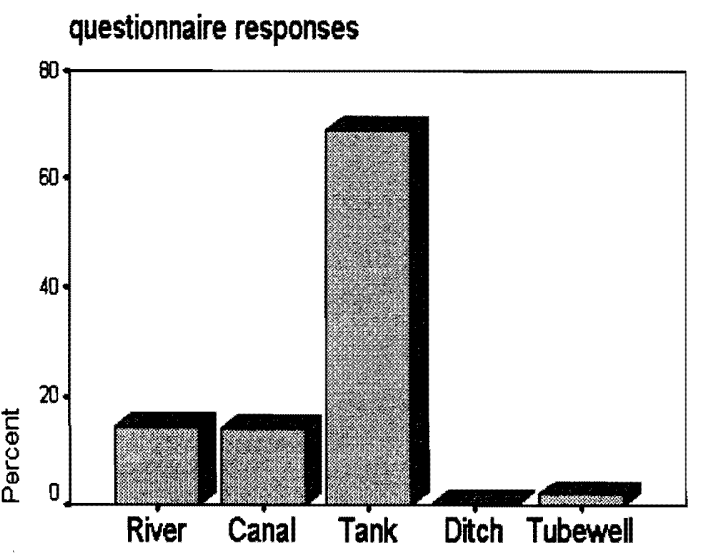

Water source 
Figure 6.18 demonstrates that tanks were the main source of water used for washing practices pre-monsoon season (approximately 67 percent), while 69 percent used tank water for washing post-monsoon (Fig. 6.19).

Figure 6.18:

Pre-monsoon: Water used for washing

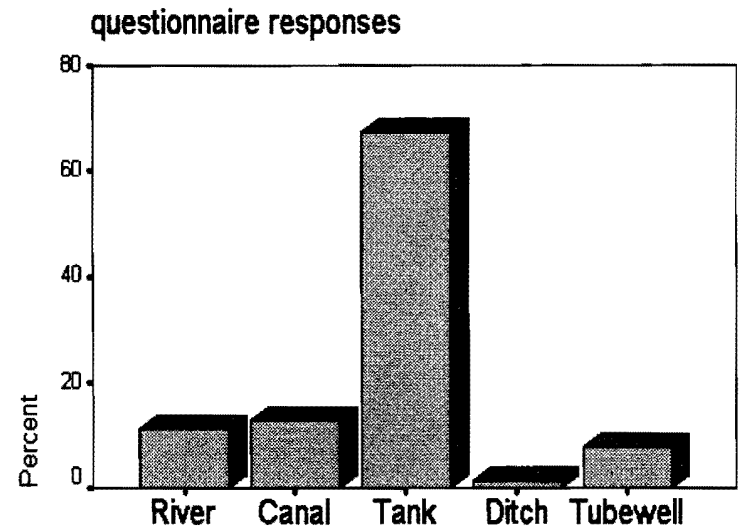

Water source
Figure 6.19:

Post-monsoon: Water used for washing

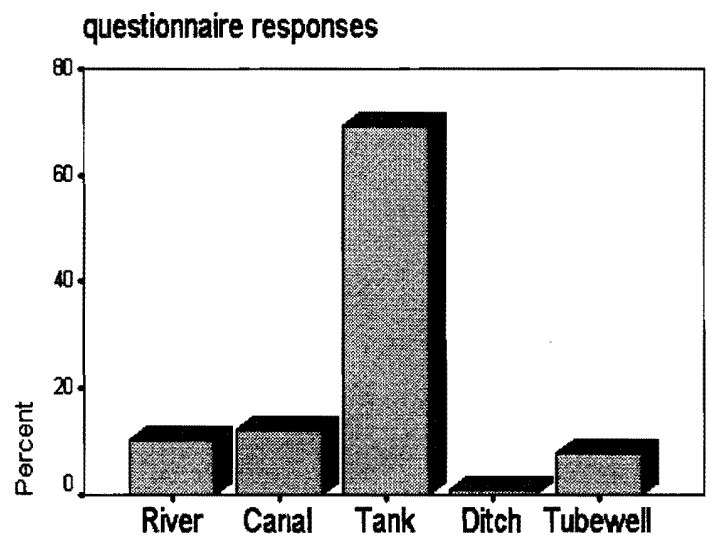

Water source

Out of 611 responses, nearly 70 percent of the participants living in Matlab have a tubewell in their bari and 69 percent of those tubewells are working (premonsoon), while only 71 percent of the 751 responses have a tubewell in their bari and of those tubewells, 69 percent were working (post-monsoon).

Ninety-nine percent of respondents used tubewell water for drinking during the pre-monsoon cholera outbreak period (Fig. 6.20), while 95 percent used this source for drinking water during the post-monsoon period (Fig. 6.21). 
Figure 6.20:

Pre-Monsoon: Tubewell used for drinking

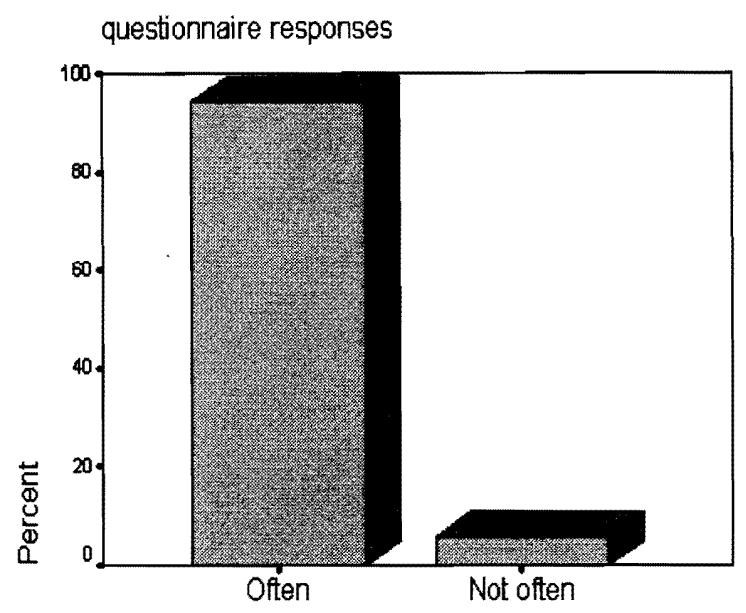

Figure 6.21:

Post-monsoon: Tubewell used for drinking

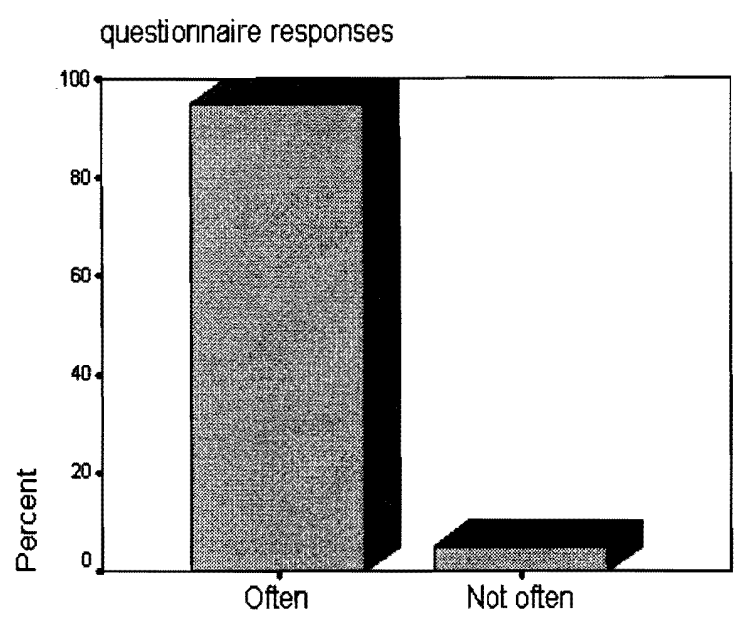

Figure 6.22 (pre-monsoon) and 6.23 (post-monsoon) show how often the respondent used river water for drinking. For both periods, approximately 95 percent did not use river water for drinking. Nearly all participants said that they rarely or never used canal or tank water for drinking water - 99 percent for both pre- and postmonsoon cholera epidemics.

Figure 6.22:

Pre-rnonsoon: Drinking river water

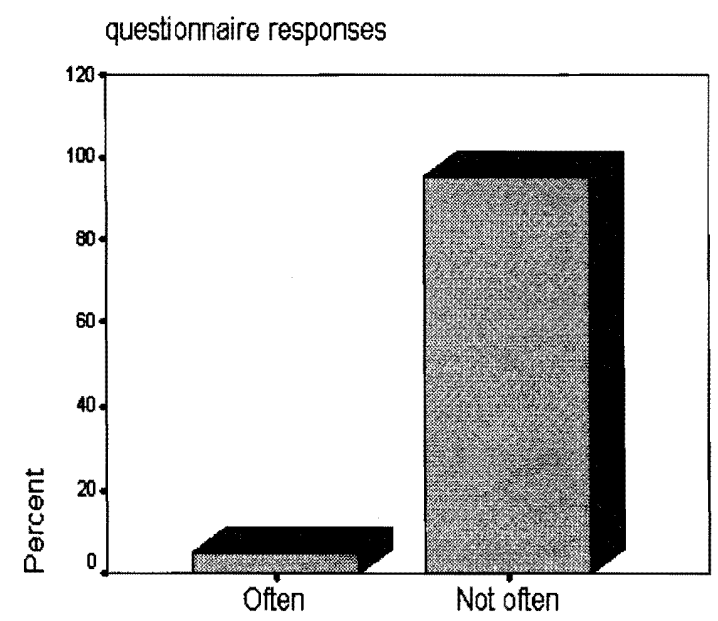

Figure 6.23:

Post-monsoon: Drinking river water

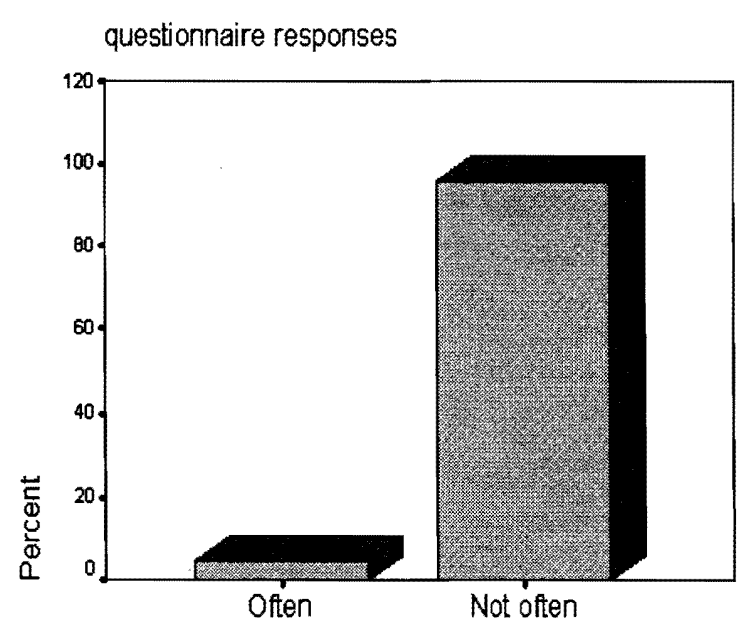


Figures 6.24 through 6.31 represent answers from respondents who were asked how often they used various water sources for cooking. Figure 6.24 shows that 92 percent did not use tubewell water for cooking (pre-monsoon), and Figure 6.25 shows that 93 percent of participants did not use tubewell water for cooking (post-monsoon).

Figure 6.24:

Pre-monsoon: Cooking w/ tubewell water

questionnaire responses

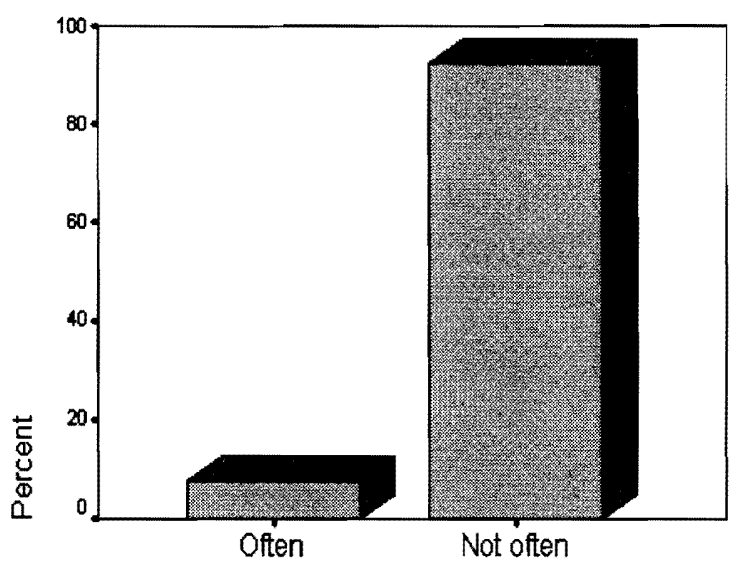

Figure 6.25:

Post-monsoon: Cooking w/ tubewell water questionnaire responses

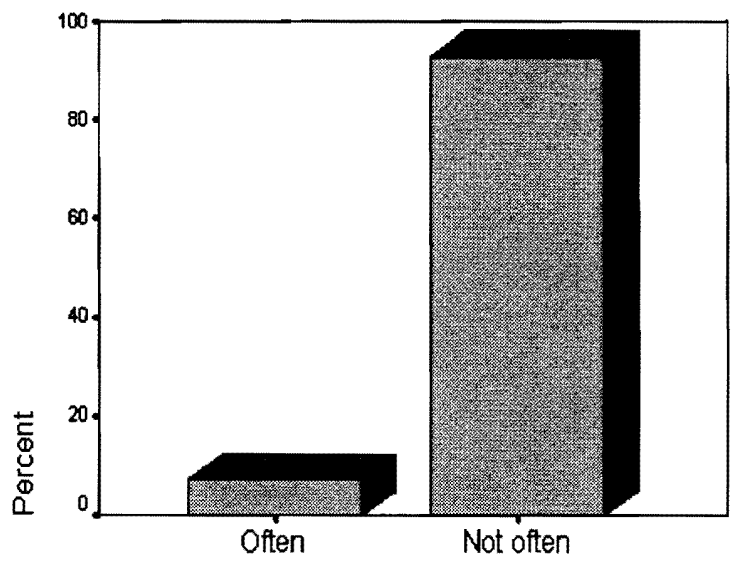

Figures 6.26 and 6.27 demonstrate that 85 percent of the respondents did not use river water for cooking during the pre-monsoon or post-monsoon cholera periods.

\section{Figure 6.26:}

Pre-monsoon: Cooking w/ river water questionnaire responses

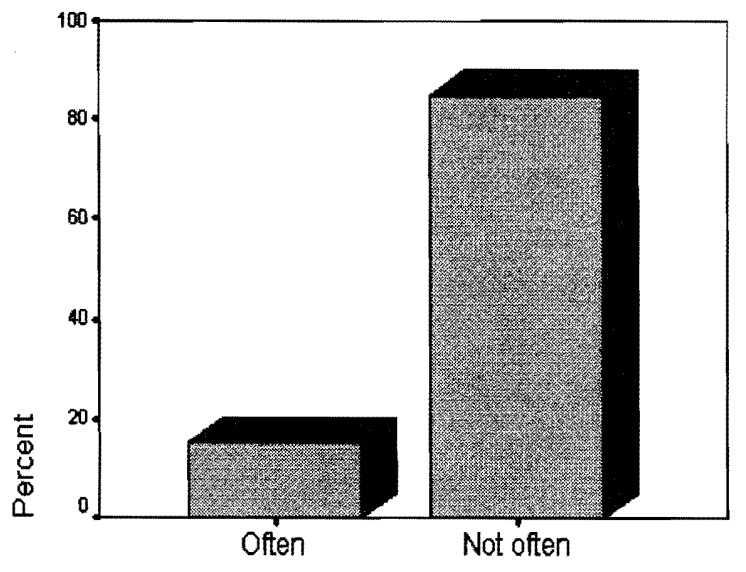

Figure 6.27:

Post-monsoon: Cooking w/ river water

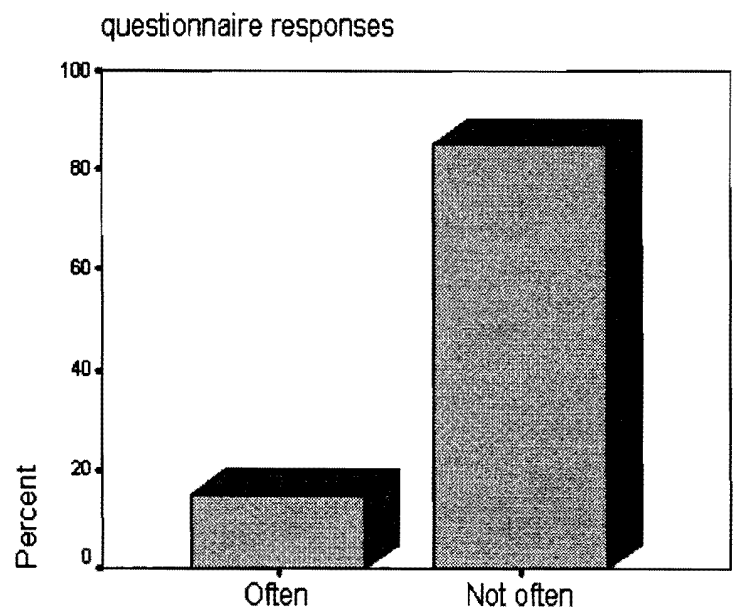


Figure 6.28 demonstrates that 83 percent of the respondents did not use canal water for cooking during the pre-monsoon. Figure 6.29 shows that 84 percent did not use canal water for cooking during the post-monsoon cholera periods.

\section{Figure 6.28:}

Pre-monsoon: Cooking w/ canal water

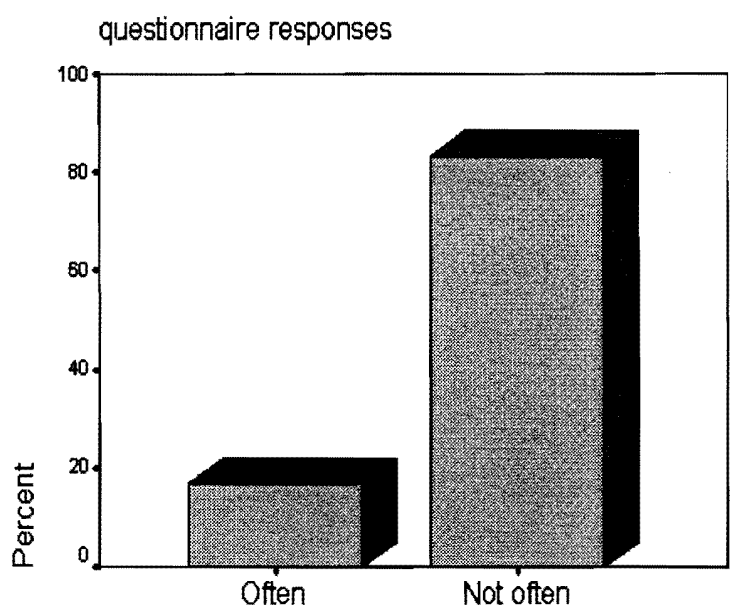

Figure 6.29:

Post-monsoon: Cooking w/ canal water

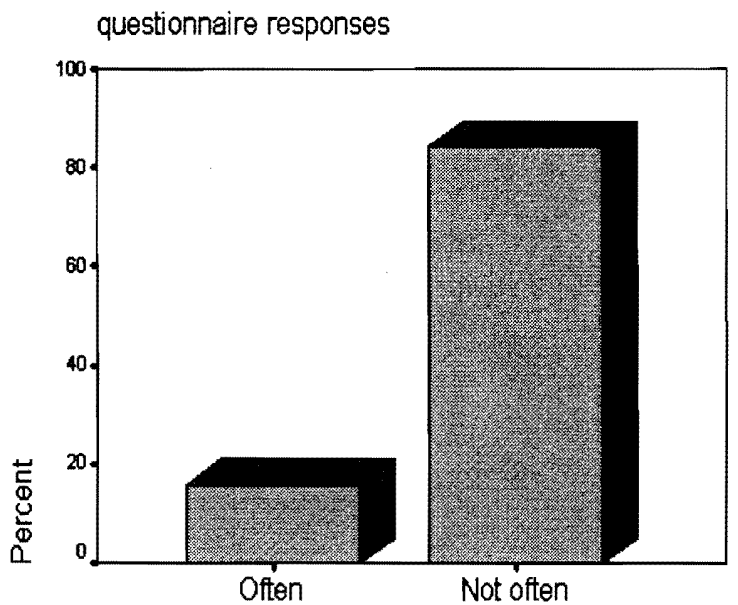

Figure 6.30 demonstrates that 64 percent of the respondents often used tank water for cooking during the pre-monsoon. Figure 6.31 shows that 66 percent did not use tank water for cooking during the post-monsoon cholera periods.

Figure 6.30:

Pre-monsoon: Cooking w/ tank water

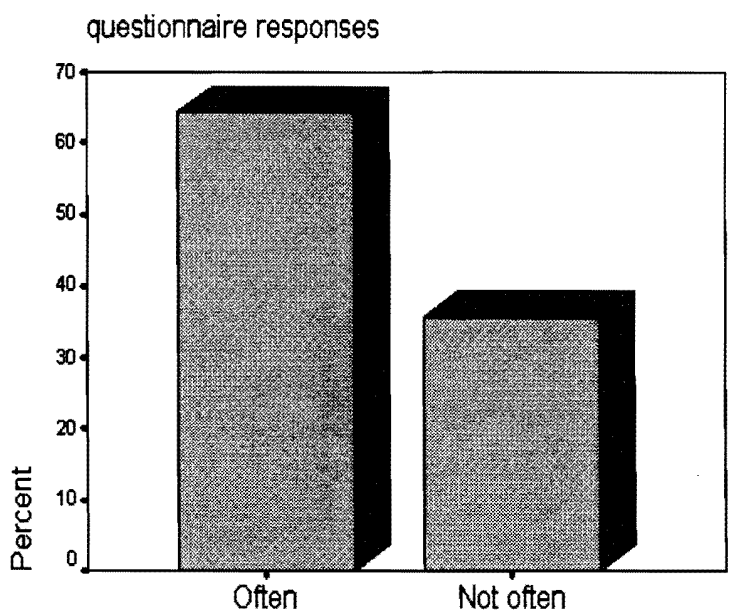

Figure 6.31:

\section{Post-monsoon: Cooking w/ tank water}

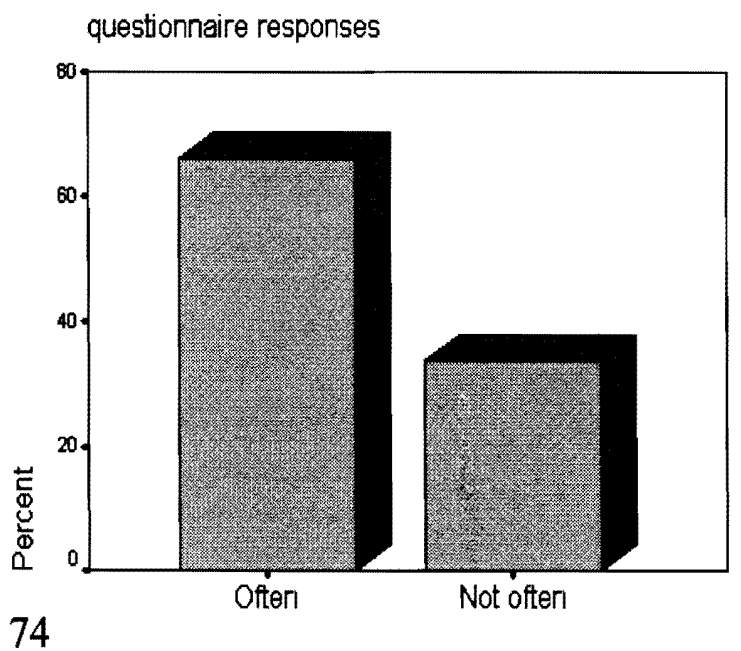


Figures 6.32 through 6.38 show responses to questions concerning how often the participant used various types of water sources for bathing. Figure 6.32 demonstrates that 98 percent of respondents did not use tubewell water for bathing during the pre- and post-monsoon cholera epidemic periods.

\section{Figure 6.32:}

\section{Pre/Post-Monsoon:}

\section{Bathing w/tubewell water}

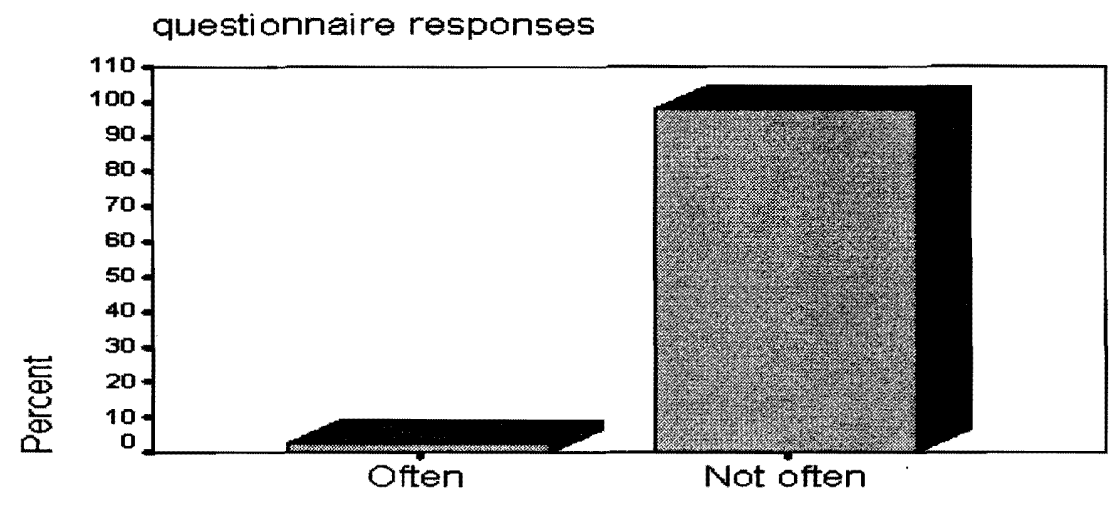

Figures 6.33 and 6.34 show the 84 percent of the respondents did not use river water for bathing (pre-monsoon) and 85 percent used sources other than river water for bathing (post-monsoon).

\section{Figure 6.33:}

Pre-monsoon: Bathing w/ river water quesitonnaire responses

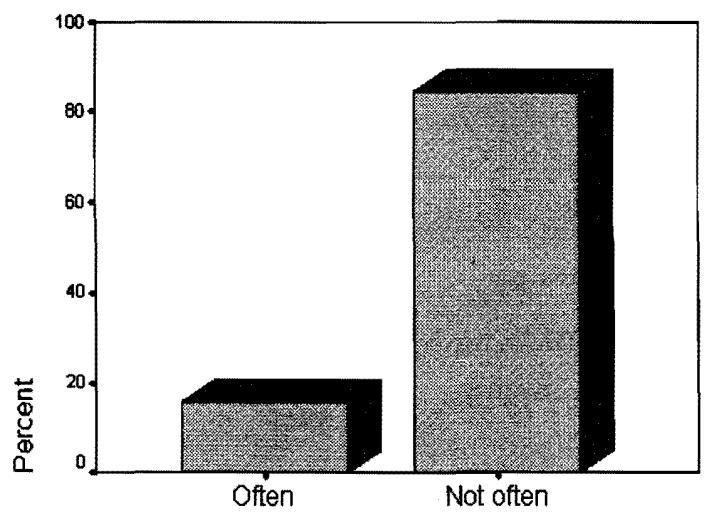

Figure 6.34:

\section{Post-monsoon: Bathing w/ river water}

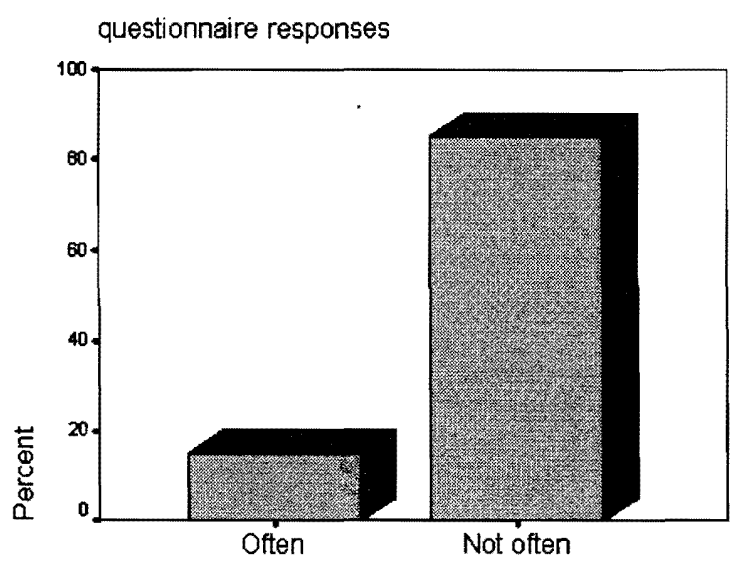


Figures 6.35 and 6.36 show the 83 percent of the respondents did not use canal water for bathing (pre-monsoon), and 85 percent used sources other than canal water for bathing (post-monsoon).

\section{Figure 6.35:}

\section{Pre-monsoon: Bathing w/ canal water}

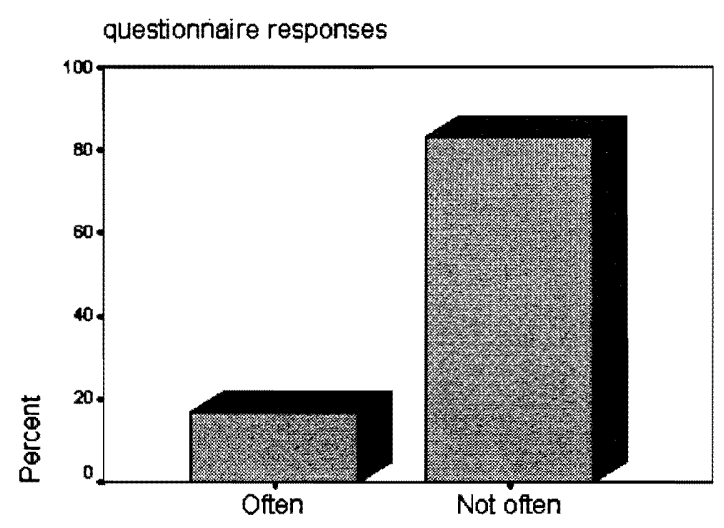

\section{Figure 6.36:}

Post-monsoon: Bathing w/ canal water

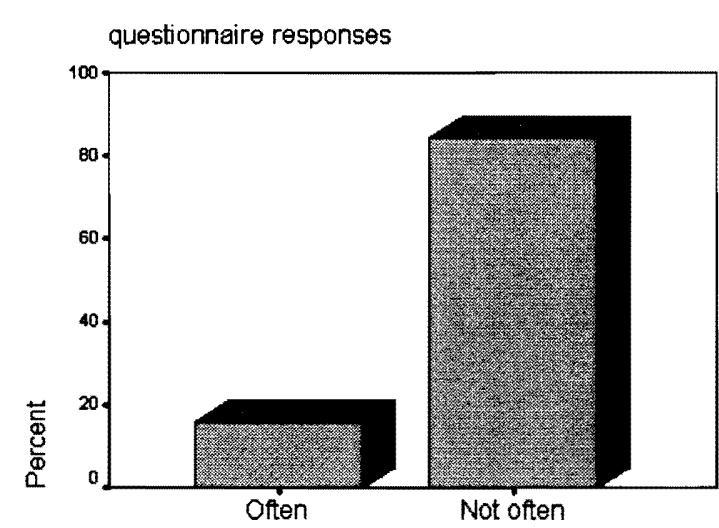

Figures 6.37 and 6.38 show the 69 percent of the respondents used tank water for bathing (pre-monsoon) and 71 percent used tank water for bathing (post-monsoon).

Figure 6.37:

Pre-monsoon: Bathing wtank water

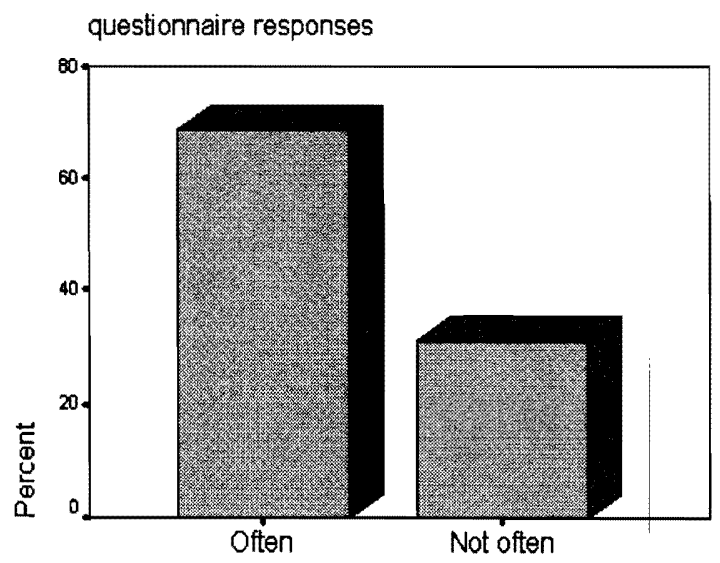

Figure 6.38:

\section{Post-monsoon: Bathing w/ tank water}

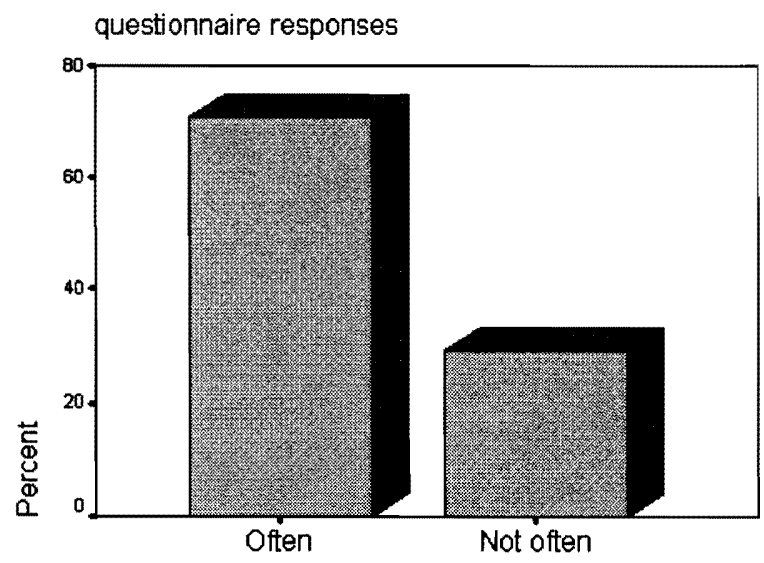


Figure 6.39 demonstrates where the adult males of the participant's family regularly defecated. Pre-monsoon, 44 percent of males used latrines, while 56 percent used another source. Figure 6.40 shows the post-monsoon responses: forty-three percent of males used latrines, and 57 percent did not latrines.

Figure 6.39: Adult males $\&$ latrine use.

Pre-monsoon: Latrine use

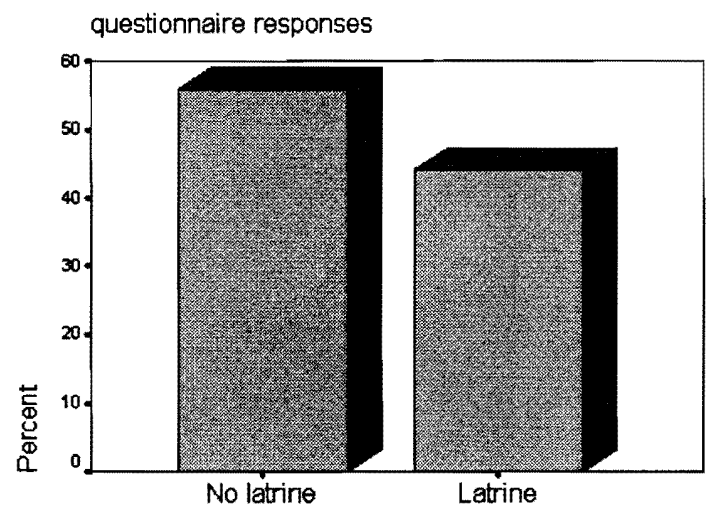

Figure 6.40: Adult males \& latrine use.

\section{Post-monsoon: Latrine use}

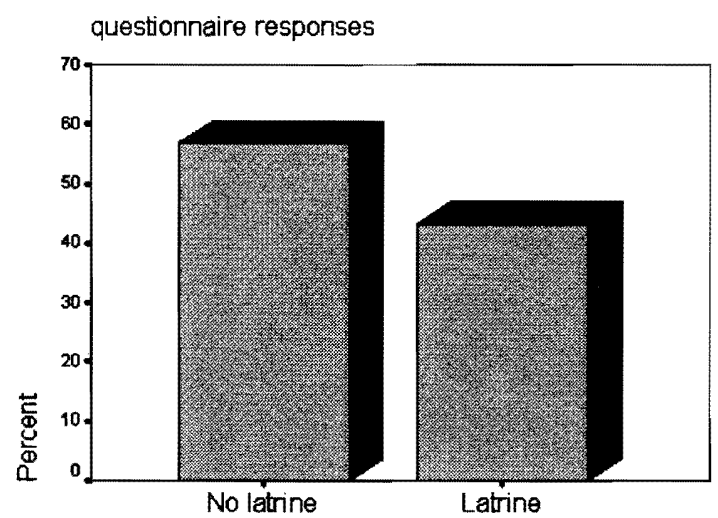

Figure 6.41 demonstrates where the adult females of the participant's family regularly defecated. Forty-three percent of females regularly used latrines, while 57 percent defecated elsewhere (pre-monsoon). In Figure 6.42 shows that 42 percent of females used latrines, and 58 percent used another source (post-monsoon).

Figure 6.41: Adult females \& latrine use.

Pre-monsoon: Latrine use

questionnaire responses

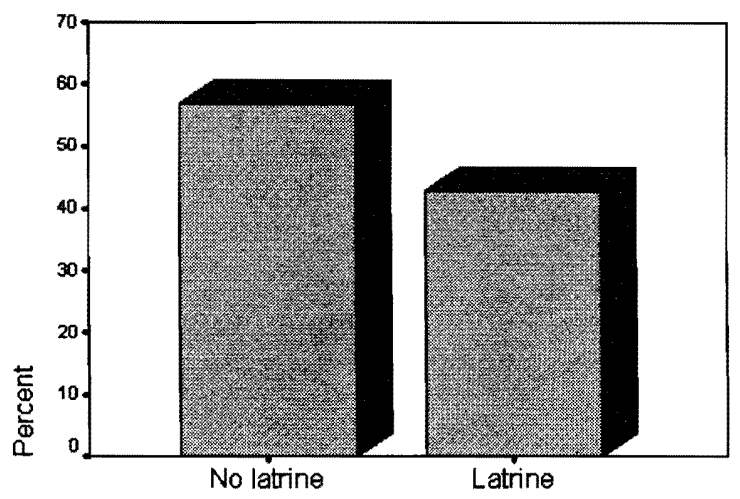

Figure 6.42: Adult females \& latrine use. Post-monsoon: Latrine use questionnaire responses

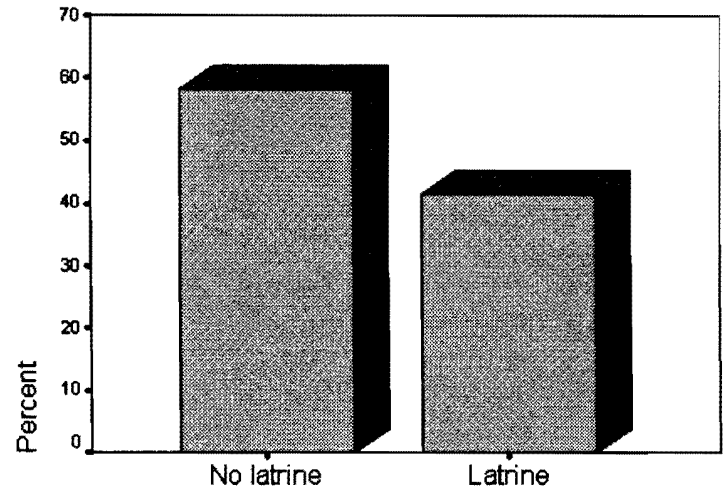


Figure 6.43 demonstrates where the male children of the participant's family regularly defecated. Thirty-seven percent of male children regularly used latrines, while 63 percent defecated elsewhere (pre-monsoon). Figure 6.44 shows that 37 percent used latrines, and 63 percent used another source (post-monsoon).

Figure 6.43: Male children \& latrine use.

Pre-monsoon: Latrine use

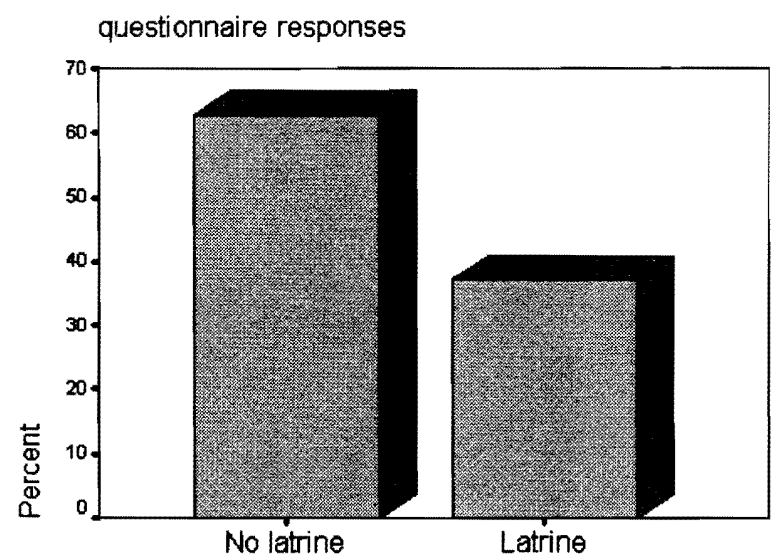

Figure 6.44: Male children \& latrine use.

Post-monsoon: Latrine use

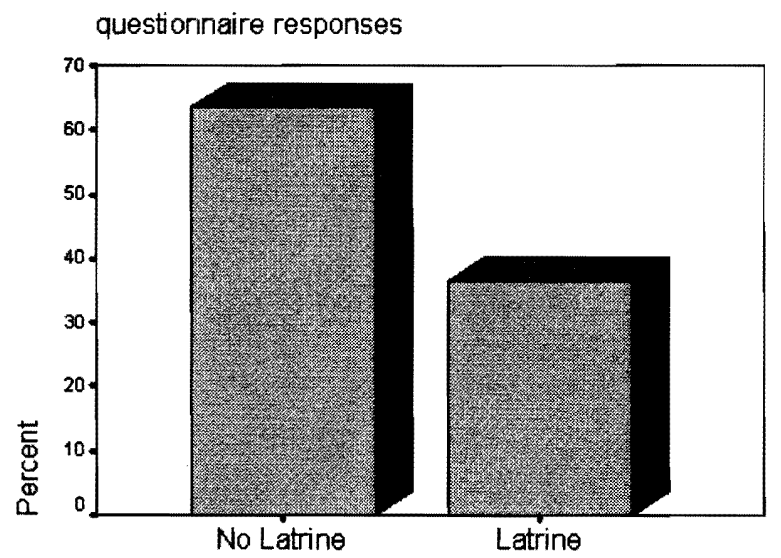

Figure 6.45 demonstrates where the female children of the participant's family regularly defecated. Thirty-eight percent of females regularly used latrines, while 62 percent defecated elsewhere (pre-monsoon). In Figure 6.46 shows that 37 percent of females used latrines, and 63 percent used another source (post-monsoon).

Figure 6.45: Female children $\&$ latrine use. Figure 6.46: Female children $\&$ latrine use. Pre-monsoon: Latrine use

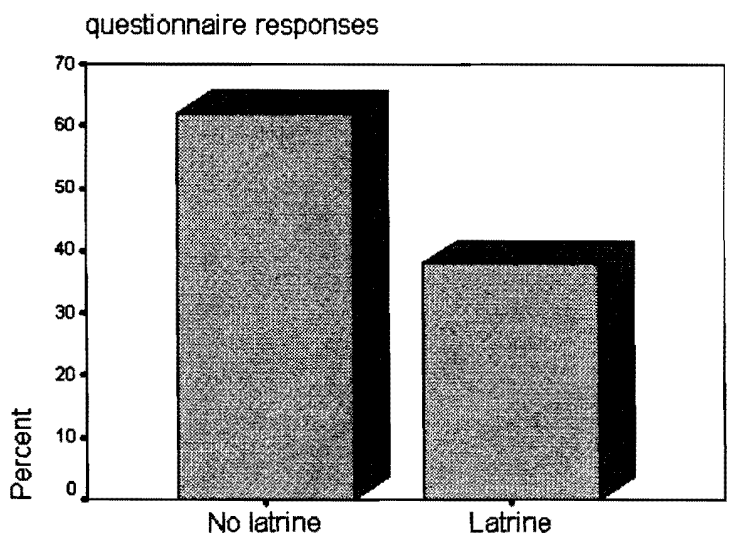

Post-monsoon: Latrine use

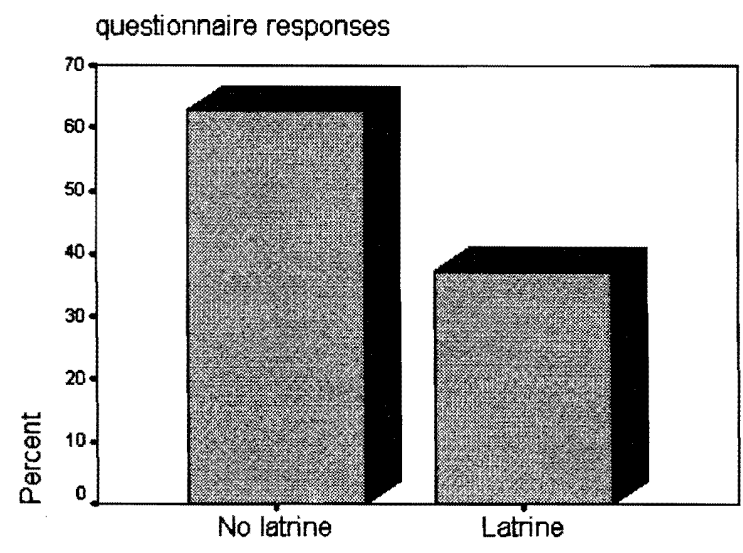


When asked if the participant had a latrine in their household 57 percent (premonsoon) and 58 percent (post-monsoon) answered no, while 43 percent (premonsoon) and 42 percent (post-monsoon) answered yes (Fig. 6.47 and 6.48). There are various ways in which the latrines in rural Bangladesh drain. The participants were asked the type of latrine drainage in their bari. Fifty-seven percent were uncertain, 12 percent of latrines were open and drained into a ditch, and 20 percent were latrines with septic (pre-monsoon and post-monsoon).

Figure 6.47:

Pre-monsoon: Number of households

sharing a latrine

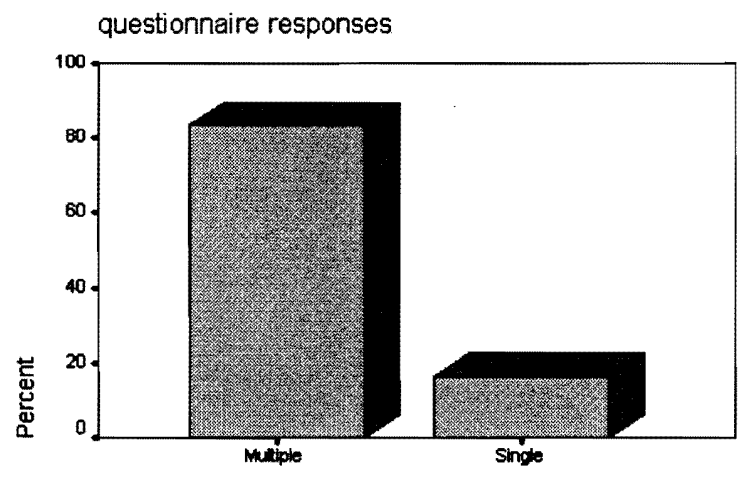

Figure 6.48:

Post-monsoon: Number of households sharing a latrine

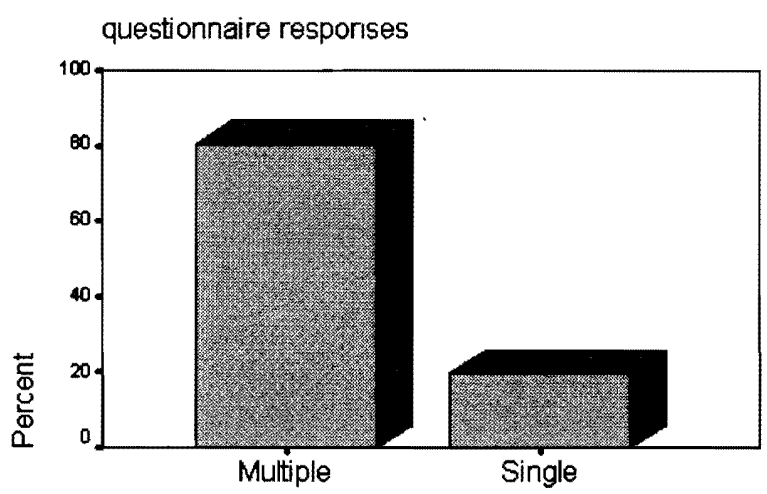

\subsection{Non-parametric case-control study for categorical variables}

The data collected and used in this study include both categorical and continuous variables. Table 6.1 shows the frequencies of cholera cases and controls of each binary variable. Non-parametric case-control methods were used to analyze the categorical variables (as discussed in Chapter 5 and in Appendix A). The relative risk of each variable was calculated at the 95 percent confidence level. The value of a 
relative risk is interpreted three ways: first, if the relative risk is equal to one (numerator $=$ denominator) than no evidence exists for any association of the disease Table 6.1: Frequencies of categorical variables.

\begin{tabular}{|c|c|c|c|c|c|c|c|}
\hline 30. & 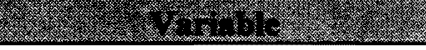 & 6. & 3 & C.5.: & 6.02 & $x+4=1$ & 8 \\
\hline Pre & Gender & Male & 290 & 85 & Female & 307 & 88 \\
\hline Post & Gender & Male & 290 & 556 & Female & 307 & 544 \\
\hline Pre & Embankment & Yes & 162 & 62 & No & 429 & 110 \\
\hline Post & Embankment & Yes & 162 & 539 & No & 429 & 537 \\
\hline Pre & $\begin{array}{l}\text { Tubewell is used for } \\
\text { cooking }\end{array}$ & Yes & 45 & 1 & No & 552 & 13 \\
\hline Post & $\begin{array}{l}\text { Tubewell is used for } \\
\text { cooking }\end{array}$ & Yes & 45 & 1 & No. & 552 & 147 \\
\hline Pre & Tubewell is used for bathing & Yes & 14 & 0 & No & 583 & 14 \\
\hline Post & Tubewell is used for bathing & Yes: & 14 & 1 & No & 583 & 153 \\
\hline Pre & $\begin{array}{l}\text { Tubewell is used for } \\
\text { washing }\end{array}$ & Yes & 47 & 0 & No & 550 & 14 \\
\hline Post & $\begin{array}{l}\text { Tubewell is used for } \\
\text { washing }\end{array}$ & Yes & 47 & 11 & No & 550 & 143 \\
\hline Pre & Working tubewell in bari & Yes & 411 & 9 & No & 9 & 0 \\
\hline Post & Working tubewell in bari & Yes & 411 & 109 & No & 9 & 1 \\
\hline Pre & Use another baris tubewell & Yes & 162 & 5 & No & 20 & 0 \\
\hline Post & Use another baris tubewell & Yes & 162 & 43 & No & 20 & 1. \\
\hline Pre & Use of tubewell for drinking & Often & 562 & 14 & $\begin{array}{c}\text { Not } \\
\text { often }\end{array}$ & 35 & 0 \\
\hline Post & Use of tubewell for drinking & Orten & 562 & 151 & $\begin{array}{l}\text { Not } \\
\text { often }\end{array}$ & 35 & 3 \\
\hline Pre & Use of river for drinking & Often & 30 & $\mathbf{0}$ & $\begin{array}{c}\text { Not } \\
\text { often }\end{array}$ & 567 & 14 \\
\hline Post & Use of river for drinking & Often & 30 & 3 & $\begin{array}{l}\text { Not } \\
\text { often }\end{array}$ & 567 & 151 \\
\hline Pre & Use of canal for drinking & Often & 6 & 0 & $\begin{array}{c}\text { Not } \\
\text { often }\end{array}$ & 591 & 14 \\
\hline Post & Use of canal for drinking & Orten & 6 & 2 & $\begin{array}{l}\text { Not } \\
\text { orten }\end{array}$ & 591 & 152 \\
\hline Pre & Use of tank for drinking & Often & 3 & 0 & $\begin{array}{l}\text { Not } \\
\text { often }\end{array}$ & 594 & 14 \\
\hline Post & Use of tank for drinking & Orten & 3 & 0 & $\begin{array}{l}\text { Not } \\
\text { often } \\
\end{array}$ & 594 & 154 \\
\hline Pre & Use of tubewell for cooking & Often & 46 & 1 & $\begin{array}{c}\text { Not } \\
\text { often }\end{array}$ & 551 & 13 \\
\hline Post & Use of tubewell for cooking & Often & 46 & 8 & $\begin{array}{l}\text { Not } \\
\text { often }\end{array}$ & 551 & 146 \\
\hline
\end{tabular}




\begin{tabular}{|c|c|c|c|c|c|c|c|}
\hline Pre & Use of river for cooking & Often & 93 & 0 & $\begin{array}{l}\text { Not } \\
\text { often }\end{array}$ & 504 & 14 \\
\hline Post & Use of river for cooking & Often & 93 & 20 & $\begin{array}{l}\text { Not } \\
\text { often }\end{array}$ & 504 & 134 \\
\hline Pre & Use of canal for cooking & Often & 98 & 4 & $\begin{array}{c}\text { Not } \\
\text { often }\end{array}$ & 499 & 10 \\
\hline Post & Use of canal for cooking & Orten & 98 & 21 & Not & 499 & 133 \\
\hline Pre & Use of tank for cooking & Often & 384 & 9 & $\begin{array}{c}\text { Not } \\
\text { often }\end{array}$ & 213 & 5 \\
\hline Post & Use of tank for cooking & Orten & 384 & 112 & $\begin{array}{l}\text { Not } \\
\text { often }\end{array}$ & 213 & 42 \\
\hline Pre & Use of tubewell for bathing & Often & 14 & 0 & $\begin{array}{c}\text { Not } \\
\text { often }\end{array}$ & 583 & 14 \\
\hline Post & Use of tubewell for bathing & Orten & 14 & 1 & $\begin{array}{l}\text { Not } \\
\text { often }\end{array}$ & 583 & 153 \\
\hline Pre & Use of river for bathing & Often & 96 & 0 & $\begin{array}{c}\text { Not } \\
\text { often }\end{array}$ & 501 & 14 \\
\hline Post & Use of river for bathing & Orten & 96 & 17 & $\begin{array}{l}\text { Not } \\
\text { often }\end{array}$ & 501 & 137 \\
\hline Pre & Use of canal for bathing & Often & 99 & 4 & $\begin{array}{l}\text { Not } \\
\text { often }\end{array}$ & 498 & 10 \\
\hline Post & Use of canal for bathing & Oiten & 99 & 20 & $\begin{array}{l}\text { Not } \\
\text { often }\end{array}$ & 498 & 134 \\
\hline Pre & Use of tank for bathing & Often & 410 & 10 & $\begin{array}{c}\text { Not } \\
\text { often }\end{array}$ & 187 & 4 \\
\hline Post & Use of tank for bathing & Orten & 410 & 121 & $\begin{array}{l}\text { Not } \\
\text { often }\end{array}$ & 187 & 33 \\
\hline Pre & Adult male defecation & Latrine & 264 & 5 & $\begin{array}{l}\text { Not in } \\
\text { latrine }\end{array}$ & 333 & 9 \\
\hline Post & Adult male defecation & Latrine & 264 & 61 & $\begin{array}{l}\text { Not in } \\
\text { latrine }\end{array}$ & 333 & 93 \\
\hline Pre & Adult female defecation & Latrine & 258 & 5 & $\begin{array}{l}\text { Not in } \\
\text { latrine }\end{array}$ & 339 & 9 \\
\hline Post & Adult female defecation & Latrine & 258 & 55 & $\begin{array}{l}\text { Not in } \\
\text { latrine }\end{array}$ & 339 & 99 \\
\hline Pre & Male children defecation & Latrine & 211 & 5 & $\begin{array}{l}\text { Not in } \\
\text { latrine }\end{array}$ & 356 & 9 \\
\hline Post & Male children defecation & Latrine & 211 & 50 & $\begin{array}{l}\text { Not in } \\
\text { latrine }\end{array}$ & 356 & 97 \\
\hline Pre & Female children defecation & Latrine & 213 & 4 & $\begin{array}{l}\text { Not in } \\
\text { latrine }\end{array}$ & 344 & 10 \\
\hline Post & Female children defecation & Latrine & 213 & 49 & $\begin{array}{l}\text { Not in } \\
\text { latrine }\end{array}$ & 344 & 97 \\
\hline Pre & Latrine in household & Yes & 258 & 5 & No & 339 & 9 \\
\hline Post & Latrine in household & Yes & 258 & 61 & No & 339 & 93 \\
\hline Pre & Type of drainage & Septic & 124 & 3 & Open & 134 & 2 \\
\hline Post & Type of drainage & Septic & 124 & 29 & Open & 134 & 32 \\
\hline Pre & \# of households using a latrine & Single & 41 & 2 & Mult. & 216 & 3 \\
\hline
\end{tabular}


Table 6.1: Frequencies of categorical variables, continued.

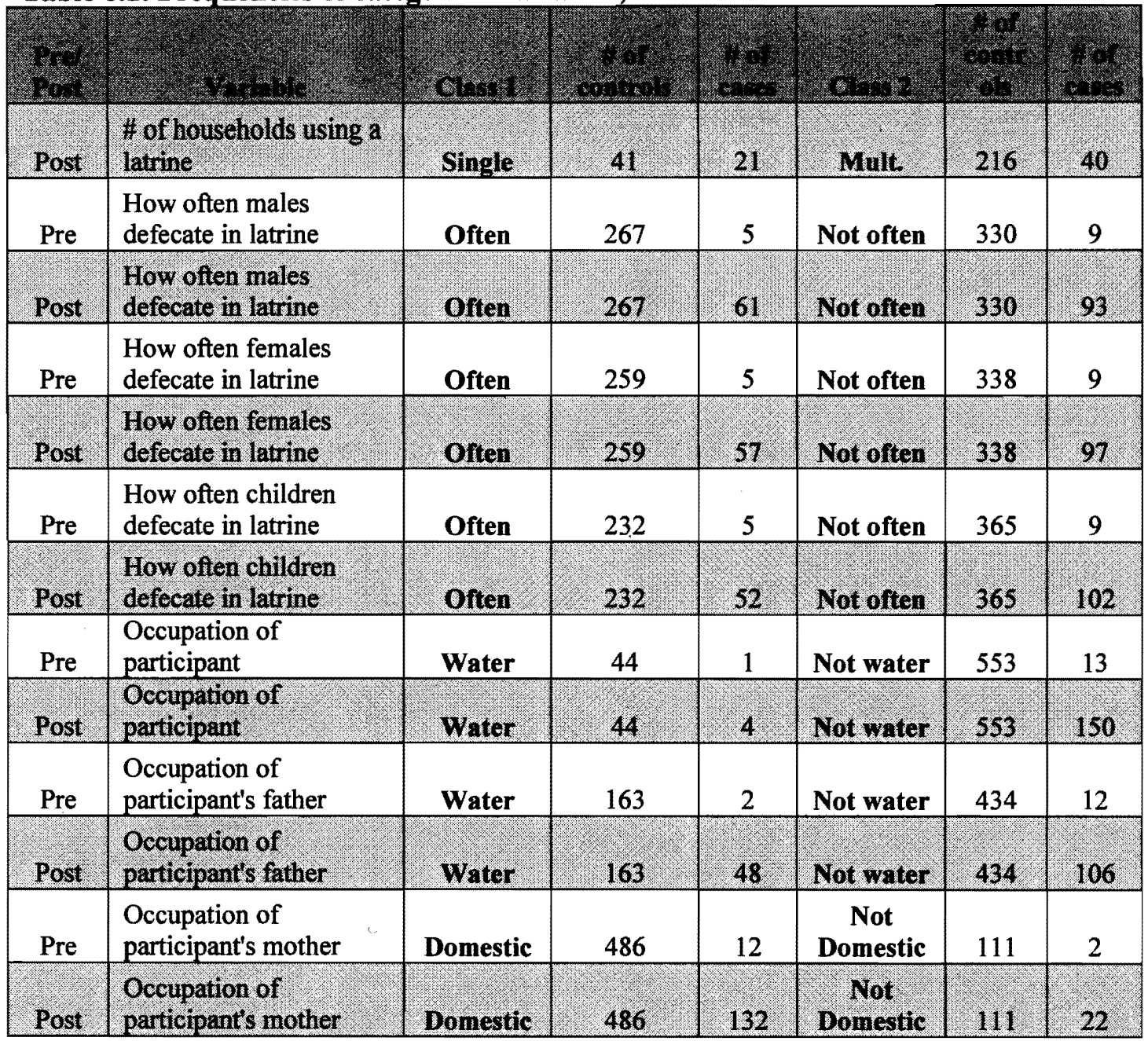


with the exposure in question; second, if the relative risk is greater than one (numerator $>$ denominator) than there is evidence of a positive association; and third, if the relative risk is less than one (numerator $<$ denominator) this indicates a negative association. The significant relative risk values for the categorical variables have an asterix beside them in Table 6.2 .

Using tank water for bathing was related to cholera incidence in the postmonsoon season, while using other water sources (tubewell, canal, river) for various activities (cooking, bathing, washing) were not associated with cholera hospitalization. The number of households using a latrine was related to post-monsoon cholera. However, the variables associated with latrine drainage and defecating in places other than latrines were not related to cholera incidence. Living in the flood-controlled area was positively associated with both pre- and post-monsoon cholera cases. The premonsoon risk ratio was 1.5, and the risk ratio in the post-monsoon period was 2.7 .

The socioeconomic variables concerning the occupation of the participant's father and mother were found to be associated to cholera incidence. Gender was not associated with cholera incidence in either the pre- or post-monsoon period. 
Table 6.2: Relative risks for categorical variables.

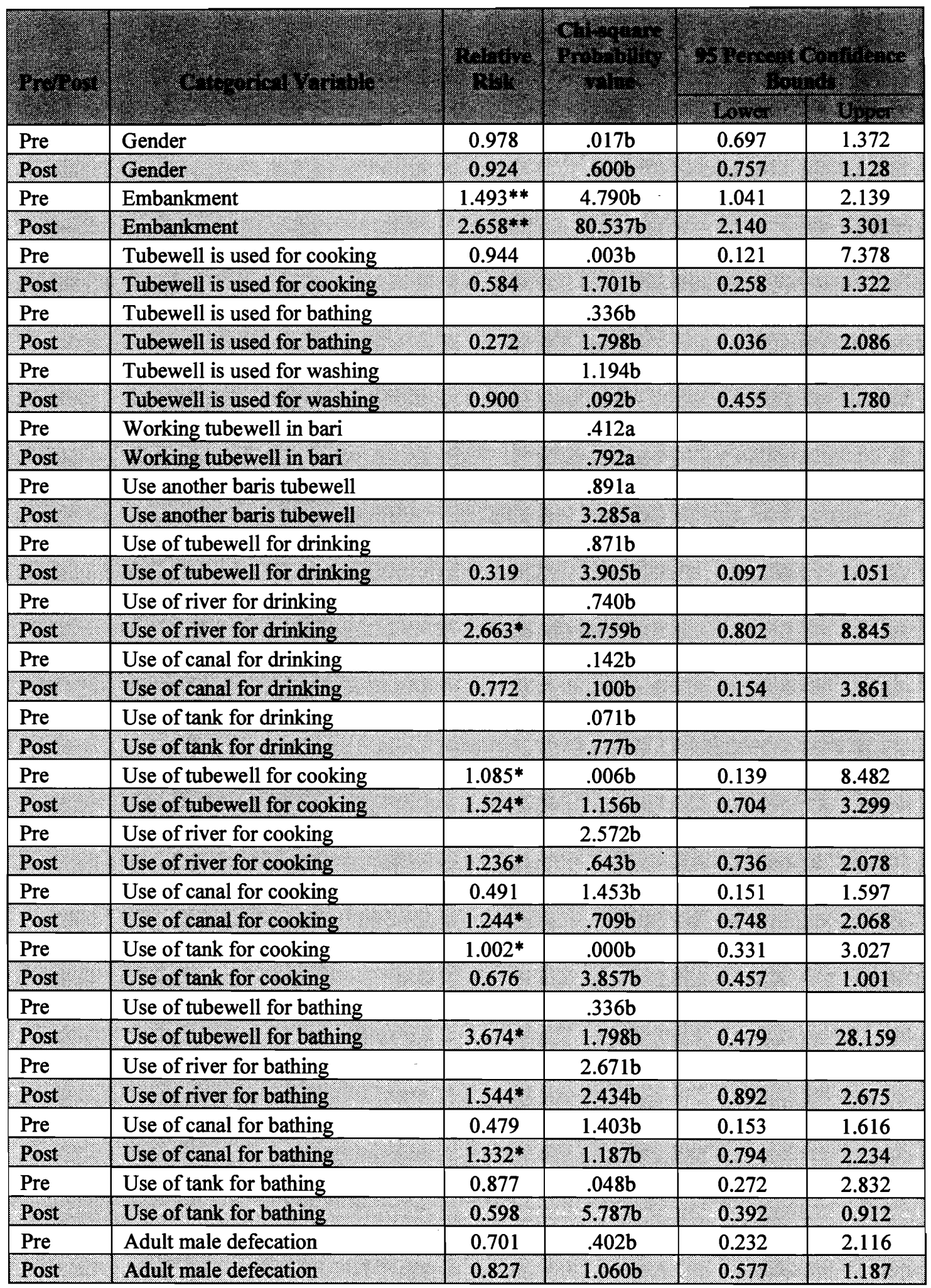


Table 6.2: Relative risks for categorical variables, continued.

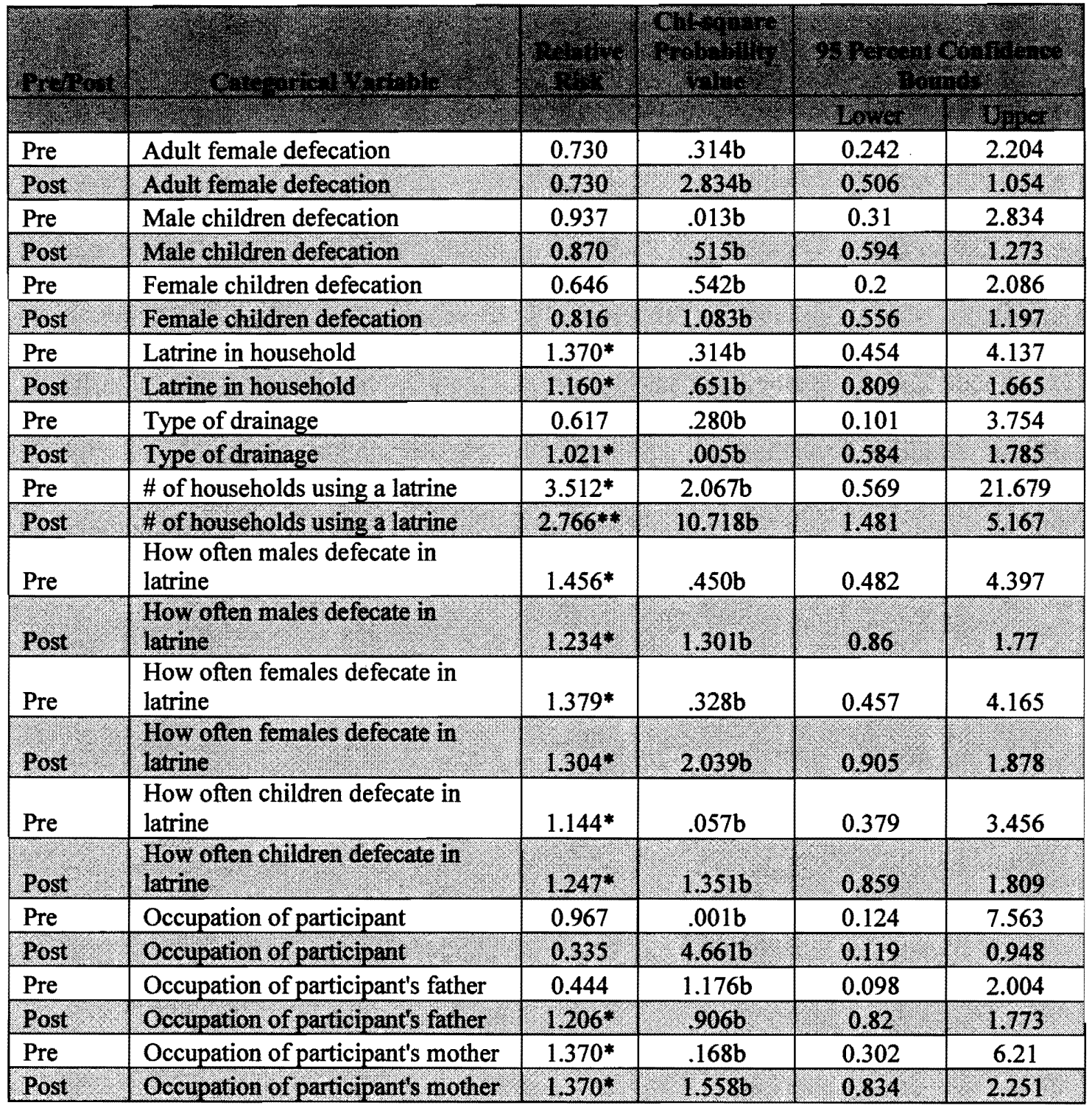




\subsection{Simple regression analysis for continuous variables}

This study included several continuous independent variables for which summary statistics are listed in Table 6.3. Simple logistic regression models were created for all of the continuous variables, and for selected categorical variables. The outputs from these regression models, using cholera as the binary dependent variable, are displayed in Table 6.4. The independent variables that were statistically significant at the 99 percent confidence levels are noted with two asterixes, and those variables at the 95 percent confidence level have one asterix. A weak relationship was accepted if there was an association at the 90 percent level. The number of open latrines was related to cholera incidence in the post-monsoon season at the 99 percent confidence level. This means that the more open latrines there were in a bari the more likely it was that a person living in that bari would be hospitalized with cholera. The number of non-septic, ringed, and concrete latrines in a bari were not positively correlated with cholera hospitalization for either pre- or post-monsoon periods. The number of households sharing a latrine in the post-monsoon season was significantly related to cholera hospitalization. Bari population was related to cholera incidence at the 95 percent confidence level for the post-monsoon epidemic, and at the 99 percent confidence level for the pre-monsoon epidemic. This means that a larger number of people living in a bari, the more likely those people will be hospitalized with cholera. Population density around baris in the post- monsoon season was related to cholera at the 99 percent confidence level. However, population density in the pre-monsoon season had little effect on cholera hospitalization. Household area in the post- 
monsoon was related to cholera at the 95 percent confidence level, and the number of households sharing a latrine post-monsoon was related at the 95 percent confidence level. Therefore, the more people who shared a latrine the more likely these individuals were hospitalized with cholera. There was a weak relationship between the variable associated with female defecation and post-monsoon cholera epidemics. The number of tubewells per 100 persons was not related to cholera incidence, nor was the number of latrines per 100 persons.

Table 6.3: Descriptive statistics for continuous independent variables.

\begin{tabular}{|l|l|c|c|c|c|}
\hline Pre & Bari population & 51.66 & 40.339 & 3 & 440 \\
\hline Post & Bari population & 59.01 & 56.062 & 4 & 498 \\
\hline Pre & $\begin{array}{l}\text { Population density around baris } \\
\text { (persons per km2) }\end{array}$ & 5779.24 & 3416.39832 & 159.09 & 23084.23 \\
\hline Post & $\begin{array}{l}\text { Population density around baris } \\
\text { (persons per km2) }\end{array}$ & 6192.05 & 3984.80059 & 159.09 & 6192.0586 \\
\hline Pre & \# of households sharing latrine & 10.04 & 8.425 & 0 & 49 \\
\hline Post & \# of households sharing latrine & 10.95 & 8.662 & 0 & 54 \\
\hline Pre & \# of households sharing tubewell & 8.78 & 8.984 & 0 & 41 \\
\hline Post & \# of households sharing tubewell & 10.02 & 9.111 & 0 & 55 \\
\hline Pre & \# of open latrines & 3.76 & 3.387 & 0 & 19 \\
\hline Post & \# of open latrines & 4.55 & 3.881 & 0 & 20 \\
\hline Pre & \# of non-septic latrines w/o ring & 0.32 & 0.687 & 0 & 5 \\
\hline Post & \# of non-septic latrines w/o ring & 0.42 & 0.864 & 0 & 5 \\
\hline Pre & \# of ring latrines w/ septic tank & 0.58 & 1.331 & 0 & 11 \\
\hline Post & \# of ring latrines w/ septic tank & 0.46 & 1.114 & 0 & 12 \\
\hline Pre & \# of concrete septic latrines & 0.14 & 0.487 & 0 & 3 \\
\hline Post & \# of concrete septic latrines & 0.17 & 0.546 & 0 & 3 \\
\hline Pre & \# of tubewells in bari & 0.27 & 0.443 & 0 & 1 \\
\hline Post & \# of tubewells in bari & 0.23 & 0.419 & 0 & 1 \\
\hline Pre & House hold area & 238.158 & 114.88596 & 59.50 & 840.00 \\
\hline Post & House hold area & 231.384 & 101.82263 & 18.00 & 840.00 \\
\hline Pre & River distance & 1085.67 & 887.315 & 0 & 3805 \\
\hline Post & River distance & 1046.99 & 877.235 & 0 & 3824 \\
\hline Pre & \# of latrines per 100 people & 2.0007 & 3.28569 & 0.00 & 18.18 \\
\hline Post & \# of latrines per 100 people & 1.8138 & 2.88467 & 0.00 & 18.18 \\
\hline Pre & \# of tubewells per 100 people & 2.8125 & 3.15032 & 0.00 & 25.00 \\
\hline Post & \# of tubewells per 100 people & 2.8507 & 2.9258 & 0.00 & 25.00 \\
\hline
\end{tabular}




\section{4: Simple logistic regression for continuous independent variables.}

\begin{tabular}{|c|l|c|c|}
\hline & & \\
\hline Pre & Bari population & -0.005 & $0.05^{*}$ \\
\hline Post & Bari population & 0.003 & $0.002^{* *}$ \\
\hline Pre & Population density around baris (persons per km2) & 0.000 & 0.723 \\
\hline Post & Population density around baris (persons per km2) & 0.000 & $0.003^{* *}$ \\
\hline Pre & \# of households sharing latrine & -0.001 & 0.967 \\
\hline Post & \# of households sharing latrine & 0.020 & $0.058^{*}$ \\
\hline Pre & \# of households sharing tubewell & -0.025 & 0.157 \\
\hline Post & \# of households sharing tubewell & 0.016 & $0.089^{*}$ \\
\hline Pre & \# of open latrines & 0.019 & 0.657 \\
\hline Post & \# of open latrines & 0.100 & $0.000^{* *}$ \\
\hline Pre & \# of non-septic latrines w/o ring & -0.348 & 0.189 \\
\hline Post & \# of non-septic latrines w/o ring & 0.150 & 0.153 \\
\hline Pre & \# of ring latrines w/ septic tank & 0.134 & 0.169 \\
\hline Post & \# of ring latrines w/ septic tank & -0.085 & 0.257 \\
\hline Pre & \# of concrete septic latrines & -0.557 & 0.200 \\
\hline Post & \# of concrete septic latrines & 0.056 & 0.724 \\
\hline Pre & \# of tubewells in bari & 0.104 & 0.749 \\
\hline Post & \# of tubewells in bari & -0.312 & 0.119 \\
\hline Pre & House hold area & -0.002 & 0.135 \\
\hline Post & House hold area & -0.002 & $0.028^{*}$ \\
\hline Pre & River distance & 0.000 & 0.924 \\
\hline Post & River distance & 0.000 & 0.200 \\
\hline Pre & \# of latrines per 100 people & 0.008 & 0.860 \\
\hline Post & \# of latrines per l00 people & -0.031 & 0.282 \\
\hline Pre & \# of tubewells per 100 people & 0.024 & 0.581 \\
\hline Post & \# of tubewells per 100 people & 0.017 & 0.556 \\
\hline
\end{tabular}

**99\% confidence level. *95\% confidence level. 
Table 6.5: Pre-monsoon logistic regression for categorical variables.

**Statistically significant. * 95\% confidence level. +Weak

\begin{tabular}{|l|c|c|}
\hline & & \\
\hline Gender & Categorical Variable & Sig \\
\hline Flood embankment & -0.022 & 0.897 \\
\hline Source of water used for cooking & 0.400 & $0.029 * *$ \\
\hline Source of water used for bathing & -0.058 & 0.956 \\
\hline Source of water used for washing & -4.473 & 0.782 \\
\hline Is tubewell in bari working & -6.532 & 0.785 \\
\hline Do you use tubewell from other bari & -0.314 & 0.562 \\
\hline How often use tubewell water for drinking & 0.064 & 0.897 \\
\hline How often use river water for drinking & 5.501 & 0.744 \\
\hline How often use canal water for drinking & 4.460 & 0.762 \\
\hline How often use tank water for drinking & 3.454 & 0.857 \\
\hline How often use tubewell water for cooking & 0.082 & 0.870 \\
\hline How often use river water for cooking & 6.619 & 0.698 \\
\hline How often use canal water for cooking & -0.711 & 0.237 \\
\hline How often use tank water for cooking & 0.002 & 0.998 \\
\hline How often use tubewell water for bathing & 4.473 & 0.782 \\
\hline How often use river water for bathing & 6.625 & 0.693 \\
\hline How often use canal water for bathing & -0.699 & 0.245 \\
\hline How often use tank water for bathing & -0.131 & 0.826 \\
\hline Where do adult males defecate & -0.356 & 0.528 \\
\hline Where do adult females defecate & -0.315 & 0.577 \\
\hline Where do male children defecate & -0.065 & 0.909 \\
\hline Do you have a latrine in household & 0.315 & 0.577 \\
\hline What kind of drainage does latrine have & -0.483 & 0.600 \\
\hline Share latrine with other household & 1.256 & 0.176 \\
\hline How often do males defecate in latrine & 0.376 & 0.505 \\
\hline How often do females defecate in latrine & 0.322 & 0.568 \\
\hline Occupation of participant & -0.034 & 0.974 \\
\hline Occupation of participant's father & -0.812 & 0.291 \\
\hline Occupation of participant's mother & 0.315 & 0.683 \\
\hline & & \\
\hline & & \\
\hline
\end{tabular}


Table 6.6: Post monsoon logistic regression for categorical variables.

**Statistically significant. *95\% confidence level. +Weak

\begin{tabular}{|c|c|c|}
\hline Categorteal Variable & Beta & Sig \\
\hline Gender & -0.079 & 0.439 \\
\hline Flood embankment & 0.978 & $0.00 * *$ \\
\hline Source of water used for cooking & -0.537 & 0.198 \\
\hline Source of water used for bathing & -1.276 & 0.214 \\
\hline Source of water used for washing & -0.105 & 0.762 \\
\hline Is tubewell in bari working & 0.010 & 0.960 \\
\hline Do you use tubewell from other bari & -0.173 & 0.332 \\
\hline How often use tubewell water for drinking & -1.142 & $0.060^{*}$ \\
\hline How often use river water for drinking & 0.972 & 0.111 \\
\hline How often use canal water for drinking & -0.259 & 0.752 \\
\hline How often use tank water for drinking & 3.844 & 0.622 \\
\hline How often use tubewell water for cooking & 0.421 & 0.286 \\
\hline How often use river water for cooking & 0.212 & 0.423 \\
\hline How often use canal water for cooking & 0.218 & 0.401 \\
\hline How often use tank water for cooking & -0.391 & $0.050 *$ \\
\hline How often use tubewell water for bathing & 1.276 & 0.214 \\
\hline How often use river water for bathing & 0.434 & 0.121 \\
\hline How often use canal water for bathing & 0.286 & 0.277 \\
\hline How often use tank water for bathing & -0.514 & $0.017^{* *}$ \\
\hline Where do adult males defecate & -0.189 & 0.304 \\
\hline Where do adult females defecate & -0.315 & $0.093+$ \\
\hline Where do male children defecate & -0.140 & 0.473 \\
\hline Do you have a latrine in household & 0.149 & 0.420 \\
\hline What kind of drainage does latrine have & 0.021 & 0.942 \\
\hline Share latrine with other household & 1.017 & $0.001 * *$ \\
\hline How often do males defecate in latrine & 0.21 & 0.255 \\
\hline How often do females defecate in latrine & 0.265 & 0.154 \\
\hline Occupation of participant & -1.093 & $0.039 *$ \\
\hline Occupation of participant's father & 0.187 & 0.342 \\
\hline Occupation of participant's mother & 0.315 & 0.214 \\
\hline
\end{tabular}


While the distance to the main river was not related to cholera incidence, if a household was located within the flood-control embankment, then residents were more likely to be hospitalized with cholera both pre- and post-monsoon epidemic seasons. How often a person used tank water for bathing and cooking post-monsoon was significantly related to cholera hospitalization; the frequency of using a tubewell for drinking water was weakly related ( 90 percent confidence level) to cholera incidence post monsoon season. The other water use variables were not significant. The socioeconomic variable associated with the participant's occupation was significantly associated with post-monsoon cholera incidence; however all other socioeconomic variables were not related to cholera hospitalization.

The previous chapters described the research questions, the theoretical foundation for this study, the methods used in this analysis, and the results of the study. Chapter 7 ties these all together by describing the significant findings and their theoretical implications. 


\section{Discussion of findings and conclusions}

This research project investigated the risk factors associated with pre- and post- monsoon cholera epidemics in rural Bangladesh from 1992 to 1994. This chapter will discuss the findings. It will be argued that this research accomplishes the following:

- Differentiates between the risk factors for the biannual cholera epidemics.

- Offers corroborating evidence that seasonal cholera epidemics are due to both human behaviors and the environmental situation, based on statistical measurements of each risk factor.

- Shows that risk factors are different seasonally; thus, epidemiology studies on cholera should consider seasonal differences when assessing risk.

This chapter will first discuss the most important risk factors for seasonal cholera, and second, discuss the variables that were found not to be associated with this phenomenon.

\subsection{Patterns of pre- and post-monsoon cholera epidemics}

There are several observable characteristics in the temporal distribution of the 1273 cholera cases for the pre- and post-monsoon epidemics. In 1992, the premonsoon cholera peak was in April. The 1993 pre-monsoon cholera epidemic was smaller and disease gradually increased in January and peaked in March. The 1994 pre-monsoon cholera epidemic had a larger number of cholera cases, with a peak in April and June. There were more cholera hospitalizations in the post-monsoon time 
period. The 1992 and 1993 post-monsoon cholera peaks occurred in October. The 1994 cholera peak occurred in November. The 1993 cholera peak was significantly higher than the other two years. While the reason for this event is unclear, one possibility may be the excessive monsoon waters in 1993 . The 1993 monsoon floods were the worst in 58 years (Greenpeace 1994). Excessive water and human interaction with water is believed to be associated with cholera incidence. It is my belief, as well as that of other researchers (Colwell et al. 1985; Emch 1999), that the seasonal pattern of cholera is due to changes in the physical environment and that both primary and secondary transmission is significant. Colwell's (1985) reported that the aquatic reservoir for cholera in rural Bangladesh is the many rivers, tanks, canals, and other water sources (except tubewells) that contain bacteria which multiply at certain times of the year because water conditions change (i.e., salinity) and the availability of attachment sites increases (i.e., plankton). After periods of cholera dormancy, individuals contract cholera from aquatic environmental sources. This may be why cholera incidence is associated with using tank water for cooking and bathing postmonsoon season. After the monsoon rains, water levels increase and climatic conditions are conducive for the bacteria to come out of dormancy and multiple in the brackish waters of the tanks.

Mapping pre- and post- monsoon cholera cases throughout the study periods showed the spatial distribution of cholera. The spatial pattern shows more disease clustering during the post-monsoon epidemics than during the pre-monsoon epidemics. The reason could be simply because there are more cases during the post-monsoon 
time period. Cholera epidemics often start in a community when an infected person interacts with contaminated water (primary transmission) and passes the disease to other people (secondary transmission). While there is no way to distinguish between primary and secondary transmission, the more dispersed the cases are, the less likely secondary transmission has occurred. Therefore, the more spread out cholera cases are, the more likely they are caused by primary transmission.

During the post-monsoon cholera time period the largest disease cluster occurs near the confluence of the Meghna and Dhonogoda Rivers. It is possible that the flood embankment is contributing to the problem, as the disease cluster is within the embankment and the embankment was found to be associated with post-monsoon cholera incidence.

\subsection{Risk factors of pre- and post-monsoon cholera epidemics}

The temporal and spatial patterns of pre- and post-monsoon cholera incidence result from a dynamic interaction between people and their environment. This disease ecology study involves the analysis of variables believed to be accountable for the coincidence of agent and host interacting in time and space. In order to determine how disease was associated with the interaction between agent and host, a number of independent variables were analyzed. It is important to note that negative relationships can be as revealing as positive relationships, although some of the negative findings are simply due to limited variation in independent variables. 
Flood-control was associated with both pre- and post-monsoon cholera. Premonsoon, individuals living in the flood controlled area were 1.49 times more likely to be hospitalized with cholera. Post-monsoon, individuals living in the flood controlled area were 2.66 times more likely to contract cholera. One theory for this phenomenon is that the flood embankment inhibits the natural flow of waters within the controlled area. In the pre-monsoon season, this can create pockets of standing water in which the pathogen can survive. In the post-monsoon season, the embankment obstructs the natural movement of contaminated waters, and may alter salinity levels. The embankment may also aggravate post-monsoon cholera bloom. Future research should be conducted on the association between seasonal cholera and the flood embankment, perhaps through comparing cholera incidence rates in other areas of rural Bangladesh.

There were a few environmental variables associated with sanitation practices and cholera incidence. An association between post-monsoon cholera incidence and households sharing a latrine was found. Households sharing a latrine in the premonsoon season were 3.51 times more likely to contract cholera pre-monsoon than those households not sharing a latrine; households sharing latrines in the postmonsoon season were 2.77 times more likely to contract cholera. This could be because sharing a latrine with other households means that there is more concentrated waste, which during the dry season could be a problem; there is less water to naturally flush the waste away. Households sharing a tubewell were found to be weakly significant $(\mathrm{p}=0.089)$ to post-monsoon cholera incidence. This may be because of 
more individual contact with contaminated persons, which can cause secondary transmission.

An association was found between cholera and the continuous variables concerned with how often men, women, and children defecate in a latrine regardless of season. The majority of the participant's answered that they did not use a latrine when defecating. In Bangladesh, poor sanitation practices provide the primary source of infection in cholera epidemics. The large amount of bacteria excreted in the feces of infected persons can cause massive environmental pollution, especially when waste is deposited outside of the proper sanitation unit. A weak relationship was found between post-monsoon cholera incidence and where adult women defecate $(\mathrm{p}=0.093)$; while there was a negative relationship between where males and children defecation and contracting the disease. It is unclear why a relationship was found between postmonsoon cholera contamination and where women defecated but not men and children.

There are a number of variables describing the characteristics of water use and sanitation practices that were found to be associated with post-monsoon cholera transmission but not pre-monsoon epidemics. Cholera transmission is caused by interacting with unclean water and poor sanitation. Not only are the climatic conditions more conducive to the pathogen's survival and growth in the post-monsoon season, there is a larger amount of water for the pathogen to inhabit. Thus, finding a relationship between cholera incidence and using tank water for cooking $(\mathrm{p}=0.050)$ and bathing $(\mathrm{p}=0.017)$ in the post-monsoon was no surprise. Tank water, more than the other water sources, was used most often for cooking practices during both the pre- 
monsoon (63 percent) and post-monsoon (65 percent) seasons. Tank water was also used most often for bathing (67 percent pre-monsoon and 69 percent post-monsoon). The higher use of tank water for cooking and bathing is one reason why a relationship was found between cholera and these variables. This finding supports another study that reported that tanks are a source of vibrio survival and contamination (Khan et al. 1984).

Using tubewell, river, and canal water for cooking and bathing were all found to be associated with cholera incidence in the post-monsoon season, but the upper and lower confidence bounds was large. What this means is that while there is an association between cooking with canal water and post-monsoon cholera incidence, there is a 95 percent probability that this association falls between 0.748 and 2.068 . Bari population $(\mathrm{p}=0.002)$, population density around baris $(\mathrm{p}=0.003)$, and household area $(\mathrm{p}=0.028)$ were all found to be significantly related to post-monsoon cholera transmission. In the pre-monsoon period, bari population was found to be statistically related $(\mathrm{p}=0.05)$ to cholera transmission. Reasons for these associations may be because individuals are in closer proximity to contaminated persons.

The socioeconomic variables associated with cholera transmission were occupation of the participant, the participant's father, and the participant's mother. A participant refers to the person for whom a questionnaire was administered (Section 5.2.4). The question concerning the occupation of the participant and the participant's father was categorized into water or non-water related jobs. The water category consisted of agricultural labor, fishing, and boatman, and in this region, men primarily 
occupy these jobs. There was a relationship between participant's occupation $(p=0.039)$ and post-monsoon cholera incidence. There was an association between the participant's father's occupation and cholera incidence. These findings could be because of their direct contact with water and/or because the fishing season is mostly during the post-monsoon season. There was also an association between the occupation of the participant's mother and pre- and post-monsoon cholera incidence. This question was grouped into domestic and non-domestic categories, with the belief that domestic labor puts women in direct contact with contaminated water. The last socioeconomic variable found to be related to post-monsoon cholera hospitalization was household area $(\mathrm{p}=0.028)$. The smaller the household the more likely people are in contact with contaminated people; thus, secondary transmission was more likely to occur. In rural Bangladesh, poorer people inhabit smaller households. They are generally disadvantaged in many parts of their lives, such as inability to invest in proper water and sanitation facilities.

There were a number of variables that had no relationship with cholera incidence in this analysis. However, this does not mean that they do not play a role in cholera transmission. For example, drinking tank water had no association to contracting the disease, but it is obvious that if a person drinks water from contaminated tank they will likely be infected. One reason why this analysis did not prove an association between these two variables is because almost all of the participants answered that they obtained their drinking water from tubewells. 
Several of the variables that describe water use and sanitation practices were not found to be associated with pre- and post-monsoon cholera epidemics. Tubewell water used for drinking, cooking, or bathing was not found to be associated with cholera incidence. Nearly all of the questionnaire participants responded that they regularly used tubewell water for drinking (95 percent, post-monsoon). Thus, according to this study, it seems that drinking water is rarely associated with cholera transmission. Tank water was used most often for washing practices (approximately 68 percent), however there was no significant association between this practice and cholera incidence.

The last continuous variable to be tested was the river distance to bari, which was found not to be related to the disease. This finding is consistent with the disease maps that show that cholera was distributed throughout the study area, not just along the main river. Thus, it is believed that aquatic reservoirs exist throughout the study area, not only near the two main rivers.

Disease ecology is about people interacting with their environment and the potential of contracting a disease. The risk factors described above prove that each season has a different group of risks associated with being hospitalized with cholera.

\subsection{The disease ecology of cholera}

In order to appreciate the disease ecology of seasonal cholera in rural Bangladesh, it is important to understand the various processes that cause epidemics to 
occur both spatially and temporally. Figure 7.1 shows the conceptual model of the disease ecology of cholera.

Figure 7.1: A conceptual model for the ecology of cholera.

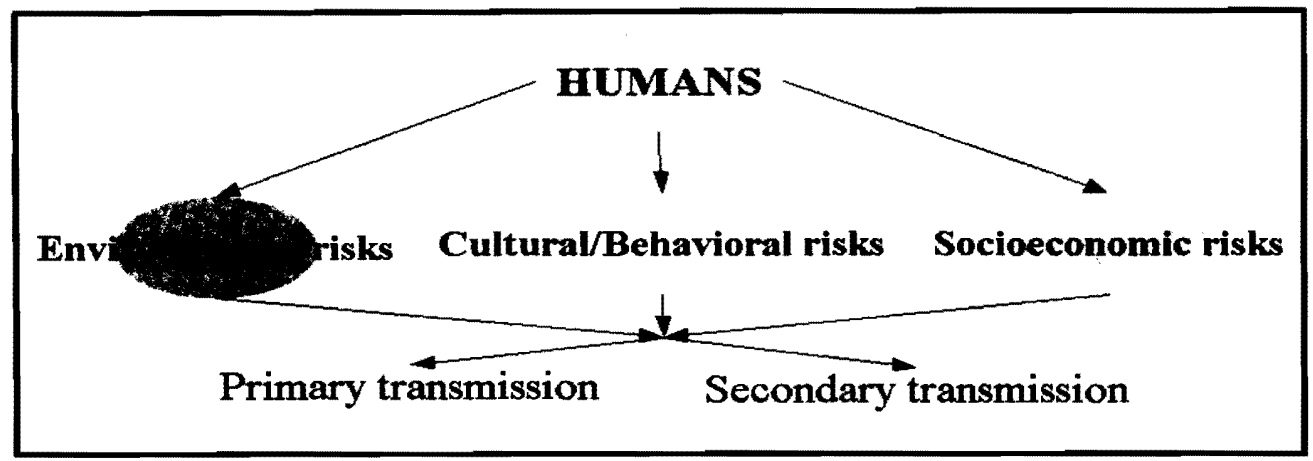

Human behavior is affected by the environmental, socioeconomic, and

cultural/behavioral risk factors, all of which control how the disease is transmitted. It is not possible to differentiate between how a disease is transmitted to a person, and because of this, understanding the disease ecology of seasonal cholera demands an understanding of the direct and indirect effects of human activities throughout a geographical space over time.

Disease ecology is concerned with how people interact with their environment and how that interaction causes a disease outbreak to occur. In rural Bangladesh people are constantly in contact with the aquatic environment. The aquatic environment provides transportation, economic benefits, and general everyday needs for survival. Figure 7.2 summarizes the statistically significant risk factors associated with pre- and post-monsoon cholera transmission. 
Figure 7.2: Variables associated with pre- and post-monsoon cholera transmission.

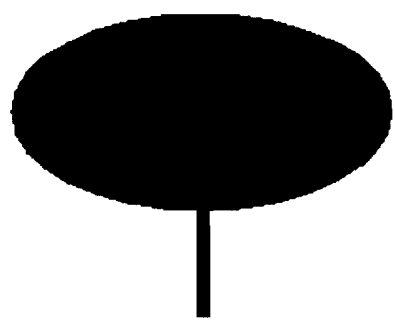

Bari population

Flood embankment

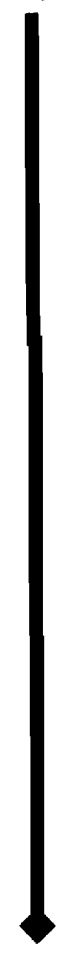

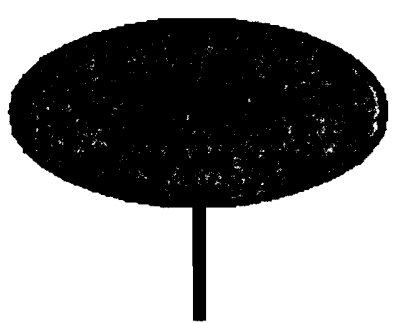

Bari population

I

Flood embankment I

Population density near bari I

Household area I

Number of open latrines

i

Multiple households sharing latrine I

Occupation of participant I

How often tank used for drinking

How often tank used for bathing

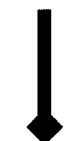




\subsection{Implications for research}

There are clear seasonal patterns to cholera epidemics in rural Bangladesh; however, until this research, no one has distinguished the risk factors for the biannual epidemics. The findings included in this study prove the necessity of separating future cholera studies by season. While the results of this analysis cover only a three-year period, these findings will provide a foundation for other researchers to delve deeper into the myriad of risks associated with pre- and post-monsoon cholera outbreaks. 


\section{REFERENCES}

Ali, M., Emch, M., Yunus, M., and Sack, R.B. 2001. Are the environmental niches of Vibrio cholerae 0139 different from those of Vibrio cholerae O1 El Tor? International Journal of Infectious Diseases. 5(4): 214-219.

Aziz, K.M.A. 1994. Matlab: Physical Setting and Cultural Background. In: Matlab: Women, Children, and Health. Ed. Fauveau, Vincent. The International Centre for Diarrhoeal Disease Research, Bangladesh. Dhaka, Bangladesh. pp 13-27.

Bairagi, R., and Datta, A.K.. 2001. Demographic transition in Bangladesh: What happened in the twentieth century and what will happen next? 16(4): 3-16. AsiaPacific Population Journal. http://www.unescap.org/esid/psis/population/journal/2001/v16n4a1.pdf. Downloaded: April 20, 2004.

Barua, D. 1992. History of cholera. In: D. Barua and W.B. Greenough III (eds.), Cholera. New York: Plenum Publishing Corporation. pp 1-36.

Becker, S., Black, R.E., Brown, K.H., and Nahar, S. 1986. Relations between socioeconomic status and morbidity, food intake and growth in young children in two villages in Bangladesh. Ecology of Food and Nutrition. 18: 251-264.

Bopp, C.A., Ries, A.A., and Wells, J.G. 1999. Labortory methods for the diagnosis of epidemic dysentery and cholera. Atlanta, Georgia: National Center for Infectious Diseases (NCID), Centers for Disease Control and Prevention (CDC). In corporation with the World Health Organization Regional Office for Africa (WHO/AFRO) Harare, Zimbabwe. pp 1-115.

http://www.cdc.gov/ncidod/dbmd/diseaseinfo/cholera/complete.pdf. Downloaded: May, 262003.

Briscoe, John. 1978. The role of water supply in improving health in poor countries (with special reference to Bangla Desh). The American Journal of Clinical Nutrition. $31: 2100-2113$.

Central Intelligence Agency (CIA). 2003. The World Factbook 2002.

http://www.cia.gov/cia/publications/factbook/geos/bg.html. Downloaded: 8 June, 2003.

Cockburn, T.A. and J.G. Cassanos. 1960. Epidemiology of endemic cholera. Public Health Reports. 75: 791-803.

Colwell, R.R. 2002. A voyage of discovery: cholera, climate and complexity. Environmental Microbiology. 4(2): 67-69. 
Colwell, R.R., and Huq. A. 1994. Vibrios in the environment: viable but nonculturable Vibrio cholerae. In: I.K. Wachsmuth, P. Blake, and O. Olsvik (eds.), Vibrio cholerae and Cholera. Washington DC: American Society for Microbiology (ASM Press). 117-133.

Colwell, R.R., and Spira, W. 1992. The ecology of Vibrio cholerae. In: D. Barua and WB Greenough (eds.), Cholera. New York: Plenum Publishing Corporation. pp 107128.

Colwell, R.R., Brayton, P.R., Grimes, D.J., Roszak, D.R., Huq, S.A., and Palmer, L.M. 1985 Viable, but non-culturable Vibrio cholerae and related pathogens in the environment: implications for release of genetically engineered micro-organisms. Bio/Technology. 3:817-820.

Colwell, R.R., West, P.A., Maneval, D., Remmers, E.F., Elliott, E.L., and Carlson, N.E. 1984. Ecology of pathogenic vibrios in Chesapeake Bay. In: R.R. Colwell (ed.), Vibrios in the environment. New York: John Wiley \& Sons. 367-387.

Dalsgaard, D.A., and Larsen, J.L. 1995. Is Vibrio cholerae serotype O139 a potential cause of a new pandemic? Ugeskr Laeger. 157: 280-283.

Emch, M., and Ali, M. 2001. Spatial and temporal patterns of diarrheal disease in Matlab, Bangladesh. Environment and Planning A. 33: 339-350.

Emch, M. 1999. Diarrheal disease risk in Matlab, Bangladesh. Social Science and Medicine. 49:519-530.

Feachem, R.G. 1982. Environmental aspects of cholera epidemiology. III. Transmission and control. Tropical Diseases Bulletin. 79: 1-47.

Finkelstein, R. 1996. Cholera, Vibrio cholerae $\mathrm{O} 1$ and O139, and other pathogenic vibrios. In: S. Baron (ed.), Medical Microbiology, $4^{\text {th }}$ ed. The University of Texas Medical Branch (Non-profit publication). http://gsbs.utmb.edu/microbook/ch024.htm. Downloaded May 20, 2004.

Glass, R.I., Becker, S., Huq, M.I., Stoll, B.J., Khan, M.U., Merson, M.H., Lee, J.V., and Black, R.E. 1982. Endemic cholera in rural Bangladesh, 1966-1980. American Journal of Epidemiology. 116(6): 959-970.

Greenpeace. 1994. Climate Change and River Flooding.

http://archive.greenpeace.org/climate/flood_report/4-4.html. Downloaded: August 23, 2003. 
Hirsch, A. 1886. Handbook of geographical and historical pathology. Churchill, London: The New Sydenham Society.

Hoeprich, Paul. (1994). Host-parasite relationships and the pathogenesis of infectious diseases. P. Hoeprich, M.C. Jordan, A. R. Ronald (eds.), Infectious Diseases, $5^{\text {th }}$ ed. J.B. Lippincott Company, Philadelphia. pp:57-68.

Hood, M.A., Ness, G.E., Rodrick, G.E., and Black, N.J. 1983. Distribution of Vibrio cholerae in two Florida estuaries. Microbial Ecology. 9:65-75.

Hughes, J.M., Boyce, J.M., Levine, R.J., Khan, M., Aziz, K.M.A., Huq, M.I., and Curlin, G.T. 1982. Epidemiology of eltor cholera in rural Bangladesh: Importance of surface water in transmission. Bulletin of the World Health Organization. 60(3): 395404.

Huq, A., Colwell, R.R., Chowdhury, M.A.R., Xu, B., and Montilla, R.1996. A simple filtration method to remove plankton-associated Vibrio cholerae in raw water supplies in developing countries. Applied Environmental Microbiology. 62: 2508-2512.

Huq, A., Colwell, R.R., Rahman, R., Ali, A., Chowdhury, M.A.R., Parveen, S., Sack, D.A., and Russek-Cohen, E. 1990. Detection of Vibrio cholerae O1 in the aquatic environment by fluorescent-monoclonal antibody and culture methods. Applied Environmental Microbiology. 56(8): 2370-2373.

Huq, A., West, P.A., Small, E.B., Huq, M.I., and Colwell, R.R. 1984. Influence of water temperature, salinity, and $\mathrm{pH}$ on survival and growth of toxigenic Vibrio cholerae serovar $\mathrm{O} 1$ associated with live copepods in laboratory microcosms. Applied Environmental Microbiology. 48: 420-424.

Islam, M.S., Miah, M.A., Hasan, M.K., Sack, R.B., and Albert, M.J. 1994. Detection of non-culturable Vibrio cholerae $\mathrm{Ol}$ associated with a cyanobacterium from an aquatic environment in Bangladesh. Transactions of the Royal Society of Tropical Medicine and Hygiene. 88:298-299.

Islam, M.S., Drasar, B.S., and Bradley, D.J. 1990. Survival of toxigenic Vibrio cholerae $\mathrm{O} 1$ with a common duckweed, Lemna minor, in artificial aquatic environments. Transactions of the Royal Society of Tropical Medicine and Hygiene. 84: pp 422-424.

Islam, M.S., and Aziz, K.M.S. 1981. Association of vibrios with some hydrophytic plants. Bangladesh Journal of Microbiology. 1: 70.

Johnson, B.L.C. 1982. Bangladesh, $2^{\text {nd }}$ ed. London: Heinemann Educational Books Ltd. 
Kay, B., Bopp, C.A., and Wells, J.G. 1994. Isolation and Identification of Vibrio cholerae O1 from Fecal Specimens. In: I.K. Wachsmuth, P. Blake, and O. Olsvik (eds.), Vibrio cholerae and Cholera. Washington DC: American Society for Microbiology (ASM Press). pp 3-25.

Khan M.U., Shahidullah, M.D., Haque, M.S., and Ahmed, W.U. 1984. Presence of vibrios in surface water and their relation with cholera in a community. Tropical and Geographical Medicine. 36: 335-340.

Khan M.U., Mosley, W.H., Chakraborty, J., Sarder, A.M., and Khan, M.R. 1981. The relationship of cholera to water source and use in rural Bangladesh. International Journal of Epidemiology. 10(1): 23-25.

Khan, M.U., and Mosley, W.H. 1967. The role of boatmen in the transmission of cholera. East Pakistan Medical Journal. 11:61.

Koch, R. 1884. An address on cholera and its bacillus. British Medical Journal. 2: 403-407, 453-459.

Lipp, E., Huq, A., and Colwell, R.R. 2002. Effects of Global Climate on Infectious Disease: the Cholera Model. American Society for Microbiology. 15(4): 757-770.

Longini, I.M., Yunus, M., Zaman, K., Siddique, A.K., Sack, R.B., and Nizam, A. 2002. Epidemic and endemic cholera trends over a 33-year period in Bangladesh. The Journal of Infectious Diseases. 186: 246-251.

Marshall, K.C. 1976. Interfaces in Microbial Ecology. Cambridge: Harvard University Press.

May, J. 1958. The ecology of human disease. New York: MD Publications, Inc.

May, J.A. 1970. Kant's concept of Geography and its relation to recent geographical thought. Toronto University, Toronto Press.

Mayer, J.D. 2000. Geography, ecology and emerging infectious diseases. Social Science \& Medicine. 50: 937-952.

Mayer, J.D. 1986. Ecological Association Analysis. In: M. Pacione (ed), Medical Geography: Progress and Prospect. Great Britain: Biddles Ltd. 64-83.

Mayer, J.D. 1984. Medical Geography: An Emerging Discipline. Journal of the American Medical Association. 251(20): 2680-2683. 
McCormack, W.M., Mosley, W.H., Fahimuddin, M., and Benenson, A.S. 1969. Endemic cholera in rural East Pakistan. American Journal of Epidemiology. 89(4): 393-404.

Meade, M., Florin, J.W., and Gesler, W.M. 1988. Medical Geography. New York: The Guilford Press.

Meade, M., and Earickson, R. 2000. Medical Geography, $2^{\text {nd }}$ ed. New York: The Guilford Press.

Morris, J.G. 1994. Cholera and other vibrioses. In: P.D. Hoeprich, M.C. Jordan, A.R. Ronald (eds.), Infectious diseases: A treatise of infectious processes. J.B. Lippincott Company. Philadelphia. pp. 753-762.

Mosley, W.H. and M. Khan. 1979. Cholera epidemiology- some environmental aspects. Progress in Water Technology. 11: 309-316.

Mukhopadhyay, A.K., Basu, A., Garg, P., Bag, P.K., Ghosh, A., Bhattacharya, S.K., Takeda, Y., and Nair, G.B. 1998. Molecular epidemiology of reemergent Vibrio cholerae O139 Bengal in India. Journal of Clinical Microbiology. 36: 2149-2152.

Nakasone, N. Iwanaga, M., and Eeckels, R. 1987. Characterization of Vibrio cholerae $\mathrm{O} 1$ recently isolate in Bangladesh. Transactions of the Royal Society of Tropical Medicine and Hygiene. 81: 876-878.

Paul, B.K. 1985. Approaches to medical geography: An historical perspective. Social Science \& Medicine. 20(4): 399-409.

Pollitzer, R. 1959. Cholera. Geneva: World Health Organization. p.1019.

Reavill, L.R.P. and T.G. Rahman. 1995. A systems-science-based analysis of the factors that influence and aggravate the effects of flooding in Bangladesh. Technological Forecasting and Social Change: An International Journal (New York). 49(1): 89-101.

Sack, B., Siddique, A.K., Longini, I.M., Nizam, A., Yunus, M.D., Islam, M.S., Morris, J.G., Ali, A., Huq, A., Nair, G.B., Qadri, F., Faruque, S.M., Sack, D.A., and Colwell, R.R. 2003. A 4-year study of the epidemiology of Vibrio cholerae in four rural areas of Bangladesh. The Journal of Infectious Diseases. 187: 96-101.

Sakazaki, R. 1992. Bacteriology of Vibrio and related organisms. In: D. Barua and W.B. Greenough III (eds.), Cholera. New York: Plenum Publishing Corporation. pp 37-55. 
Shaw, R. 1992. Nature, culture, and disasters: floods and gender in Bangladesh. In: E. Croll and D. Parkin (eds.), Bush base: Culture, environment and development. New York, NY: Routledge, Chapman and Hall, Inc. pp 200-217.

Semple, E.C. 1911. Influences of Geographies environment on the basis of Ratzel 's system of anthropogeography. New York, Russell and Russell.

Spira, W.M. 1981. Environmental factors in diarrhea transmission: the ecology of Vibrio cholerae $\mathrm{O} 1$ and cholera. In: T. Holme, et al. (eds.), Acute enteric infections in children: new prospects for treatment and prevention. Amsterdam: Elsevier/NorthHolland Biomedical Press. 273-288.

Spira, W.M., Huq, A., Ahmed, Q.S., and Saeed, Y.A. 1981. Uptake of Vibrio cholerae biotype eltor from contaminated water by water hyacinth (Eichornia crassipes). Applied Environmental Microbiology. 42: 550-553.

Spira, W.M., Khan, M.U., Saeed, Y.A., and Sattar, M.A. 1980. Microbiological surveillance of intra-neighborhood El Tor cholera transmission in rural Bangladesh. Bulletin of the World Health Organization. 58: 731-740.

Tamplin, M.L., Gauzens, A.L., Huq, A., Sack, D.A., and Colwell, R.R. 1990. Attachment of Vibrio cholerae serogroup $\mathrm{O} 1$ to zooplankton and phytoplankton of Bangladesh waters. Applied and Environmental Microbiology. 56(6): 1977-1980.

World Health Organization (WHO). 2000. Cholera: Fact sheet N107. World Health Organization (WHO). http://www.who.int/inf-fs/en/fact107.html. Downloaded: 19 May, 2003.

Xu, H.S., Roberts, N., Singleton, F.L., Attwell, R.W., Grimes, D.J., and Colwell, R.R. 1982. Survival and viability of nonculturable Escherichia coli and Vibrio cholerae in the estuarine and marine environment. Microbial Ecology. 8: 313-323.

Yusuf, M., Hussain, and A.M. Zakir. (1990). Sanitation in rural communities in Bangladesh. Bulletin of the World Health Organization (Geneva). 68(5): 619-624.

Zhu J., Miller M.B., Vance R.E., Dziejman M., Bassler B.L., and Mekalanos J.J. 2002. Quorum-sensing regulators control virulence gene expression in Vibrio cholerae. Proceedings of the National Academy of Sciences. 5:99(5):3129-34. 


\section{APPENDIX A: Description of independent variables}

Chapter 5 summarizes each of the independent variables that are believed to be potential risk factors for pre- and post-monsoon cholera epidemics. This appendix explains how each independent variable was measured and/or calculated. I will first explain the continuous independent variables and move on to the categorical independent variables.

Summary of continuous independent variables.

\begin{tabular}{|c|c|c|}
\hline Bari population & $\begin{array}{l}\text { cultural/behavioral, } \\
\text { socioeconomic }\end{array}$ & count \\
\hline $\begin{array}{l}\text { Number of households sharing a } \\
\text { latrine }\end{array}$ & $\begin{array}{l}\text { socioeconomic \& } \\
\text { environmental }\end{array}$ & count \\
\hline $\begin{array}{l}\text { Households sharing a tubewell in a } \\
\text { bari }\end{array}$ & $\begin{array}{l}\text { socioeconomic \& } \\
\text { environmental }\end{array}$ & count \\
\hline Number of latrines per 100 people & $\begin{array}{l}\text { socioeconomic \& } \\
\text { environmental }\end{array}$ & count \\
\hline Number of tubewells per 100 people & $\begin{array}{l}\text { socioeconomic \& } \\
\text { environmental }\end{array}$ & count \\
\hline Number of open latrines & environmental & count \\
\hline $\begin{array}{l}\text { Number of latrines with non-septic } \\
\text { without ring }\end{array}$ & environmental & count \\
\hline Number of ring latrine w/ septic tank & environmental & count \\
\hline $\begin{array}{l}\text { Number of latrines with concrete } \\
\text { septic }\end{array}$ & environmental & count \\
\hline Number of tubewells in a bari & environmental & count \\
\hline House Hold area & socioeconomic & square feet \\
\hline Distance from main river & environmental & $\begin{array}{l}\text { meters within } \\
10 \text { kilometer } \\
\text { radius }\end{array}$ \\
\hline
\end{tabular}


- Bari population: The number of people living in a bari was determined from DSS records. A simple regression model was used to estimate if population density impacted seasonal cholera epidemics.

- Number of households sharing a latrine: A household-level tubewell and latrine survey was used to determine the number of households sharing a latrine. A simple regression model was used to estimate if the number of people sharing a latrine impacted seasonal cholera epidemics.

- Households sharing a tubewell in a bari: A household-level tubewell and latrine survey was used to determine the number of households sharing a tubewell in a bari. A simple regression model was used to estimate if the number of people sharing a tubewell impacted seasonal cholera epidemics.

- Number of latrines per 100 people: The number of latrines was determined from a household-level tubewell and latrine survey except all open latrines; and the number of people was determined from the DSS records. The calculation produced the number of latrines per 100 people. A simple regression model was used to estimate if the number of people sharing latrines impacted seasonal cholera epidemics.

- Number of tubewells per 100 people: The number of tubewells was determined from a household-level tubewell and latrine survey; and the number of people was determined from the DSS records. The calculation produced the number of latrines per 100 people. A simple regression model 
was used to estimate if the number of people sharing tubewells impacted seasonal cholera epidemics.

- Number of open latrines: Data was obtained from a household-level tubewell and latrine survey. A simple regression model was used to estimate if the number open latrines impacted seasonal cholera epidemics.

- Number of latrines with non-septic without ring: Data was obtained from a household-level tubewell and latrine survey. A simple regression model was used to estimate if the number of non-septic latrines without a ring impacted seasonal cholera epidemics.

- Number of ring latrine w/ septic tank: Data was obtained from a householdlevel tubewell and latrine survey. A simple regression model was used to estimate if the number of septic latrines with a ring impacted seasonal cholera epidemics.

- Number of latrines with concrete septic: Data was obtained from a household-level tubewell and latrine survey. A simple regression model was used to estimate if the number of concrete septic latrines impacted seasonal cholera epidemics.

- Number of tubewells in a bari: Data was obtained from a household-level tubewell and latrine survey to determine the number of tubewells in Matlab's baris. A simple regression model was used to estimate if the number of tubewells in a bari impacted seasonal cholera epidemics. 
- House Hold area: Data collected by the community health workers to determine the household area in square feet. A simple regression model was used to estimate if household area impacted seasonal cholera epidemics.

- Distance from main river: Using the GIS database the distance of each bari was calculated to the closest main river (Meghna or Dhonogoda). A simple regression model was used to estimate if proximity of bari to river impacted seasonal cholera epidemics. 


\section{Summary of categorical independent variables.}

\begin{tabular}{|c|c|c|}
\hline Flood embankment & environmental & yes or no \\
\hline Source of water used for cooking & $\begin{array}{l}\text { cultural/behavioral, } \\
\text { environmental }\end{array}$ & $1=$ yes, $0=$ no \\
\hline Source of water used for bathing & $\begin{array}{l}\text { cultural/behavioral, } \\
\text { environmental }\end{array}$ & $1=$ yes, $0=$ no \\
\hline Source of water used for washing & $\begin{array}{l}\text { cultural/behavioral, } \\
\text { environmental }\end{array}$ & $1=$ yes, $0=$ no \\
\hline Working tubewell & $\begin{array}{l}\text { cultural/behavioral, } \\
\text { environmental }\end{array}$ & yes or no \\
\hline Use another baris tubewell & $\begin{array}{l}\text { cultural/behavioral, } \\
\text { environmental }\end{array}$ & yes or no \\
\hline How often tubewell used for drinking & $\begin{array}{l}\text { cultural/behavioral, } \\
\text { environmental }\end{array}$ & $0=$ often, $1=$ not often \\
\hline How often river used for drinking & $\begin{array}{l}\text { cultural/behavioral, } \\
\text { environmental }\end{array}$ & $0=$ often, $1=$ not often \\
\hline How often tubewell used for cooking & $\begin{array}{l}\text { cultural/behavioral, } \\
\text { environmental }\end{array}$ & $0=$ often, $1=$ not often \\
\hline How often river used for cooking & $\begin{array}{l}\text { cultural/behavioral, } \\
\text { environmental }\end{array}$ & $0=$ often, $1=$ not often \\
\hline How often canal used for cooking & $\begin{array}{l}\text { cultural/behavioral, } \\
\text { environmental }\end{array}$ & $0=$ often, $1=$ not often \\
\hline How often tank used for cooking & $\begin{array}{l}\text { cultural/behavioral, } \\
\text { environmental }\end{array}$ & $0=$ often, $1=$ not often \\
\hline How often tubewell used for bathing & $\begin{array}{l}\text { cultural/behavioral, } \\
\text { environmental }\end{array}$ & $0=$ often, $1=$ not often \\
\hline How often river used for bathing & $\begin{array}{l}\text { cultural/behavioral, } \\
\text { environmental }\end{array}$ & $0=$ often, $1=$ not often \\
\hline How often canal used for bathing & $\begin{array}{l}\text { cultural/behavioral, } \\
\text { environmental }\end{array}$ & $0=$ often, $1=$ not often \\
\hline How often tank used for bathing & $\begin{array}{l}\text { cultural/behavioral, } \\
\text { environmental }\end{array}$ & $0=$ often, $1=$ not often \\
\hline Location of adult male defecation & $\begin{array}{l}\text { cultural/behavioral, } \\
\text { environmental }\end{array}$ & $1=$ latrine, $0=$ other \\
\hline Location of adult female defecation & $\begin{array}{l}\text { cultural/behavioral, } \\
\text { environmental }\end{array}$ & $1=$ latrine, $0=$ other \\
\hline Location of male child defecation & $\begin{array}{l}\text { cultural/behavioral, } \\
\text { environmental }\end{array}$ & $1=$ latrine, $0=$ other \\
\hline Location of female child defecation & $\begin{array}{l}\text { cultural/behavioral, } \\
\text { environmental }\end{array}$ & $1=$ latrine, $0=$ other \\
\hline Latrine in your household & $\begin{array}{l}\text { socioeconomic \& } \\
\text { environmental }\end{array}$ & yes or no \\
\hline Type of latrine drainage & environmental & $1=$ open, $0=$ septic \\
\hline \# of households sharing a latrine & environmental & $0=$ single, $1=$ multiple \\
\hline $\begin{array}{l}\text { How often males/females defecate in } \\
\text { latrine }\end{array}$ & $\begin{array}{l}\text { cultural/behavioral \& } \\
\text { environmental }\end{array}$ & $0=$ often, $1=$ not \\
\hline Occupation of participant $\&$ father & socioeconomic & $1=$ water, $0=$ nonwater \\
\hline Occupation of participant's mother & socioeconomic & $1=$ domestic, $0=$ notdomestic \\
\hline
\end{tabular}


- Flood embankment: Data was collected from aerial photographs and digitized into a GIS database. The embankment protects part of the study area from flooding, while the area outside the embankment remains unprotected. Using relative risk ratios and regression models, this study determined whether each bari inside or outside the embankment had an influence on seasonal cholera epidemics.

- Source of water used regularly for cooking: A questionnaire determined whether or not tubewell water was used regularly for cooking. Using relative risk ratios and regression models, this study determined whether using tubewell water for cooking had an influence on seasonal cholera epidemics.

- Source of water used regularly for bathing: A questionnaire determined whether or not tubewell water was used regularly for bathing. Using relative risk ratios and regression models, this study determined whether using tubewell water for bathing had an influence on seasonal cholera epidemics.

- Source of water used regularly for washing: A questionnaire determined whether or not tubewell water was used regularly for washing. Using relative risk ratios and regression models, this study determined whether using tubewell water for washing had an influence on seasonal cholera epidemics.

- Working tubewell: A questionnaire was administered to determine whether or not there was a working tubewell in a bari. Using relative risk ratios and regression models, this study determined whether or not a bari with a working tubewell had any influence on seasonal cholera epidemics. 
- Use another baris tubewell: A questionnaire was administered to determine if there was not a working tubewell in a bari, if the participant used a tubewell from another bari. Using relative risk ratios and regression models, this study determined whether or not this variable had any influence on seasonal cholera epidemics.

- How often is tubewell used for drinking: A questionnaire determined how often tubewell water was used for drinking. Using relative risk ratios and regression models, this study determined whether this variable had an influence on seasonal cholera epidemics.

- How often is river water used for drinking: A questionnaire determined how often river water was used for drinking. Using relative risk ratios and regression models, this study determined whether this variable had an influence on seasonal cholera epidemics.

- How often is tubewell used for cooking: A questionnaire determined how often tubewell water was used for cooking. Using relative risk ratios and regression models, this study determined whether this variable had an influence on seasonal cholera epidemics.

- How often is river water used for cooking: A questionnaire determined how often river water was used for cooking. Using relative risk ratios and regression models, this study determined whether this variable had an influence on seasonal cholera epidemics. 
- How often is canal used for cooking: A questionnaire determined how often canal water was used for cooking. Using relative risk ratios and regression models, this study determined whether this variable had an influence on seasonal cholera epidemics.

- How often is tank used for cooking: A questionnaire determined how often tank water was used for cooking. Using relative risk ratios and regression models, this study determined whether this variable had an influence on seasonal cholera epidemics.

- How often is tubewell used for bathing: A questionnaire determined how often tubewell water was used for bathing. Using relative risk ratios and regression models, this study determined whether this variable had an influence on seasonal cholera epidemics.

- How often is river water used for bathing: A questionnaire determined how often river water was used for bathing. Using relative risk ratios and regression models, this study determined whether this variable had an influence on seasonal cholera epidemics.

- How often is canal used for bathing: A questionnaire determined how often canal water was used for bathing. Using relative risk ratios and regression models, this study determined whether this variable had an influence on seasonal cholera epidemics.

- How often is tank used for bathing: A questionnaire determined how often tank water was used for bathing. Using relative risk ratios and regression 
models, this study determined whether this variable had an influence on seasonal cholera epidemics.

- Location of adult male defecation: A questionnaire determined if the adult males defecated in a latrine or not. Using relative risk ratios and regression models, this study determined whether this variable had an influence on seasonal cholera epidemics.

- Location of adult female defecation: A questionnaire determined if the adult females defecated in a latrine or not. Using relative risk ratios and regression models, this study determined whether this variable had an influence on seasonal cholera epidemics.

- Location of male child defecation: A questionnaire determined if the male children defecated in a latrine or not. Using relative risk ratios and regression models, this study determined whether this variable had an influence on seasonal cholera epidemics.

- Location of female child defecation: A questionnaire determined if the female children defecated in a latrine or not. Using relative risk ratios and regression models, this study determined whether this variable had an influence on seasonal cholera epidemics.

- Latrine in your household: A household-level tubewell and latrine survey determined whether or not there was a latrine in each household. Using relative risk ratios and regression models, this study determined whether this variable had an influence on seasonal cholera epidemics. 
- Type of latrine drainage: A household-level tubewell and latrine survey determined whether household latrines were septic or not. Using relative risk ratios and regression models, this study determined whether this variable had an influence on seasonal cholera epidemics.

- Number of households sharing a latrine: A household-level tubewell and latrine survey determined how many household shared latrines. Using relative risk ratios and regression models, this study determined whether this variable had an influence on seasonal cholera epidemics.

- How often males \& females defecate in latrine: A questionnaire determined how regularly males and females regularly defecated in a latrine. Using relative risk ratios and regression models, this study determined whether this variable had an influence on seasonal cholera epidemics.

- Occupation of participant: A questionnaire determined the occupation of the participant father had anything to do with agriculture labor, catches fish, boatman. These were classified as water $=1$; all other answers were classified as not water $=0$. Using relative risk ratios and regression models, this study determined whether this variable had an influence on seasonal cholera epidemics.

- Occupation of participant's father: A questionnaire determined the occupation of the participant's father had anything to do with agriculture labor, catches fish, boatman. These were classified as water $=1$; all other answers were classified as not water $=0$. Using relative risk ratios and regression models, 
this study determined whether this variable had an influence on seasonal cholera epidemics.

- Occupation of participant's mother: A questionnaire determined the occupation of the participant's mother had anything to do with cottage industry, housewife, domestic labor, unskilled labor, unskilled service, unemployed, or housewife. These were classified as domestic $=1$; all other answers were classified as not domestic $=0$. Using relative risk ratios and regression models, this study determined whether this variable had an influence on seasonal cholera epidemics. 
APPENDIX B: English translation of questionnaire and consent form

1) CID

2) RID

3) Bari ID

4) What source of water do you regularly use for drinking?

$$
\begin{array}{lll}
1=\text { river } & 2=\text { canal } & 3=\text { tank } \\
4=\text { ditch } & 5=\text { tubewell } & 6=\text { other (specify) } \\
9=\text { unknown } & &
\end{array}
$$

5) What source of water do you regularly use for cooking?

$$
\begin{array}{lll}
1=\text { river } & 2=\text { canal } & 3=\text { tank } \\
4=\text { ditch } & 5=\text { tubewell } & 6=\text { other (specify) } \\
9=\text { unknown } & &
\end{array}
$$

6) What source of water do you regularly use for bathing?

$$
\begin{array}{lll}
1=\text { river } & 2=\text { canal } & 3=\text { tank } \\
4=\text { ditch } & 5=\text { tubewell } & 6=\text { other (specify) } \\
9=\text { unknown } & &
\end{array}
$$

7) What water source do you regularly use for washing cooking utensils?

$$
\begin{array}{lll}
1=\text { river } & 2=\text { canal } & 3=\text { tank } \\
4=\text { ditch } & 5=\text { tubewell } & 6=\text { other (specify) } \\
9=\text { unknown } & &
\end{array}
$$

8) Is there a tubewell in your bari? $(1=$ yes; $2=$ no $)$

9) Is the tubewell in working condition? $(1=$ yes; $2=$ no $)$

10) With how many households do you share the tubewell?

11) If you do not have a tubewell in your bari do you use tubewell water from another bari (note bari identification number)?

12) How often do you use tubewell water for drinking?

$$
\begin{array}{lll}
1=\text { always } & 2=\text { usually } & 3=\text { sometimes } \\
4=\text { seldom } & 5=\text { never }
\end{array}
$$

13) How often do you use river water for drinking?

$$
\begin{aligned}
& 1=\text { always } \\
& 2 \text { = usually } \\
& 3=\text { sometimes } \\
& 4=\text { seldom } \\
& 5=\text { never }
\end{aligned}
$$


14) How often do you use canal water for drinking?

$$
\begin{array}{ll}
1=\text { always } & 2=\text { usually } \\
4=\text { seldom } & 5=\text { never }
\end{array}
$$

15) How often do you use tank water for drinking?

$$
\begin{array}{lll}
1=\text { always } & 2=\text { usually } & 3 \text { = sometimes } \\
4=\text { seldom } & 5=\text { never }
\end{array}
$$

16) How often do you use tubewell water for cooking?

$$
\begin{array}{lll}
1=\text { always } & 2=\text { usually } & 3=\text { sometimes } \\
4=\text { seldom } & 5=\text { never } &
\end{array}
$$

17) How often do you use river water for cooking?

$$
\begin{aligned}
& 1=\text { always } \quad 2 \text { = usually } \quad 3 \text { =sometimes } \\
& 4=\text { seldom } \quad 5=\text { never }
\end{aligned}
$$

18) How often do you use canal water for cooking?

$$
\begin{array}{lll}
1=\text { always } & 2=\text { usually } & 3=\text { sometimes } \\
4=\text { seldom } & 5=\text { never } &
\end{array}
$$

19) How often do you use tank water for cooking?

$$
\begin{array}{ll}
1=\text { always } & 2=\text { usually } \\
4=\text { seldom } & 5=\text { never }
\end{array}
$$

20) How often do you use tubewell water for bathing?

$$
\begin{aligned}
& 1=\text { always } \quad 2 \text { = usually } \quad 3 \text { = sometimes } \\
& 4=\text { seldom } \quad 5=\text { never }
\end{aligned}
$$

21) How often do you use river water for bathing?

$$
\begin{array}{ll}
1=\text { always } & 2=\text { usually } \\
4=\text { seldom } & 5=\text { never }
\end{array}
$$

22) How often do you use canal water for bathing?

$$
\begin{aligned}
& 1=\text { always } \quad 2=\text { usually } \quad 3=\text { sometimes } \\
& 4=\text { seldom } \quad 5=\text { never }
\end{aligned}
$$

23) How often do you use tank water for bathing?

$$
\begin{array}{ll}
1=\text { always } & 2=\text { usually } \\
4=\text { seldom } & 5=\text { never }
\end{array}
$$

24) Where do the adult males of your family regularly defecate?

$$
\begin{array}{lll}
1 \text { = latrine } & 2=\text { fixed site that is not a latrine } & 3=\text { field } \\
4 \text { = courtyard } & 5=\text { no fixed site } & 6=\text { other (specify) }
\end{array}
$$


25) Where do the adult females of your family regularly defecate?

$$
\begin{array}{lll}
1 \text { = latrine } & 2=\text { fixed site that is not a latrine } & 3=\text { field } \\
4=\text { courtyard } & 5=\text { no fixed site } & 6=\text { other (specify) }
\end{array}
$$

26) Where do the male children of your family regularly defecate?

$$
\begin{array}{lll}
1 \text { = latrine } & 2=\text { fixed site that is not a latrine } & 3=\text { field } \\
4=\text { courtyard } & 5=\text { no fixed site } & 6=\text { other (specify) }
\end{array}
$$

27) Where do the female children of your family regularly defecate?

$$
\begin{array}{lll}
1 \text { = latrine } & 2 \text { = fixed site that is not a latrine } & 3=\text { field } \\
4=\text { courtyard } & 5=\text { no fixed site } & 6=\text { other (specify) }
\end{array}
$$

28) Do you have a latrine in your household? $(1=$ yes; $2=$ no $)$

29) What kind of drainage does the latrine have (by observation if possible)?

$$
\begin{array}{lll}
1=\text { open to river } & 2=\text { open to pond } & 3=\text { open to ditch } \\
4=\text { open to field } & 5=\text { pit without septic } & 6=\text { pit with septic }
\end{array}
$$

30) Is the latrine shared with another/other household(s)? $(1=$ yes; $2=$ no $)$

31) If yes then what is/are the family number(s) of that/those household(s)?

32) How often do the adult male members of your family defecate in a latrine?

$$
\begin{aligned}
& 1=\text { always } \quad 2=\text { usually } \quad 3=\text { sometimes } \\
& 4=\text { seldom } \quad 5=\text { never }
\end{aligned}
$$

33) How often do the adult female members of your family defecate in a latrine?

$$
\begin{aligned}
& 1=\text { always } \quad 2 \text { = usually } \quad 3 \text { =sometimes } \\
& 4=\text { seldom } \quad 5=\text { never }
\end{aligned}
$$

34) How often do the children of your family defecate in a latrine ?

$$
\begin{aligned}
& 1=\text { always } \quad 2=\text { usually } \quad 3=\text { sometimes } \\
& 4=\text { seldom } \quad 5=\text { never }
\end{aligned}
$$

35) Does your family consume shellfish? $(1=$ yes; $2=$ no $)$

36) If yes, then how often (times per month)?

37) For how many years has the study participant been educated?

38) In what type of educational institution has the participant been educated?

$$
\begin{array}{ll}
0=\text { unknown } & 1=\text { secular } \\
2=\text { madrasha } & 3=\text { maktab }
\end{array}
$$


39) For how many years has the study participant's mother been educated?

40) For how many years has the study participant's father been educated?

41) What is the occupation of the participant?
01 = landowner/ worker
$02=$ landowner/ does not work
$03=$ rent land/share crop
$04=$ catches fish
$05=$ sell fish
$06=$ rent fishing equipment
$07=$ agricultural labor
$08=$ domestic labor
$09=$ mill worker
$10=$ unskilled labor
$11=$ skilled labor
$12=$ boatman
$13=$ cottage industry
$14=$ unskilled service
$15=$ skilled service
$16=$ businessman
17 = beggar
$18=$ student
$19=$ disabled
$20=$ unemployed
$21=$ housewife
$22=$ unknown
$23=$ other (specify)

42) What is the occupation of the participant's father?
$01=$ landowner $/$ worker
$02=$ landowner $/$ does not work
$03=$ rent land/share crop
$04=$ catch fish
$05=$ sell fish
$06=$ rent fishing equipment
$07=$ agricultural labor
$08=$ domestic labor
$09=$ mill worker
$10=$ unskilled labor
$11=$ skilled labor
$12=$ boatman
$13=$ cottage industry
$14=$ unskilled service
$15=$ skilled service
$16=$ businessman
$17=$ beggar
$18=$ student
$19=$ disabled
$20=$ unemployed
$21=$ housewife
$22=$ unknown
$23=$ other (specify)

43) What is the occupation of the participant's mother?
$01=$ landowner/ worker
$02=$ landowner/ does not work
$03=$ rent land/share crop
$04=$ catch fish
$05=$ sell fish
$06=$ rent fishing equipment
$07=$ agricultural labor
$08=$ domestic labor
$09=$ mill worker
$10=$ unskilled labor
$11=$ skilled labor
$12=$ boatman
$13=$ cottage industry
$14=$ unskilled service
$15=$ skilled service
$17=$ beggar
$16=$ businessman
$19=$ disabled
$18=$ student
$20=$ unemployed 


$$
21=\text { housewife } \quad 22=\text { unknown } \quad 23=\text { other }(\text { specify })
$$

44) What do you think causes diarrhea?

$$
1=\text { microorganisms } \quad 2=\overline{\text { unknown }} \quad 3=\text { other (specify) }
$$

45) What can you do to prevent diarrhea?

$1=$ wash hands

$2=$ drink tubewell water

$3=$ bath in clean water source

$4=$ other (specify)

46) What is the source of diarrhea?

$$
\begin{array}{ll}
1=\text { water } & 2=\text { fish } \\
3=\text { food } & 4=\text { other (specify) }
\end{array}
$$

47) How many of each of the following household articles do you own?
a) quilt
b) bicycle
e) hurricane (kerosene lantern)
c) radio
f) watch
d) lamp (quiet)
g) remittance
h) other (specify)

48) How many boats do you own?

49) How much land do you own? (in decimals)

50) How much of your farm land is (insert each of the following)? (in decimals)
a) self cultivated
b) rented out
c) share cropped
d) other (specify)

51) How many cows do you own?

52) How many goats do you own?

53) How many chickens do you own?

54) What is your cash income? (annual)

55) If the participant migrated out of the study area, in what month and year did he/she migrate? (This question should be asked of neighbor or family member. Please specify who answered questions 55 and 56.)

56) If they migrated out of the study area then why? 